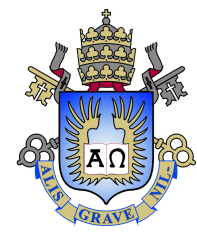

Guilherme Sant'Anna Varela

\title{
Anotação Profunda de Papéis Semânticos para o Português
}

Dissertação apresentada como requisito parcial para obtenção do grau de Mestre pelo Programa de Pós-graduação em Informática da PUC-Rio.

Orientador: Prof. Sérgio Colcher 


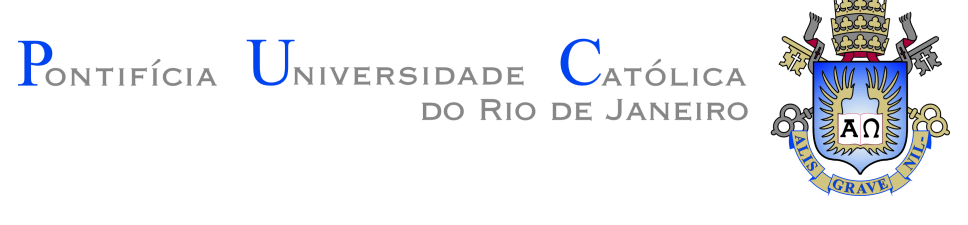

Guilherme Sant'Anna Varela

\title{
Anotação Profunda de Papéis Semânticos para \\ o Português
}

Dissertação apresentada como requisito parcial para obtenção do grau de Mestre pelo Programa de Pós-graduação em Informática da PUC-Rio. Aprovada pela Comissão Examinadora abaixo assinada.

\author{
Prof. Sérgio Colcher \\ Orientador \\ Departamento de Informática - PUC-Rio \\ Profa. Maria Claudia de Freitas \\ Departamento de Letras - PUC-Rio
}

Prof. Leandro Guimarães Marques Alvim

- UFRRJ

Prof. Ruy Luiz Milidiú

Departamento de Informática - PUC-Rio

Prof. Márcio da Silveira Carvalho

Coordenador Setorial do Centro

Técnico CientíficoDepartamento de Informática - PUC-Rio 
Todos os direitos reservados. É proibida a reprodução total ou parcial do trabalho sem autorização da universidade, do autor e do orientador.

\section{Guilherme Sant'Anna Varela}

Graduaded in electrical engeneering by the Pontifícia Universidade Católica do Rio de Janeiro (PUC-Rio). His research is focused in Machine Learning and Natural Language Processing.

Ficha Catalográfica

Varela, Guilherme Sant'Anna

Anotação Profunda de Papéis Semânticos para o Português / Guilherme Sant'Anna Varela; orientador: Sérgio Colcher. - 2019.

$74 \mathrm{f}$ : il. color. ; $30 \mathrm{~cm}$

Dissertação (mestrado) - Pontifícia Universidade Católica do Rio de Janeiro, Departamento de Informática, 2019.

Inclui bibliografia

1. Informática - Teses. 2. Aprendizado de Máquina;. 3. Aprendizado de Máquina Profundo;. 4. Processamento de Linguagem Natural;. 5. Anotação de Papéis Semânticos;. I. Colcher, Sérgio. II. Pontifícia Universidade Católica do Rio de Janeiro. Departamento de Informática. III. Título. 


\section{Agradecimentos}

O primeiro obrigado vai para o meu orientador, Prof. Ruy Luiz Milidiú com quem a convivência e as conversas geraram contribuições tanto profissionais como pessoais. Sou grato também pela revisão minunciosa da Prof a Maria Claudia de Freitas, que enriqueceram esse trabalho ( os eventuais erros residuais são de autoria minha). Ao Prof. Sérgio Colcher obrigado pelo apoio nessa jornada.

Obrigado à PUC-Rio que me proporcionou essa oportunidade de crescimento pessoal.

O presente trabalho foi realizado com apoio da Coordenação de Aperfeiçoamento de Pessoal de Nível Superior - Brasil (CAPES) - Código de Financiamento 001.

Aos meus amigos Rafael Rocha e Luís Müller, obrigado pelas conversas construtivas sobre aprendizado de máquina. Ao Miguel Brito, rato de laboratório, um abraço. Ao time do Digibot agradeço pela camaradagem infinita.

À diretoria do AML é uma tremenda honra trabalhar com vocês.

À minha família agradeço o apoio.

À minha noiva, nós conseguimos. 


\section{Resumo}

Varela, Guilherme Sant'Anna; Colcher, Sérgio. Anotação Profunda de Papéis Semânticos para o Português. Rio de Janeiro, 2019. 74p. Dissertação de Mestrado - Departamento de Informática, Pontifícia Universidade Católica do Rio de Janeiro.

Vivemos em um mundo complexo, no qual incontáveis fatores aparentemente desconexos - tais como a lei de Moore que dita um aumento exponencial da capacidade de processamento em um chip de silício, a queda do custo de espaço de armazenamento e a adoção em massa de smartphones colaboram para a formação de uma sociedade progressivamente interdependente. Todos os dias são criados 2,5 quintilhões de bytes de dados, de fato $90 \%$ dos dados no mundo foram criados nos últimos dois anos. Domar os padrões salientes aos dados separando informação do caos torna-se uma necessidade iminente para a tomada de decisão dos indivíduos e para sobrevivência de organizações. Nesse cenário a melhor resposta dos pesquisadores de Processamento de Linguagem Natural encontra-se na tarefa de Anotação de Papéis Semânticos. APS é a tarefa que tem o audacioso objetivo de compreender eventos, buscando determinar 'Quem fez o que e aonde', 'Quais foram os beneficiados?' ou 'Qual o meio utilizado para atingir os fins'. APS serve como tarefa intermediária para várias aplicações de alto nível e.g information extraction, question and answering e agentes conversacionais. Tradicionalmente, resultados satisfatórios eram obtidos apenas com alta dependência de conhecimento específico de domínio. Para o português, através desta abordagem, o sistema estado da arte da tarefa para é de 79,6\% de pontuação F1. Sistemas mais recentes dependem de uma série de subtarefas, obtém $58 \%$ de pontuação F1. Nessa dissertação, exploramos um novo paradigma utilizando redes neurais recorrentes, para o idioma do português do Brasil, e sem subtarefas intermediárias obtendo uma pontuação de 66,23

\section{Palavras-chave}

Aprendizado de Máquina; Aprendizado de Máquina Profundo; Processamento de Linguagem Natural; Anotação de Papéis Semânticos; 


\section{Abstract}

Varela, Guilherme Sant'Anna; Colcher, Sérgio (Advisor). Deep

Semantic Role Labeling for Portuguese. Rio de Janeiro, 2019.

74p. Dissertação de Mestrado - Departamento de Informática,

Pontifícia Universidade Católica do Rio de Janeiro.

We live in a complex world in which a myriad of seemingly unrelated factors - such as Moore's law which states that the processing capacity on a silicon wafer should increase exponentially, the fall of storage costs and mass adoption of smart-phones contribute to the formation of an increasingly inter-dependent society: 2.5 quintillion bytes of data are generated every day, in fact ninety percent of the world's data were created in the last few years. Harnessing the emerging patterns within the data, effectively separating information from chaos is crucial for both individual decision making as well as for the survival of organizations. In this scenario the best answer from Natural Language Processing researchers is the task of Semantic Role Labeling. SRL is the task the concerns itself with the audacious goal of event understanding, which means determining 'Who did what to whom', 'Who was the beneficiary?' or 'What were the means to achieve some goal'. APS is also an intermediary task to high level applications such as information extraction, question and answering and chatbots. Traditionally, satisfactory results were obtained only by the introduction of highly specific domain knowledge. For Portuguese, this approach is able to yields a F1 score of $79.6 \%$. Recent systems, rely on a pipeline of sub-tasks, yielding a $\mathrm{F} 1$ score of $58 \%$. In this dissertation, we adopt a new paradigm using recurrent neural networks for the Brazilian Portuguese, that does not rely on a pipeline, our system obtains a score of $66.23 \%$.

\section{Keywords}

Machine Learning; Deep Learning; Natural Language Processing; Semantic Role Labeling; 


\section{Sumário}

1 Introdução $\quad 12$

$\begin{array}{lll}1.1 & \text { Contextualização } & 12\end{array}$

$\begin{array}{lll}1.2 & \text { Objetivo } & 13\end{array}$

$\begin{array}{lll}1.3 & \text { Organização } & 14\end{array}$

2 Anotação Automática de Papéis Semânticos $\quad 15$

2.1 Score $F_{1} \quad 15$

2.2 Decomposição em Subtarefas 16

$\begin{array}{ll}\text { 2.2.1 Poda de Árvore Sintagmática } & 16\end{array}$

2.2.2 Identificação de Argumentos 17

$\begin{array}{ll}\text { 2.2.3 Classifição de Argumentos } & 18\end{array}$

$\begin{array}{lll}2.2 .4 & 18 \text { Inferência } & 18\end{array}$

2.2.5 Reconhecimento de predicado alvo 19

2.3 Trabalhos Relacionados 19

2.3.1 Idioma: Inglês 19

2.3.2 Idioma: Português 24

3 Anotação de Papéis Semânticos $\quad 26$

3.1 Teoria Lingüística 26

$\begin{array}{lll}3.2 & \text { PropBank } & 29\end{array}$

$\begin{array}{lll}\text { 3.3 PropBank.Br } & 32\end{array}$

4 Aprendendo Seqüências $\quad 36$

4.1 Representação de Palavras $\quad 36$

4.1.1 Word2Vec 38

4.1.1.1 CBOW: Sacola de palavras contínua 38

$\begin{array}{ll}\text { 4.1.1.2 Skipgram } & 39\end{array}$

$\begin{array}{ll}4.1 .2 \text { Wang2 } \mathrm{Vec} & 39\end{array}$

$\begin{array}{ll}4.1 .3 \text { GloVe } & 39\end{array}$

4.2 Redes Neurais Recorrentes 40

4.2.1 Redes Neurais Recorrentes Bidirecionais 41

4.2.2 O problema do gradiente minguante explosivo 42

4.2.3 Long Short Term Memory 43

4.3 Predição Estruturada 44

4.3.1 Conditional Random Fields 45

$\begin{array}{lll}\text { 4.3.2 Perceptron Estruturado } & 47\end{array}$

5 Metodologia $\quad 53$

5.1 Pré processamento 53

5.1.1 Seleção de atributos padrão ouro 53

5.1.2 Transformação de tokens 54

5.1.3 Extração de atributos $\quad 55$

5.2 Redes Neurais Recorrentes 56

5.2.1 BiLSTM 56 
$\begin{array}{lll}\text { 5.2.2 DBLSTM } & 57\end{array}$

$\begin{array}{lll}5.3 & \text { Predição Estruturada } & 57\end{array}$

6 Resultados Experimentais $\quad 59$

6.1 Etapa $1 \quad 59$

$\begin{array}{lll}6.2 & \text { Etapa } 2 & 61\end{array}$

7 Conclusão $\quad 64$

8 Referências bibliográficas $\quad 65$

$\begin{array}{ll}\text { A Apêndice } & \mathbf{7 3}\end{array}$

A.1 O Grafo de Computação $\quad 73$ 


\section{Lista de figuras}

Figura 2.1 Sintaxe e Semântica (fonte: PropBank.Br) 17

Figura 2.2 Rede Convolutiva (28). 21

$\begin{array}{lll}\text { Figura 2.3 Atributos no sistema (9). } & 21\end{array}$

Figura 2.4 Sentença segundo um mecanismo de atenção (33). 23

Figura 2.5 Seqüência de subtarefas (22). 25

$\begin{array}{lll}\text { Figura 3.1 Classe de verbo spray. } & 28\end{array}$

Figura 3.2 Três proposições do PropBank 32

Figura 3.3 Exemplo do PropBank.Br 34

$\begin{array}{lll}\text { Figura } 4.1 \quad \text { word2vec (53) } & 37\end{array}$

Figura 4.2 CBOW: sacola contínua de palavras (53) 38

$\begin{array}{lll}\text { Figura 4.3 Skipgram (53) } & 39\end{array}$

Figura 4.4 O grafo de computação de uma RNR 40

Figura 4.5 O grafo de computação de uma Bi RNR 41

Figura 4.6 O grafo de computação de uma LSTM 43

Figura 4.7 O perceptron (62) 47

Figura 4.8 Treliça 48

$\begin{array}{lll}\text { Figura } 4.9 \text { Treliça } & 50\end{array}$

Figura 4.10 Mapa de custo $t=0 \quad 50$

Figura 4.11 Mapa de custo $t=1 \quad 51$

Figura 4.12 Mapa de custo $t=2 \quad 51$

Figura 4.13 Mapa de custo $t=2 \quad 51$

Figura 4.14 Mapa de custo $t=4 \quad 52$

Figura 5.1 Pré processamento $1^{\mathrm{a}}$ etapa. $\quad 54$

Figura 5.2 Pré processamento $2^{\mathrm{a}}$ etapa. $\quad 55$

Figura 5.3 Pré processamento $3^{\mathrm{a}}$ etapa. $\quad 56$

$\begin{array}{lll}\text { Figura 5.4 BiLSTM Diagrama } & 57\end{array}$

$\begin{array}{lll}\text { Figura 5.5 DBLSTM Diagrama } & 58\end{array}$

$\begin{array}{lll}\text { Figura A.1 O gráfico de computação. } & 73\end{array}$

$\begin{array}{lll}\text { Figura A.2 Desdobramento do grafo de computação. } & 74\end{array}$ 


\section{Lista de tabelas}

Tabela 2.1 Leaderboard para sistema de APS para o inglês. 23

Tabela 2.2 Leaderboard para sistema de APS para o português. $\quad 24$

Tabela 3.1 Os Proto-Papéis de Dowty 28

Tabela 3.2 Descrição dos argumentos dos verbos comprar e vender 30

Tabela 3.3 Papéis usualmente assumidos pelos argumentos 30

Tabela 3.4 Papéis adjuntos (45) 30

Tabela 3.5 PropBank.Br v1.0 partições. 35

Tabela 5.1 Part-of-Speech 54

$\begin{array}{lll}\text { Tabela 6.1 Resultados da experimentais } 1 . & 60\end{array}$

Tabela 6.2 Resultados etapa $2 . \quad 62$

Tabela 6.3 Resultados finais. 63

Tabela 6.4 Sistemas por atributos padrão ouro 63

Tabela 6.5 Sistemas por sub tarefas 63 


\title{
Lista de Abreviaturas
}

\author{
APS - Anotação de Papéis Semânticos \\ AAPS - Anotação Automática de Papéis Semânticos \\ PLN - Processamento de Linguagem Natural \\ RN - Redes Neurais (Artificiais) \\ MLP - Multi Layer Perceptron \\ SVM - Support Vector Machines \\ RNR - Redes Neurais Recorrentes \\ LSTM - Long Short-Term Memory Networks \\ PGME - Problema do Gradiente Minguante/Explosivo
}




\section{Introdução}

\section{1}

\section{Contextualização}

A análise de semântica do texto, em nível da sentença, é voltada para a caracterizacão de eventos tais quais determinar 'quem' fez 'oque' à 'quem', 'aonde', 'como' e 'quando'. O predicado de uma oração (tipicamente o verbo) estabelece 'oque' ocorreu e os demais constituintes da sentença expressam participantes desse evento tais como ('como' e 'quando'). É prerrogativa da anotação de papéis semânticos (APS) indicar exatamente quais são os relacionamentos semânticos entre esses participantes e propriedades, essas relações são limitadas à uma determinada lista pré especificada pelo predicado (ou classe de predicados). A fim de atingir esse objetivo, os argumentos constituintes que assumem algum papel precisam ser primeiramente identificados e seus papéis devem ser devidamente alocados. (5) A tarefa possui a dupla atribuição: Identicação dos constituintes que possuem um papel semântico, inclusive aqueles que não possuem papel algum, e a conseqüente classicação destes papéis. Conforme (1) (72):

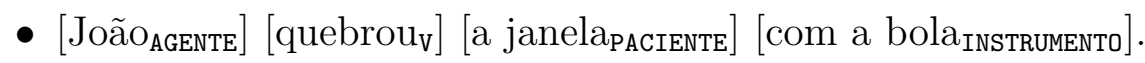

- [Os turistas EXPerienciador] [admiraramv] [a paisagem Tema $_{\text {Ta }}$.

A tarefa de anotação automática de papéis semânticos foi criada em 2002 (24) quando pesquisadores utilizaram o recurso lexical disponível chamado FrameNet (3) para fazer anotação de papéis específicos tais como vendedor, comprador e orador. A pesquisa no entanto seria propulsionada apenas em 2004 e 2005 quando a tarefa de anotação automática de papéis semânticos, se tornou tema da ConLL Shared Task 2004 e ConLL Shared Task 2005 respectivamente. As competições tornaram o recurso lexical PropBank (43) disponível para pesquisadores. O PropBank diferentemente do FrameNet é o primeiro recurso lexical produzido com o objetivo explícito de servir de corpus para a pesquisa em Processamento de Linguagem Natural. E desde o seu lançamento outros recursos lexicais têm sido produzidos com esse mesmo objetivo; OntoNotes (73), NomBank (74). Em multíplos idiomas; Português (47), 
Catalão, Chinês, Czeco, Alemão, Japonês e Espanhol (76). E por meio de diferentes competições; ConLL Shared Task 2005 (45), SemEval 2007 Task 9 (76), ConLL Shared Task 2012 (73).

Anotação automática de papéis semânticos serve como tarefa intermediária para uma série de aplicações tais como extração de informações $(10,11)$, sistemas de pergunta resposta (12), resumo de texto (13) e tradução automática $(14,15,16)$. Tais aplicações são orientadas à prover capacidade interpretativa e consequente exploração da progressiva geração de dados ${ }^{1}$ por parte da humanidade. A tarefa é também desafiadora, tendo no espaço de uma década modesta melhora da pontuação $F_{1}$ 1,9\% partindo de 79,4\% (8) em 2005 para $82,8 \%$ (9) em 2015. A pontuação estado da arte para o idioma Inglês é $F_{1}$ $86,4 \%(32)$.

O recurso lexical do PropBank.Br (47) segue os padrões de anotação estabelecidos pelo PropBank, e embora tenha recebido atualizações a versão mais utilizada por pesquisadores de anotação de papéis semânicos para o Português é a 1.0. Os trabalhos para o Português seguem abordagens semelhantes à literatura para o Inglês, o primeiro trabalho foi produzido por Alva Machego, 2013 (20) baseado em (8). O trabalho faz amplo uso de atributos sintático tais como arvores sintagmáticas padrão ouro e é fruto de uma sequência de subtarefas. Tendo obtido uma pontuação $F_{1} 79,7 \%$. O segundo trabalho, foi produzido por Fonseca, 2013 (41) baseado em (28), e utiliza uma rede neural convolutiva, obtendo uma pontuação $F_{1} 57,25 \%$. O terceiro trabalho, foi produzido por Garrido, 2017 (22), e utilizando uma sequência de subtarefas com atributos linguísticos estimados através de CRF. O trabalho obteve uma pontuação $F_{1} 58,00 \%$.

\section{2}

\section{Objetivo}

Esta dissertação propõe um modelo para anotação de papéis semânticos para o português do Brasil, utilizando o recurso lexical PropBank.Br. A arquitetura do modelo faz uso de redes neurais recorrentes, que são redes neurais multicamadas voltadas ao aprendizado de seqüências. A escolha de redes neurais recorrentes é inspirada no trabalho (9), que foi o primeiro no idioma do inglês a superar (8) mesmo sem utilizar sequência de subtarefas e apenas empregando o predicado padrão ouro. O objetivo do trabalho é desenvolver um sistema apenas com a informação do predicado padrão ouro, e produzir um sistema fim-a-fim para o português do Brasil.

\footnotetext{
${ }^{1}$ https://www-01.ibm.com/common/ssi/cgi-bin/ssialias?htmlfid=WRL12345USEN
} 


\section{3 \\ Organização}

Este documento está organizado conforme descrito a seguir: O Capítulo 2 traz a evolução da tarefa de APS tanto para o inglês quanto para o português, avaliada de forma objetiva através da métrica $F_{1}$ e de forma qualitativa abordando características como a prevalência de atributos linguísticos, ou se utiliza ou não multíplas subtarefas para a resolução sua resolução. O Capítulo 3 apresenta a teoria lingüística que orientou o desenvolvimento do PropBank. Naturalmente, o PropBank também é apresentado assim como a sua variante no idioma do português do Brasil - o PropBank.Br. O Capítulo 4 traz os modelos de representação de texto word2vec assim como as arquiteturas de apredizado profundo que vêm sendo empregadas por pesquisadores para a resolução da tarefa. No Capítulo 5, apresentamos a arquitetura adotada para rodar os experimentos. O Capítulo 7 traz as conclusões deste trabalho, bem como recomendações para trabalhos futuros. 


\section{2}

\section{Anotação Automática de Papéis Semânticos}

Este Capítulo é dedicado à exposição da evolução da tarefa de anotação de papéis semânticos conforme registrada na literatura, para os idiomas do Inglês e do Português.

A motivação é que, o volume de publicações para o Inglês é predominante, sendo assim os autores dos trabalhos em Português tendem a adaptar sistemas do Inglês para o Português. Alguns trabalhos para AAPS em Português como Hartmann e Aluísio, 2017 (17) e Amancio e Aluísio 2009 (18), não são diretamente comparáveis com o sistema apresentado já que utilizam um corpus diferente ou são dedicados a modelar apenas as etiquetas A0 e A1 do PropBank.Br.

Além do score $F_{1}$ os sistemas, podem ser qualificados pela sua dependência de atributos linguísticos e naqueles que apresentam multitarefas. A adoção de arquiteturas de aprendizado profundo possibilitou, que os sistemas fossem treinados de maneira fim à fim, isto é sem a necessidade da resolução de sub tarefas intermediárias que efetivamente limitam a pontuação $F_{1}$ máxima. Enquanto, ao mesmo tempo, reduziu a dependência de atributos linguísticos.

\section{1}

Score $F_{1}$

O score $F_{1}$ é a principal métrica de avaliação de um sistema de anotação de papéis semânticos, ela é composta de precisão $(p)$ e cobertura $(c)$. Precisão é a proporção de argumentos preditos que estão corretas. Cobertura é a proporção de argumentos corretos que é predita pelo sistema. $F_{1}$ é a média harmônica entre precisão e cobertura definida como:

$$
F_{1}=\frac{2 p c}{p+c}
$$

A métrica é calculada utilizando as predições do sistema em um conjunto de teste com exemplos não vistos durante a etapa de treino. No caso específico da ConLL 2005 Shared Task há dois conjuntos de teste que são avalidados conjuntamente. É o conjunto de teste WSJ seção 21 (in-sample) e um outro corpus anotado Brown. Autores tendem a divulgar os scores também de forma separada. 


\section{2 \\ Decomposição em Subtarefas}

Os primeiros sistemas de anotação automática de papéis semânticos, são predominantemente dependentes de uma seqüência de tarefas que são executadas de forma serial, $(8,19,20)$. Então os pesquisadores estavam concentrados em entender a dependência entre sintaxe e semântica, utilizando duas construções lingüísticas. As árvores sintagmáticas (parse trees ou synthactic tree) e sintagmas (shallow parsing ou chunk) são dois dos atributos linguísticos que contribuem para a tarefa de APS. A Figura 2.1 ilustra um exemplo de árvore de sintágmas, e os respectivos papéis semânticos em diferentes formatos.

As arquiteturas eram compostas dos seguintes estágios: Poda de Árvore de Sintagmas, Identificação de Argumentos, Classificação de Argumentos e Inferência. Em particular o objetivo das etapas de poda e identificação é identificar candidatos para um dado predicado. Nos primeiros três estágios decisões são feitas de maneira independente, i.e informações entre argumentos não é incorporada e são combinadas no estágio de inferência, com a introdução de restrições lingüísticas (27). Adicionalmente, sistemas que processam texto bruto implementam a tarefa de Identificação de predicado com o objetivo de identificar o verbo que faz o papel de predicado na sentença.

Trabalhos mais recentes têm empregado algumas dessas tarefas como He, et al 2017 (21) utilizam a etapa de inferência com um algoritmo the menor caminho A*. Enquanto Garrido, 2017 (22) fazem identificação de argumentos, classificação de argumentos e identificação de predicados.

\subsection{1}

\section{Poda de Árvore Sintagmática}

O objetivo da poda é excluir constituintes da árvore com poucas chances de se tornar argumento. Trata-se de um algoritmo recursivo em dois passos Xue e Palmer, 2004 (23). O algoritmo seleciona os constituintes vizinhos ao verbo, caso o tipo de constituinte seja PP os filhos também são retornados. O passo recursivo faz com que o próximo nó seja o pai do constituinte VP, o algoritmo se encerra quando chega à raiz. No caso do exemplo na Figura 2.1 os candidatos à argumentos são: [A direção de o novo semanal ${ }_{\mathrm{NP}}$ ], [por Ewaldo Ruy $_{\mathrm{PP}}$ ], [Ewaldo Ruy $\mathrm{NP}$ ] 


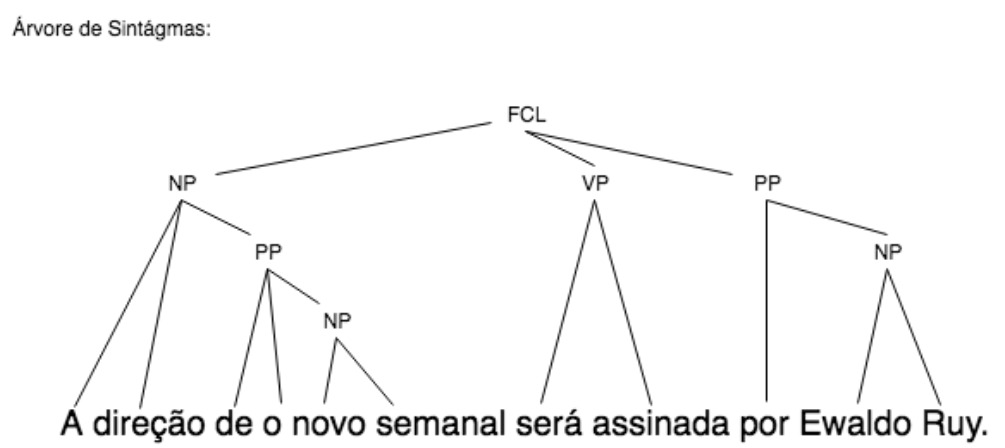

Sintágmas:

[A direção $\mathrm{NP}_{\mathrm{NP}}$ [de $\mathrm{O}_{\mathrm{PP}}$ ] [novo semanal $\left.\right|_{\mathrm{NP}}$ ] [será assinadav] [por ${ }_{\mathrm{PP}}$ [ [Ewaldo RuyNP].

APS (arvore plana):

[A direção de o novo semanal ${ }_{A 1}$ ] [será assinadav] [por Ewaldo RuyAo].

APS (IOB):

B-A1 I-A1 I-A1 I-A1 I-A1 I-A1 B-V I-V B-A0 I-A0 I-A0 O

APS (IOBES):

B-A1 I-A1 I-A1 I-A1 I-A1 E-A1 B-V E-V B-A0 I-A0 E-A0 O

Figura 2.1: Sintaxe e Semântica (fonte: PropBank.Br)

\subsection{2}

\section{Identificação de Argumentos}

Nesta fase os constituintes que participam de um argumento para o predicado alvo são delimitados. Quando existe a árvore sintática os sintagmas gerados no passo anterior devem ser classificados por um classificador binário que gera os candidatos. No caso do exemplo na Figura 2.1 a saída desta etapa seria [A direção de o novo semanal 1 ], [por Ewaldo Ruy 1 ], [Ewaldo Ruyo].

Quando apenas chunks estão disponíveis então os classificadores devem discriminar entre início e final de intervalo. Para representar intervalos a partir tokens são utilizados IOB e IOBES.

1. IOB Tokens que marcam o início de um argumento são marcados com a etiqueta B. Demais tokens participando de um argumento são marcados com a etiqueta I. Se um token não participa de um argumento para determinado predicado então serão marcados com a etiqueta 0.

2. IOBES A principal distinção está no tratamento de argumentos maiores que um token. Para tais intervalos, a etiqueta $\mathrm{B}$ marca o inicío do argumento, a etiqueta E marca o final do argumento, já os tokens intermediários são marcados com a etiqueta I. Se um argumento tem 
tamanho um então recebe a etiqueta $\mathrm{S}$ e finalmente se um token não é argumento este recebe etiqueta 0.

Uma representação da saída da etapa de indentificação de argumentos seria:

IOB: IOBES:

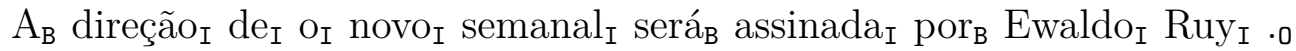

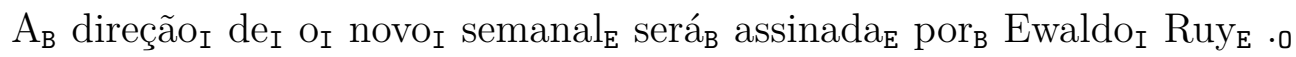

\subsection{3}

\section{Classifição de Argumentos}

Nesta fase, os argumentos delimitados provindos da etapa de identificação de argumentos são classificados. Uma etiqueta NULL ou 0 adicionada para denominar candidatos a argumentos que não são válidos (no caso é o ponto final).

IOB: IOBES:

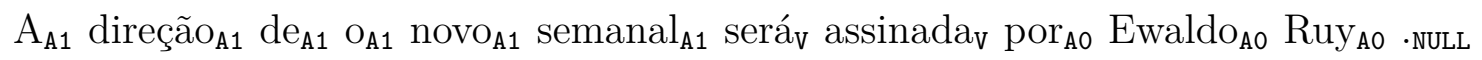
$A_{A 1} \operatorname{direção}_{A 1}$ de $_{A 1} o_{A 1}$ novo $_{A 1}$ semanal $_{A 1}$ seráv assinada por $_{A 0}$ Ewaldo $_{A 0}$ Ruy $_{A 0}$-NuLL

\subsection{4 \\ Inferência}

$\mathrm{Na}$ fase de inferência, regras lingüísticas e de consistência são utilizadas para unir as saídas das etapas anteriores (27) (21), este processo garante um formato válido de saída. Entre as restrições utilizadas estão:

- Argumentos não podem se sobrepor ao predicado.

- Argumentos devem estar contidos em uma oração.

- Se um predicado está fora da oração, seus argumentos não podem estar dentro do escopo desta oração.

- Classes de argumento A0-A5 não podem se repetir.

- Dado um predicado, algumas classes de argumentos são proibidas por exemplo o verbo 'escrever' não aceita argumento A5. 


\subsection{5}

\section{Reconhecimento de predicado alvo}

Trata-se de um classificador binário que associa à cada token se ele é ou não predicado para alguma sentença. Nas competições da CoNLL 2004 Shared Task e CoNLL 2005 Shared Task esta etapa é considerada como resolvida e o predicado é desconsiderado durante o computo da métrica $F_{1}$ para a competição.

$\mathrm{A}_{0}$ direção $_{0}$ de $_{0} \mathrm{o}_{0}$ novo $_{0}$ semanal $_{0}$ será $_{1}$ assinada $_{1}$ por $_{0}$ Ewaldo $_{0}$ Ruy $_{1} \cdot 0$

\section{3}

\section{Trabalhos Relacionados}

\subsection{1}

\section{Idioma: Inglês}

Em 2002, Gildea and Jurafksy (24) desenvolveram o primeiro sistema para anotar de forma automática papés para 50.000 sentenças em um corpus manufaturado em acordo com o formato estabelecido no FrameNet (25). O sistema foi capaz de determinar Agente e Tema de uma sentença e alguns predicados específicos como Orador e Mensagem.

Em 2004, AAPS foi o tema da conferência CoNLL 2004 Shared Task, onde seis seções do Wall Street Journal que é parte do Penn Treebank (26) foram anotadas com os papéis semânticos, as seções 15-18 foram utilizadas como treino, seção 20 foi reservada para desenvolvimento e finalmente a seção 21 foi utilizada como teste (51). O sistema prevalente à época, Hacioglu, et al 2004 (19) desenvolve um anotador sintático (e.g chunks NP, PP, VP), que por sua vez são reclassificados como argumentos semânticos (e.g B-A0, I-A1), em formato IOB. O anotador usa um separador $\mathrm{SVM}^{1}$ e obteve desempenho na medida de $F_{1} 69.49 \%$.

Em 2005, CoNLL 2005 Shared Task também foi dedicada à AAPS, em comparacão com o ano anterior teve a introdução de anotação de árvores sintagmáticas, aumento no número de exemplos e avaliação cruzada no Brown corpus. As seções WSJ 02-21 foram utilizadas como treino, 24 para desenvolvimento e 23 para teste. E mais as três seções no Brown corpus anotadas utilizando as regras do PropBank (45). O anotador é composto por uma pipeline de quatro estágios: (i) poda: apenas constintuintes da árvore sintagmática são considerados como argumentos e uma heurística é utilizada para podar

${ }^{1}$ SVM Support Vector Machines 
candidatos pouco prováveis. (ii) Identificação de argumentos: utiliza um classificador binário para identificar se um cadidato é ou não um argumento. (iii) Classificação de argumentos: aos argumentos identificados na etapa anterior, o anotador associa uma classe. (iv) Inferência: nesse estágio restrições lingüísticas (e.g 'cada verbo aceita apenas um argumento' e 'argumentos não se sobrepõe') são aplicadas de forma a combinar argumentos. O sistema obteve um score $F_{1}$ $79,44 \%$ no conjunto de teste oficial WSJ e um score $F_{1} 67,75 \%$ no conjunto de extra oficial Brown para um total combinado de score $F_{1} 77,92 \%$ WSJ + Brown. Alguns anos depois em 2008, Punyakanok, et al (27) afirmam que os atributos sintáticos são necessários para obter resultados satisfatórios nessa tarefa.

Em 2011, Collobert, et al (28) preconizou a aplicação de arquiteturas de aprendizado profundo no domínio de PLN, o sistema SENNA ${ }^{2}$ é uma rede convolutiva multicamadas, entre as inovações introduzidas: (i) Modelo de linguagem: um modelo de linguagem foi treinado separadamente para capturar relacionamentos entre as palavras. (ii) Redes neurais convolutivas multicamadas em detrimento de uma pipeline (iii) Uma arquitetura, várias tarefas ao invés da composição de várias sub tarefas. (iv) Menor dependência de atributos linguísticos, no caso de APS apenas árvores sintagmáticas foram utilizadas. A Figura 2.2 ilustra a arquitetura proposta, primeiro os atributos textuais passam por uma operação de table lookup, depois passam por uma operação de convolução e max poolling gerando filtros, a próxima camada combina os resultados e aplica uma função de ativação, a última camada produz uma função de perda em nível de seqüência. SENNA obteve estado da arte para as tarefas de PoS tagging, NER e Chunking. O mesmo não se aplicou a tarefa de Anotação de Papéis Semânticos e tendo obtido um $F_{1}$ $75,49 \%$ no conjunto de teste oficial WSJ.

Em Zhou e Xu, 2015 (9) os autores propõe uma outra estrutura de aprendizado profundo, trata-se de um sistema de rede neutral recorrente. Alimentado por proposições do corpus; as palavras são convertidas para vetores de tamanho 50, utilizando GloVe. e propagados pela RNR com 8 camadas de unidades LSTM ligadas de forma interlaçada. As representações são fornecidas para uma camada $\mathrm{CRF}$, que então é treinada com uma representação das etiquetas em formato IOB. A Figura 2.3 ilustra um exemplo utilizado pelo sistema: (i) time significa a posição do token dentro da proposição. É reiniciado em 1 à cada novo exemplo. (ii) argu o token em si, (iii) pred o predicado padrão ouro, (iv) $c t x-p$ uma janela de tamanho fixo em torno do predicado, que é obtida nesse exemplo coletando tokens precedentes e sucessores been e

${ }^{2}$ Semantic/syntactic Extraction using a Neural Network Architecture 


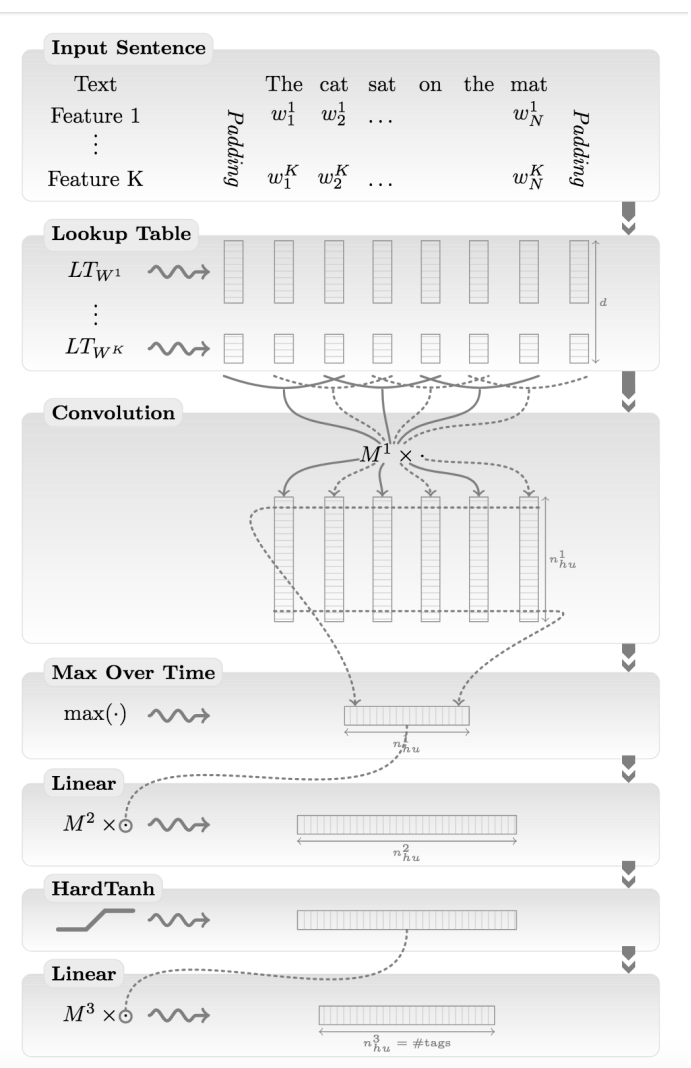

Figura 2.2: Rede Convolutiva (28).

set respectivamente. (v) $m_{r}$ serve como um marcador da região do predicado, trata-se de uma variável booleana que assume 0 se o predicado não foi visto e 1 se o predicado já foi encontrado em um tempo anterior. A motivação para os atributos (iv) e (v) é apenas a informação do predicado não é suficiente para descrever toda a variação de sentidos que o mesmo pode assumir. Seu sistema obteve um score $F_{1} 81,07 \%$ no conjunto de teste oficial WSJ + Brown da CoNLL 2005 Shared Task estebelecendo o novo estado da arte. E reverteu o consenso estabelecido de que as árvores sintagmáticas são necessárias para haja um bom desempenho em AAPS.

\begin{tabular}{|l|l|l|l|l|l|}
\hline time & argu & pred & ctx-p & $m_{r}$ & label \\
\hline 1 & A & set & been set . & 0 & B-A1 \\
2 & record & set & been set . & 0 & I-A1 \\
3 & date & set & been set . & 0 & I-A1 \\
4 & has & set & been set . & 0 & O \\
5 & n't & set & been set . & 0 & B-AM-NEG \\
6 & been & set & been set . & 1 & O \\
7 & set & set & been set . & 1 & B-V \\
8 & . & set & been set . & 1 & O \\
\hline
\end{tabular}

Figura 2.3: Atributos no sistema (9).

Em He, et al 2017 (21), os pesquisadores ainda utilizando redes neurais recorrentes, introduzem uma série de inovações; orientadas à minimização do tempo de treino como; (i) Simplificação da camada de saída; de CRF 
para Softmax. Ao alívio do PGME: (ii) Highway Connections Srivastava, et al 2015 (29) Zhang, et al 2016 (30) (iii) Dropout Recorrente (31) E a técnicas estabelecidas no campo de PLN, voltadas à melhoria da qualidade de previsão; (iv) Decodificação com etiquetas BIO, com restrições lingüísticas (v) Introdução de comitê de especialistas. O sistema obteve um score $F_{1} 84,6 \%$ no conjunto de teste oficial WSJ e um score $F_{1} 73,6 \%$ no conjunto de extra oficial Brown para um total combinado de score $F_{1} 83,2 \%$ WSJ + Brown.

Em Tan, et al 2017 (32), os autores utilizam um mecanismo de autoatenção (33) para combinar representações geradas por redes neurais artificiais, redes neurais recorrentes e redes neurais convolutivas. A motivação por trás do uso do mecanismo de atenção é contornar duas limitações das RNRs. A primeira delas está relacionada com a compressão de memória Cheng, et al 2016 (34). Como toda a memória do contexto está codificada em um vetor de tamanho fixo, isto implica que para que haja representação efetiva de contextos mais longos, maior capacidade de memória faz-se necessária. Em contrapartida, para sentenças menores, esse excesso de capacidade torna-se ocioso. A segunda delas está relacionada com a estrutura interna das sentenças que é hierárquica, RNR não são equipadas para representar estururas do tipo árvore e o número de não linearidades será sempre relacionada ao número de palavras. A Figura 2.4 reproduz a visualização de um mecanismo de atenção, diferentes seções da sentença ligadas à palavra atual making, estão ativadas (coloridas), diferentes heads (linhas) atendem à diferentes porções da rede. De acordo com os autores o sistema DeepAtt é capaz de representar dependências globais nas proposições de entrada. Portanto, duas palavras arbitrariamente distantes podem interagir de forma por menores caminhos $(\mathrm{O}(\mathrm{n})$ vs $\mathrm{O}(1))$. DeepAtt obteve uma pontuação $F_{1} 86.1 \%$ no conjunto de teste oficial WSJ e pontuação $F_{1}$ $74.80 \%$ no conjunto de teste extra oficial Brown para um total combinado de 84,60\% da CoNLL 2005 Shared Task.

Em He, et al 2018 (35), os pesquisadores integram os resultados Lee, et al. (36) para a tarefa de Resolução de Coreferência $(37,38)$. O sistema é capaz de prever conjuntamente predicados e argumentos, para tanto constrói representações para spans de argumentos e para predicados. As palavras passam por uma camada de embeddings e são alimentadas para uma RNR, as saídas da rede servem de entrada para uma ANN. O sistema obteve um score $F_{1} 86,00 \%$ no conjunto de teste oficial (WSJ) e score $F_{1} 76,1 \%$ no conjunto de teste Brown da CoNLL 2005 Shared Task.

Em Straubell, et al 2018 (39), os pesquisadores retornam à abordagem multitarefas (40). Esta decisão foi tomada após a análise de trabalhos anteriores ((21) entre outros) que indicam que aumentos substanciais em 


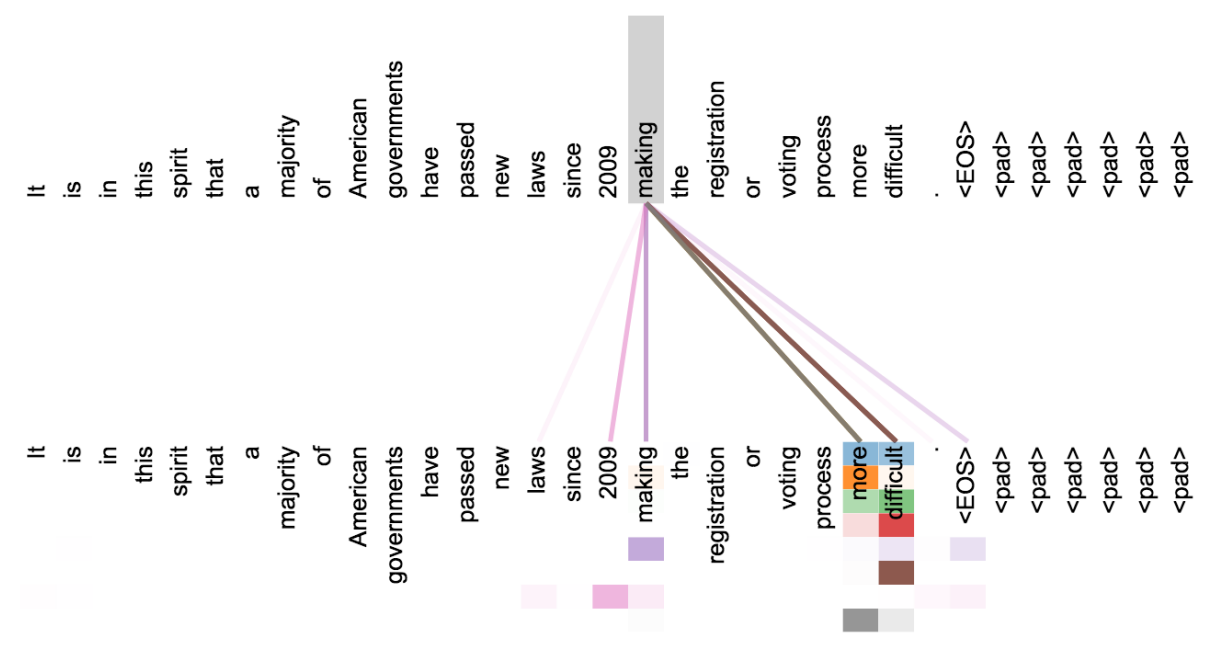

Figura 2.4: Sentença segundo um mecanismo de atenção (33).

acurácia podem ser obtidos, com a reintrodução de atributos sintáticos. O sistema LISA $^{3}$, combina a abordagem multitarefas com os mecanismos de atenção (33) e desempenha as seguites tarefas: (i) realiza a predição conjunta do predicado e da PoS (ii) parsing sintático (iii) atenta aos parentes sintáticos do token e (iv) os associa aos devidos papéis semânticos. De forma que camadas inferiores realizam a tarefa de detecção do predicado e PoS e associam os papéis semânticos em paralelo ao invés de em série. LISA obteve um score $F_{1} 86,90 \%$ no conjunto de teste oficial (WSJ) e score $F_{1} 74,66 \%$ no conjunto de teste Brown. da CoNLL 2005 Shared Task estebelecendo o novo estado da arte.

A Tabela 2.3.1 resume os resultados da pesquisa em Anotação de Papéis Semânticos para o Inglês ordenados, em ordem descrescente, a partir do score $F_{1}$ no conjunto de teste do WSJ. As colunas Comp. se referem à proporção dos exemplos preditos de forma perfeita. Avaliação no conjunto de teste Brown também foram disponibilizados. A coluna $\mathrm{W}+\mathrm{B}$ é o score $F_{1}$ dos dois datasets combinados.

Tan et al, 2017

Straubell et al, 2018

He et al, 2018

He et al, 2017

Zhou e Xu, 2015

Koomen et al, 2005

Collobert et al, 2011

$$
F_{1}
$$

$86,10 \%$

$86,04 \%$

$86,00 \%$

$84,6 \%$

$82,8 \%$

$79,4 \%$

$75,49 \%$
Brown $\quad \mathrm{W}+\mathrm{B}$

Comp. $\quad F_{1} \quad$ Comp. $\quad F_{1}$ $69.0 \% \quad 74,8 \% \quad 48,6 \% \quad 84,6 \%$

- $76,57 \% \quad-\quad-$

$-76,10 \%$

$66.5 \%$

$73.6 \%$

$69.4 \%$

$46.5 \%$

$83 \%$

$81 \%$

$53,8 \% \quad 67,8 \% \quad 32,2 \% \quad 77,9 \%$

Tabela 2.1: Leaderboard para sistema de APS para o inglês.

\footnotetext{
${ }^{3}$ Linguistically-informed self-attention
} 


\subsection{2}

\section{Idioma: Português}

Em Alva Manchego, 2013 (20), é proposto um modelo baseado em SVM, é composto de 4 subtarefas que conjuntamente possibilitam a anotação de papéis semânticos; (i) Identificação do predicado, identifica qual palavra serve como predicado da proposição. (ii) Poda, isto é a identificação de palavras, através da árvore de constituintes, que não possuem papel semântico na proposição. (iii) Identificação de Argumentos, treina-se um classificador binário para identificar se um uma palavra é argumento para o predicado ou não. (iv) Classificação de Argumentos, nessa fase aloca-se as etiquetas aos candidatos da fase anterior. O trabalho faz amplo uso da árvore sintagmática, conforme surgerido na literatura $(24,27)$ entre outros, gerando atributos derivados como caminho de uma determinada palavra até o verbo. O sistema obtém um score $F_{1} 79,70 \%$ na tarefa de anotação de papéis semânticos,

No mesmo ano Fonseca, 2013 (41), propõe dois modelos de distribuição de palavras, $\mathrm{HAL}^{4}$ e $\mathrm{RI}^{5}$ para converter as palavras em vetores. Estes vetores então são alimentados para uma rede neural convolutiva, conforme Collobert e Weston, 2008 (42), esta rede pode ter um ou dois estágios. A rede com um estágio segmenta os argumentos e os classifica. A rede com dois estágios é um sistema multitarefas; (i) A identificação de predicados. (ii) A classificação dos argumentos. O sistema obtém um score $F_{1} 57,25 \%^{6}$

Em Garrido, 2017 (22), o autor desenvolve um sistema de sub tarefas capaz de anotar textos brutos. O sistema é baseado em CRF e é composto por uma seqüência de subtarefas: (i) POS tagging, (ii) Identificação de Predicados, (iii) Identificação de Chunkings Sintáticos, (iv) Identificação de Argumentos, (v) Classificação de Argumentos. A Figura 2.5 mostra a pipeline de tarefas. O sistema obtém um score $F_{1} 58,00 \%$.

A Tabela 2.3.2 resume os resultados da pesquisa em Anotação de Papéis Semânticos para o Português ordenados, em ordem descrescente, avaliados com o script oficial de avaliação da ConLL 2004 Shared Task.

$\begin{array}{lc} & F_{1} \\ \text { Alva Manchego, 2013 } & 79,70 \\ \text { Garrido, 2017 } & 58,00 \\ \text { Fonseca, 2013 } & 57,25\end{array}$

Tabela 2.2: Leaderboard para sistema de APS para o português.

\footnotetext{
${ }^{4}$ Hyperspace Analogue to Language

${ }^{5}$ Random Indexing

${ }^{6}$ Utilzando os scripts daConLL 2004 Shared Task conforme (22) na tarefa de anotação de papéis semânticos.
} 


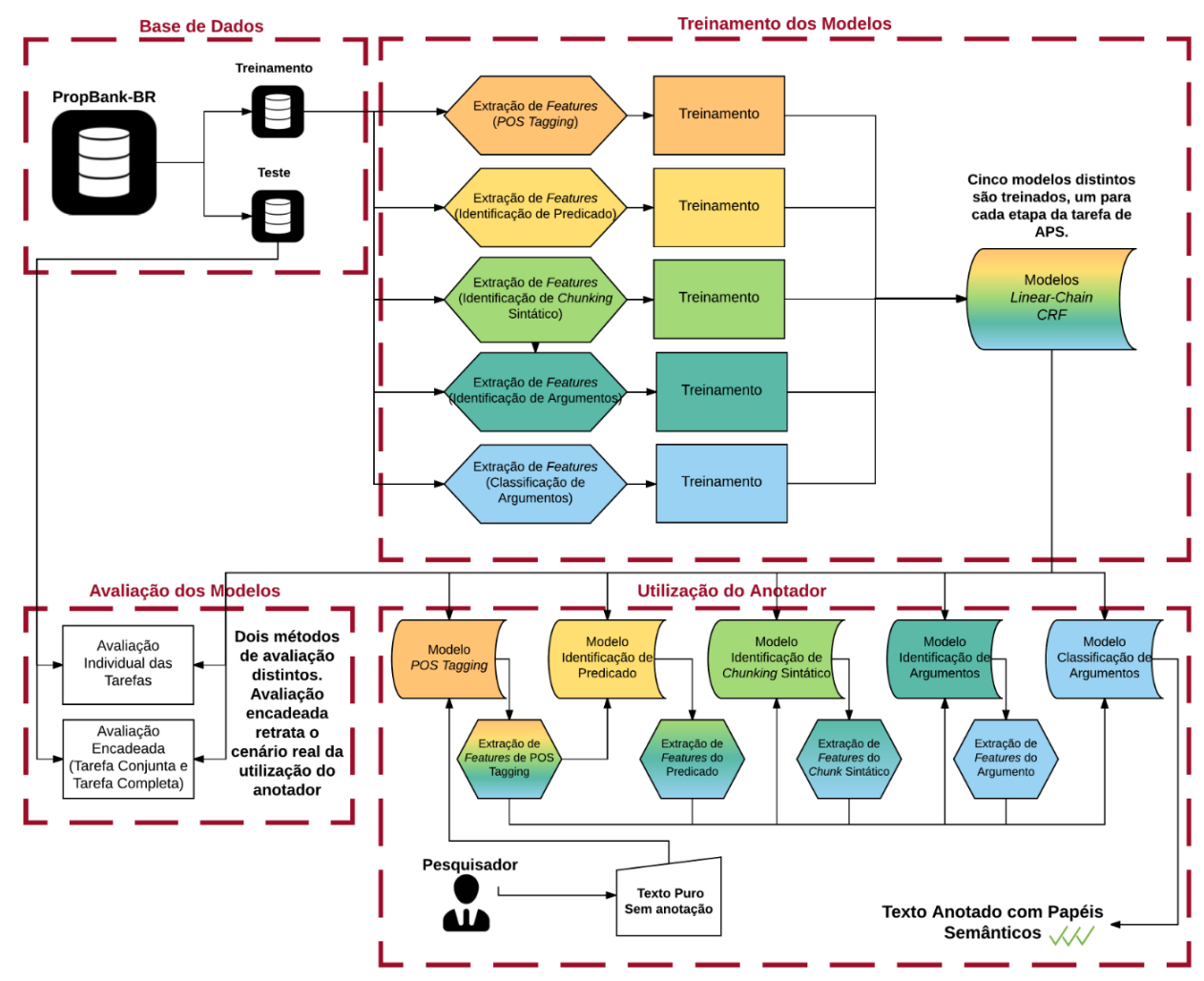

Figura 2.5: Seqüência de subtarefas (22).

Diferentemente do que ocorre na literatura dos sistemas em Inglês, o sistema prevalente em termos da métrica $F_{1}$ para o Português é amplamente baseado no trabalho de Koomen, et al 2005 e portanto faz uso de uma extensiva pipeline de tarefas (e.g as saídas de um classificador binário alimenta um classificador de argumentos) Adicionalmente, faz amplo uso da prática de engenharia de atributos, criando atributos sintéticos, a partir de conhecimento prévio linguístico tais como existência ou não de voz passiva. Ou o caminho na árvore sintagmática da palavra até o verbo. A príncipal razão apontada pelos autores dos trabalhos em português é o baixo número de exemplos. Com poucos exemplos a abordagem da construção automática de representações intermediátria pelas camadas de aprendizado profundo perde muito em eficácia. 


\section{3}

\section{Anotação de Papéis Semânticos}

Neste Capítulo restringimos a exposição da teoria lingüística aquela necessária para entender a motivação por trás do desenvolvimento do PropBank. o padrão PropBank é apresentado com exemplos, de forma a esclarecer os desafios enfrentados pelos pesquisadores. Essa dissertação, no entanto, versa sobre o PropBank.Br a variante do PropBank para o português do Brasil. Uma comparação entre os dois modos de anotação é feita dado que os resultados desse trabalho são afetados por eles. A escolha da versão 1.0 é justificada por ser a mesma versão utilizada por outros autores. E finalmente, as estatísticas para o corpus são apresentadas.

\section{1}

\section{Teoria Lingüística}

A descoberta de papéis semânticos foi feita por Panini, um gramático indiano, por volta de 4 A.C para o sânscrito. Mas o interesse dos pesquisadores foi reavivado por Fillmore em 1968. Neste trabalho, o autor defende que as orações são compostas por duas estruturas interrelacionadas: A forma de superfície, ou sintaxe regida pelas funções gramaticais usuais; sujeito, verbo, objeto e advérbio. E a forma profunda - semântica, regida pela gramática de casos. Fillmore identifica 6 desses casos gramaticais e assim como as suas restrições (1):

- Agente (A): O caso em que um ser animado instiga a ação identificado pelo verbo.

- Instrumento (I): O caso em que um força inanimada ou objeto é de forma causal envolvido na ação ou estado identificado pelo verbo.

- Dativo (D): O caso do ser animado sendo afetado pela ação descrita pelo verbo.

- Factivo (F): O caso do objeto ou ser sendo o resultado de alguma ação ou estado identificado pelo verbo, ou compreendido como parte do verbo.

- Locativo (L): O caso que define a localidade ou a orientação espacial do estado ou ação identificados pelo verbo. 
- Objetivo (0): O caso mais neutro, o caso de qualquer coisa representável pelo substantivo cujo papel na ação ou estado é identificado pelo verbo é identificável apenas pela interpretação semântica do verbo; provavelmente o conceito deve ser limitado para coisas que são afetadas pela ação ou estado identificado pelo verbo. O termo, não deve ser confundido com a noção objeto direto, nem com o nome do caso de superfície sinônimo ao acusativo.

Cada verbo, está associado à número de casos este relacionamento entre verbos e casos é chamado de case frames. Que por sua vez têm as seguintes propriedades:

- Eles ocorrem apenas uma vez na sentença.

- Cada verbo determina quais casos são obrigatórios e quais são opcionais. Casos obrigatórios não podem ser excluídos com o risco de produzir sentenças incorretas gramaticalmente. O verbo abrir, requer um AGENTE ou OBJETIVO:

$\checkmark\left[\mathrm{João}_{\mathrm{A}}\right]$ abriu $[$ a porta $\mathrm{O}]$ [com a chave $\left.\mathrm{I}\right]$.

$\checkmark\left[\mathrm{A} \mathrm{porta}_{0}\right]$ abriu.

$\times\left[\mathrm{J}_{\mathrm{O} a \tilde{O}} \mathrm{~A}_{\mathrm{A}}\right]$ abriu.

$\times\left[\mathrm{João}_{\mathrm{A}}\right]$ abriu $[$ com a chave $\mathrm{I}]$.

- Hierarquia para a escolha do sujeito:

- $\left[\mathrm{J}_{\mathrm{O}} \mathrm{O}_{\mathrm{A}}\right]$ abriu [a porta 0 .

- $\left[\mathrm{A}\right.$ chave $\left._{\mathrm{I}}\right]$ abriu [a porta 0 .

- $\left[\right.$ A porta $\left.{ }_{0}\right]$ abriu.

Estas definições não são exaustivas tendo sido revisadas por $(2,3)$. Atualmente, não existe um consenso entre pesquisadores com relação ao número de papéis ou ao seu respectivo grau de especificidade. Papéis semânticos têm variado de granularidade de um extremo ligado à uma situações extremamente específicas como por exemplo o verbo prender evoca os papéis de Suspeito, Autoridade e Ofensa em (3). Enquanto Dowty, 1991 (4) defende que os papeis semânticos podem ser descritos por um ou mais atributos de dois Proto-Papéis; o ProtoAgente e o Proto-Paciente conforme a Tabela 3.1. Um AGENTE prototípico teria todas as qualidades de Proto-Agente. Um EXPERIENCIADOR teria as propriedades Proto-Agente (b) e (e) e a propriedade Proto-Paciente (h).

A incerteza gerada pela falta de acordo no conceito linguístico se propaga para o trabalho de anotação automática de papéis semânticos. Papéis menos específicos tais como AGENTE e PACIENTE, são menos controversos e geram 


\begin{tabular}{l|l} 
Proto-Agente & Proto-Paciente \\
\hline a. envolvimento ativo & f. mudança de estado \\
b. senciência (ou percepção) & g. tema incremental \\
c. causa mudança de estado & h. afetado de forma causal \\
d. movimento (relativo à) & i. estacionário (relativo à) \\
e. existência independente & j. existência dependente
\end{tabular}

Tabela 3.1: Os Proto-Papéis de Dowty

menos esparsidade nos dados, e.g o AGENTE assume o papel de motorista para o verbo dirigir e o papel de orador para o verbo discursar (5).

Em Levin, 1993 (6) o foco do estudo dá-se na categorização de verbos em classes distintas. A hipótese levantada por Levin é que verbos que compartilham o mesmo padrão de alternância sintática retêm certa semelhança semântica. Por exemplo, verbos que admitem alternância entre tema (0) e locativo (L) pertencem a classe spray ${ }^{1}$. Verbos da classe spray, como load ou paint, envolvem mover alguma coisa para dentro ou sobre uma localidade e ocorre em verbos que encapsulam a idéia de colocação e cobertura. A alternância no entanto expressa diferenças entre completude e parcialidade, com uma variação é interpretada (ii) como enchendo um contêiner ou localidade completamente e outra alternação (i) não tem essa interpretação, conforme Figura 3.1. Enquanto os verbo acertar admite alternância entre tema (0) e

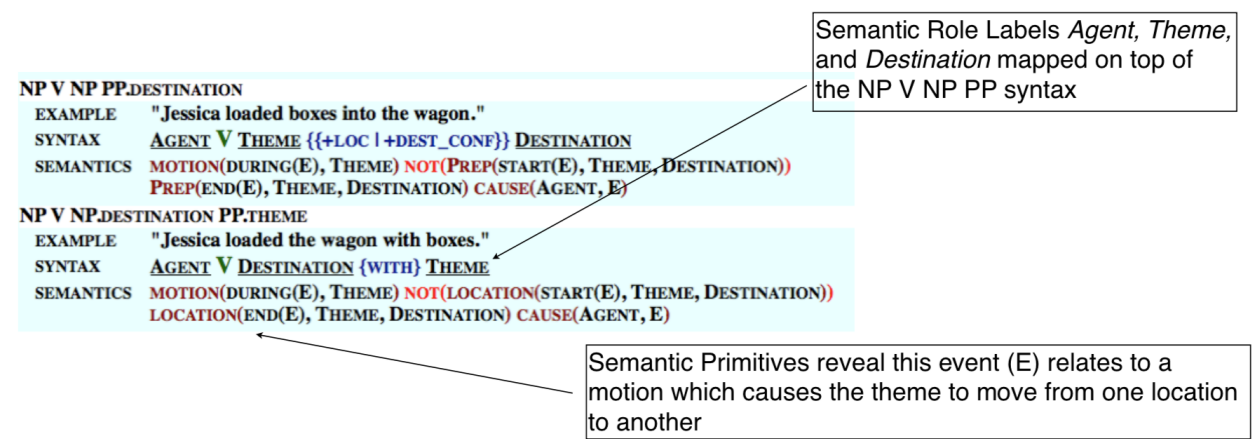

Figura 3.1: Classe de verbo spray.

instrumento (I) enquanto quebrar não.

- Luís acertou a cerca com o martelo.

- Luís acertou o martelo contra a cerca.

- Luís quebrou o muro com o martelo.

- Luís quebrou o martelo contra o muro.

${ }^{1}$ http://verbs.colorado.edu/verb-index/VerbNet_Guidelines.pdf 
Verbos são classificados de maneira hierárquica de acordo com a sua assinatura sintática, baseados nesses tipos de alternância. Ainda que as classes de verbo de Levin estejam explicitamente hierarquizadas de acordo com a estrutura de alternância sintática, verbos em classes similares retêm alguma semelhança semântica. O verbo quebrar implica mudança de estado e está associado à alguma causa. O verbo acertar está associado ao movimento e ao contato enquanto o verbo tocar implica a idéia de contato.

Levin, categorizou 3.100 verbos em 47 classes para o inglês. O suficiente para cobrir metade dos verbos do Penn Treebank. Outras limitações incluem; poucos sentidos para cada verbo e verbos ou expressões polissêmicos encontram pouca representatividade. E finalmente, algumas classes de verbo distintas possuem assinaturas sintáticas idênticas (7).

O trabalho de Levin não apenas serviu para a construção do léxico VerbNet mas também estabeleceu a fundação teórica para a criação das frame files que compõe o PropBank.

\section{2}

\section{PropBank}

PropBank é um corpus composto por proposições, que são os predicados (verbos) anotados e seus argumentos (papéis semânticos). Como cada sentença é composta por um ou mais predicados - cada conjunto de atributos pode ter mais que uma saída. Todas as anotações são feitas sobre o as árvores frasais do Penn TreeBank Marcus, et al 1993 (26) no sub-corpus de finanças referente ao Wall Street Journal (WSJ). O processo de anotação tem três partes principais: a rotulação de argumentos, a rotulação de modificadores adverbiais e a escolha de um sentido para o predicado. O objetivo de fornecer os argumentos juntamente com os sentidos é manter a consistência entre diferentes realizações sintáticas do mesmo verbo:

- $\left[\mathrm{JoãO}_{\mathrm{ARGO}}\right]$ quebrou [a janela $\left.\mathrm{ARG}_{\mathrm{AR}}\right]$.

- $\left[\right.$ A janela $\left.a_{\text {ARG1 } 1}\right]$ quebrou.

A rotulação de argumentos consiste na alocação de um argumento numerado $\mathrm{A} 0, \mathrm{~A} 1$, ... A5 para categorizar um papel semântico. Como supramencionado os papéis dependem do predicado e de um sentido. A Figura 3.2 trás os significados dos argumentos para os predicados comprar e vender (43): Uma generalização entre todos os argumentos não é possível, mas usualmente tem-se que os argumentos numerados assumem os papéis semânticos de acordo com a Tabela 3.3.

A rotulação de modificadores adverbiais do tipo AM consiste na escolha de seguimentos que atuam modificando o verbo tais como maneira (MNR), 


\begin{tabular}{l|l|l} 
& Comprar & Vender \\
\hline A0 & Comprador & Vendedor \\
A1 & Coisa comprada & Coisa vendida \\
A2 & Vendedor & Comprador \\
A3 & Preço Pago & Preço Pago \\
A4 & Beneficiário & Beneficiário
\end{tabular}

Tabela 3.2: Descrição dos argumentos dos verbos comprar e vender

\begin{tabular}{l|l} 
A0 & agente \\
A1 & paciente \\
A2 & instrumento, beneficiário ou atributo \\
A3 & ponto de partida, beneficiário ou atributo \\
A4 & ponto de chegada \\
A5 & modificador
\end{tabular}

Tabela 3.3: Papéis usualmente assumidos pelos argumentos

locativo (LOC) e temporal (TMP) conforme exemplo abaixo (44), enquanto a Tabela 3.4 trás a listagem completa dos argumentos adjuntos do tipo ARG-M:

O sr. Bush o encontrou privadamente, na Casa Branca, na quinta-feira.

- A0: sr. Bush

- A1: o

- AM-MNR: privadamente

- AM-LOC: na Casa Branca

- AM-TMP: na quinta-feira

\begin{tabular}{l|l} 
AM-ADV & propósito geral \\
AM-CAU & causa \\
AM-DIR & direção \\
AM-DIS & discurso \\
AM-EXT & extensão \\
AM-LOC & localidade \\
AM-MNR & maneira \\
AM-MOD & modo \\
AM-NEG & negação \\
AM-PNC & propósito \\
AM-PRD & predicador \\
AM-REC & recíproco \\
AM-TMP & temporal
\end{tabular}

Tabela 3.4: Papéis adjuntos (45) 
Adicionalmente às anotações dos papéis semânticos, e dos modificadores de verbo o padrão estabelece que um sentido deve ser dado aquele predicado naquela proposição. Os rolesets consistem na tripla; predicado, sentido e argumentos. Um verbo polissêmico pode ter mais de um roleset quando as diferenças em significado são distintas o suficientes à ponto de exigir um conjunto distinto de papel para cada roleset (43) segue o exemplo de dois rolesets do verbo em inglês leave ${ }^{2}$ :

leave.01: move away from

- ARG0: entity leaving

- ARG1: place left

- ARG2: attribute of place left

Exemplos:

- Intransitive: $\left[J_{o h n} n_{\mathrm{ARGO}}\right]$ left.

- Transitive: [This flight $_{\mathrm{ARGO}}$ ] leaves [Phoenix ARG1 $_{\mathrm{A}}$ [ at midnight ARGM-TMP $_{\text {] }}$.

- Attribute: [The move ARG0 $_{\text {Th }}$ left companies $\left._{\mathrm{ARG} 1}\right]$ [as outside bidders ARG2 $_{\mathrm{AR}}$. leave.02: to give

- ARG0: giver leaver

- ARG1: thing given

- ARG2: benefective given to

Exemplos:

- Transitive: [The buyout $\left._{\mathrm{ARG}}\right]$ left [about $\$ 130$ million $\left._{\mathrm{ARG} 1}\right]$ [in the bank ARGM-LOC].

- Ditransitive: $\left[\right.$ John $\left._{\mathrm{ARG} 0}\right]$ left [ cookies $\left._{\mathrm{ARG} 1}\right]\left[\operatorname{Mary}_{\mathrm{ARG} 2}\right]$.

- Double object: [John $\left.n_{\mathrm{ARGO}}\right]$ left [Mary ARG2 $_{\text {[ }}$ [ collection of run-down clocks ARG1].

- With variant: $\left[\right.$ An ambitious expansion $\left.{ }_{\mathrm{ARGO}}\right]$ has left $\left[\mathrm{Magma}_{\mathrm{ARG} 2}\right]$ [with excess capacity ARG1].

O exemplo ilustra também as dificuldades na aplicação de rolesets entre dois idiomas distintos: No português leave.01 assume o sentido de 'partir' enquanto leave.02 de 'deixar'.

A versão do PropBank, utilizada na ConLL 2005 Shared Task conta com anotações de papéis semânticos para as seções, do WSJ, 02-21 para treino,

2 http://www.lsi.upc.edu/ srlconll/resources/pb-frames.tar.gz 
23 para teste e 24 para validação, adicionalmente três seções do Brown corpus foram utilizadas. A Figura 3.2 mostra um exemplo de proposição do PropBank. As colunas se referem à (01) palavras, (02) Part-of-Speech tag, (03) Árvore sintagmática completa, (04) Entidades nomeadas, (05) Sentido do verbo de acordo com a frame file, (06) Predicados, (07) Argumentos para o verbo say, com A0 sendo o falante e A1 é aquilo que foi dito (08) Argumentos para o verbo brief, (09) Argumentos para o verbo leave com A0 sendo aquele que deixou e AM-DIR foi o destino. Opcionalmente, os atributos de base chunks e clauses também são fornecidos.

\begin{tabular}{|c|c|c|c|c|c|c|c|c|}
\hline Administration & NN & ( $\mathrm{S} 1$ ( S $(\mathrm{NP} *$ & * & - & - & $(\mathrm{A} 0 *$ & * & $*$ \\
\hline officials & NNS & *) & * & - & - & *) & * & * \\
\hline say & VBP & (VP* & * & 1 & say & $(\mathrm{V} *)$ & * & $*$ \\
\hline President & NNP & (SBAR (S (NP* & * & - & - & (A1* & (A1* & $(\mathrm{A} 0 *$ \\
\hline Bush & NNP & *) & (PER*) & - & - & $*$ & *) & *) \\
\hline was & AUX & (VP* & $*$ & - & - & * & $*$ & $*$ \\
\hline briefed & VBD & (VP* & * & 1 & brief & * & $(\mathrm{V} *)$ & $*$ \\
\hline throughout & IN & (PP* & * & - & - & * & (AM-TMP* & * \\
\hline Friday & NNP & (NP* & * & - & - & * & $*$ & * \\
\hline afternoon & NN & $*$ & * & - & - & * & * & * \\
\hline and & $\mathrm{CC}$ & * & * & - & - & * & * & * \\
\hline evening & NN & *)) & * & - & - & * & *) & $*$ \\
\hline , & , & * & $*$ & - & - & $*$ & * & $*$ \\
\hline even & RB & (SBAR* & * & - & - & * & (AM-TMP* & * \\
\hline after & IN & $*$ & * & - & - & * & * & * \\
\hline leaving & VBG & (S $(V P *$ & * & 1 & leave & * & * & $(V *)$ \\
\hline for & IN & $(\mathrm{PP} *$ & * & - & - & * & * & (AM-DIR* \\
\hline Camp & NNP & (NP* & * & - & - & $*$ & * & * \\
\hline David & NNP & (*)()(1)(1)(1) & (PER*) & - & - & *) & *) & *) \\
\hline . & . & *)) & $*$ & - & - & $*$ & * & * \\
\hline
\end{tabular}

Figura 3.2: Três proposições do PropBank

\section{3}

\section{PropBank.Br}

A metodologia de anotação do PropBank.Br seguiu, devido à restrições, um curso diferente ao do PropBank. Onde o primeiro passo foi a construção das frame files que descrevem os frame sets e a compilação de um guia de anotação, Anotator's Guidelines. Desta forma o trabalho pôde ser distribuído, com baixo índice de discordância entre anotadores. Para proposição foi adotado um esquema de anotação duplo-cego, cada desacordo era automaticamente detectado e resolvido por um adjucador. Em contrapartida, o projeto PropBank.Br (47) adotou o mesmo guia e as frame files do Inglês mas para o Português. E na primeira etapa foram anotados apenas os papéis semânticos, sem o sentido do verbo correspondente. A ferramenta de anotação utilizada, tanto para a construção das frame files quanto para a anotação do corpus foi SALTO (46) desenvolvida para a anotação de um projeto FrameNet para o alemão e ajustada pelos pesquisadores. Em uma segunda fase, 137 frame files específicas foram geradas para verbos em português. E camadas de anotações 
foram adicionadas posteriormente, como a adição de árvores de dependência e sentido do verbo, dando origem à 4 versões do corpus até o momento.

O objetivo dos pesquisadores Magali Duran e Sandra Aluísio (47) ao desenvolver o PropBank.Br é a criação de anotadores automáticos. E como o PropBank uma nova camada de anotação foi adicionada à um corpus anotado sintáticamente e revisado manualmente. O corpus escolhido foi a porção Brasileira do Bosque, o sub-corpus manualmente revisado da Floresta Sintá(c)tica ${ }^{3}$ (48) utilizando o parser PALAVRAS (49). O Bosque conta com 9368 sentenças, 4213 delas correspondem à variante Brasileira, tendo sido extraidas do jornal Folha de São Paulo em 1994.

O PropBank.Br está disponível em 4 versões distintas. Para manter o caráter comparativo à outros trabalhos, optou-se utilizar a versão 1.0 da base, porém abaixo estão listadas todas as versões (22):

- 1.0: Mesma utilizada por outras implementações de anotação de papel semântico para o português. Dividido em treino e teste com as mesmas partições utilizadas por outros autores (20, 41, 22). Esta versão apresenta as correções realizadas e descritas por (41) em seu trabalho.

- 1.1: Versão apresenta algumas correções realizadas, identificação do sentido do verbo em português e anotação de árvores de dependência.

- 2.0: Originado por uma extração do corpus PLN-BR sobre árvores não revisadas usando dois anotadores para cada sentença (anotação duplocego) (50).

- 3.0: Novamente geradas pelo parser PALAVRAS, o corpus utilizado foi retirado pelo particionamento do Buscapé (17), um corpus de opniões de usuários sobre produtos. As árvores sintáticas da amostra não foram revisadas por humanos.

A Figura 3.3 mostra uma sentença do corpus PropBank.Br ${ }^{4}$ versão 1.0: As colunas se referem à:

1. ID Posição da FORM, usualmente tempo, começa em 1 à cada nova proposição.

2. FORM forma da palavra. Palavras com hifén, e.g 'quinta-feira' ou que formam um sentido semântico, e.g 'Primeiro Mundo' são unidas pelo caracter ','

3. $\boldsymbol{L} \boldsymbol{E} \boldsymbol{M} \boldsymbol{M A}$ gold-standard é uma normalização da $F O R M$ as flexões são retiradas de artigos e verbos.

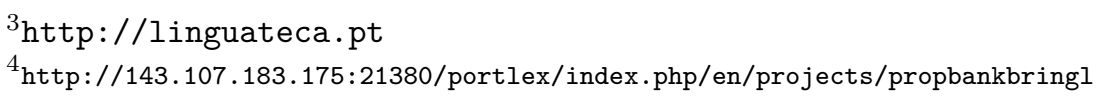


4. GPOS gold-standard etiquetas part-of-speech.

5. MORPH gold-standard atributos morfológicos da FORM

6. $\boldsymbol{S E N T E N C E ~ g o l d - s t a n d a r d ~ m a r c a d o r e s ~ d a ~ s e n t e n c ̧ a . ~}$

7. $\boldsymbol{C L} \boldsymbol{A} \boldsymbol{U} \boldsymbol{S} \boldsymbol{E}$ gold-standard tipo de oração no caso FCL a oração está na forma finita.

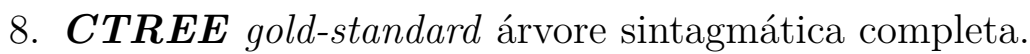

9. $\boldsymbol{P} \boldsymbol{R} \boldsymbol{E D}$ predicados semânticos da proposição.

10. $\boldsymbol{A} \boldsymbol{R} \boldsymbol{G}$ argumentos relativos ao predicado afirmar.

11. $\boldsymbol{A} \boldsymbol{R} \boldsymbol{G}$ argumentos relativos ao predicado ler.

Uma descrição completa do conteúdo de cada uma dessas colunas está além do escopo dessa dissertação. Os leitores interessados podem se referir à dissertações $(20,67)$ ou ao sítio do manual lingüístico da Floresta Sintá(c)tica ${ }^{5}$ :

\begin{tabular}{|c|c|c|c|}
\hline $1 \ll$ & - & $\mathrm{PU}$ & - \\
\hline $2 \hat{E}$ & ser & V-FIN & $\mathrm{PR}|3 \mathrm{~S}| \mathrm{IND}$ \\
\hline 3 uma & um & ART & $\mathrm{F} \mid \mathrm{S}$ \\
\hline 4 coisa & coisa & $\mathrm{N}$ & $\mathrm{F} \mid \mathrm{S}$ \\
\hline 5 de & de & PRP & - \\
\hline 60 & $\circ$ & ART & $\mathrm{M} \mid \mathrm{S}$ \\
\hline 7 Primeiro_Mundo & Primeiro_Mundo & PROP & $\mathrm{M} \mid \mathrm{S}$ \\
\hline $8 \gg$ & - & PU & - \\
\hline 9 , & - & $\mathrm{PU}$ & - \\
\hline 10 afirmou & afirmar & V-FIN & PS $|3 S| I N D$ \\
\hline 110 & $\circ$ & ART & $\mathrm{M} \mid \mathrm{S}$ \\
\hline 12 levantador & levantador & $\mathrm{N}$ & $\mathrm{M} \mid \mathrm{s}$ \\
\hline 13 Maurício & Maurício & PROP & $\mathrm{M} \mid \mathrm{S}$ \\
\hline $14 !$ & - & $\mathrm{PU}$ & - \\
\hline 15 leia & ler & V-FIN & $\mathrm{PR}|1 / 3 \mathrm{~S}| \mathrm{S}$ \\
\hline 16 matéria & matéria & $\mathrm{N}$ & $\mathrm{F} \mid \mathrm{S}$ \\
\hline 17 a & a & PRP & - \\
\hline $18 \circ$ & $\circ$ & ART & $\mathrm{M} \mid \mathrm{S}$ \\
\hline 19 lado & lado & $\mathrm{N}$ & $\mathrm{M} \mid \mathrm{S}$ \\
\hline 20) & - & PU & - \\
\hline 21. & - & $\mathrm{PU}$ & - \\
\hline
\end{tabular}

\begin{tabular}{|c|c|c|c|c|c|}
\hline (S) $\mathrm{S}^{*}$ & (FCL) $\mathrm{FCL} *$ & $\left(\mathrm{FCL} / \mathrm{FCL}^{*}\right.$ & - & $\left(\mathrm{A} 1^{*}\right.$ & * \\
\hline 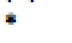 & 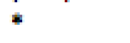 & $\left(V P^{*}\right)$ & - & $*$ & * \\
\hline$*$ & $*$ & $\left(\mathrm{NP}^{*}\right.$ & - & $*$ & $*$ \\
\hline * & * & * & - & $*$ & $*$ \\
\hline * & * & $(\mathrm{PP} *$ & - & * & * \\
\hline * & * & (NP* & - & * & * \\
\hline * & $*$ & $\left.\left.{ }^{*}\right)\right)$ & - & * & * \\
\hline *) & *) & *) & - & *) & $*$ \\
\hline$*$ & $*$ & $*$ & - & $*$ & * \\
\hline$*$ & * & $\left(V P^{*}\right)$ & afirmar & $\left(V^{*}\right)$ & $*$ \\
\hline * & $*$ & $\left(\mathrm{NP}^{*}\right.$ & - & $\left(\mathrm{AO}^{*}\right.$ & $*$ \\
\hline * & * & $*$ & - & $*$ & * \\
\hline$*$ & $*$ & $\left.\left(\mathrm{NP}^{*}\right)\right)$ & - & *) & * \\
\hline * & $*$ & $*$ & - & $*$ & $*$ \\
\hline (S* & $\left(\mathrm{FCL}^{*}\right.$ & (FCL(VP*) & ler & $*$ & $\left(\mathrm{~V}^{*}\right)$ \\
\hline 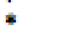 & $*$ & $\left(\mathrm{NP}^{*}\right)$ & - & $*$ & $\left(\mathrm{~A} 1^{*}\right)$ \\
\hline * & * & $\left(\mathrm{PP} \mathrm{P}^{*}\right.$ & - & * & (AM-LOC* \\
\hline * & $*$ & $\left(\mathrm{NP}^{*}\right.$ & - & $*$ & $*$ \\
\hline *) & *) & $*))$ & - & $*$ & *) \\
\hline$*$ & $=$ & $*$ & - & $*$ & $*$ \\
\hline *) & *) & *) & - & $*$ & $*$ \\
\hline
\end{tabular}

Figura 3.3: Exemplo do PropBank.Br

Adicionalmente, a mesma partição utilizada para essa dissertação, é a mesma utilizada para os autores $(20,22,41)$ 


\begin{tabular}{lccc} 
& Treino & Validação & Teste \\
\hline Sentenças & 3.011 & 151 & 141 \\
Proposições & 5.299 & 235 & 239 \\
Verbos Distintos & 989 & 148 & 165 \\
Argumentos & 12.520 & 553 & 541 \\
\hline A0 & 2.820 & 121 & 125 \\
A1 & 4.794 & 214 & 213 \\
A2 & 1.027 & 45 & 38 \\
A3 & 106 & 7 & 2 \\
A4 & 66 & 8 & 1 \\
A5 & 0 & 0 & 0 \\
AM-ADV & 338 & 13 & 20 \\
AM-CAU & 150 & 6 & 1 \\
AM-DIR & 12 & 1 & 2 \\
AM-DIS & 271 & 13 & 11 \\
AM-EXT & 78 & 3 & 1 \\
AM-LOC & 722 & 29 & 28 \\
AM-MED & 0 & 0 & 0 \\
AM-MNR & 377 & 17 & 18 \\
AM-NEG & 302 & 16 & 19 \\
AM-PNC & 159 & 7 & 5 \\
AM-PRD & 179 & 10 & 7 \\
AM-REC & 60 & 0 & 5 \\
AM-TMP & 1.059 & 43 & 45
\end{tabular}

Tabela 3.5: PropBank.Br v1.0 partições. 


\section{4}

\section{Aprendendo Sequiências}

O sistema de anotação automática de papéis semânticos aqui proposto é inspirado em Zhou e Xu (9), e composto por três camadas; (i) modelos para representação de palavras, (ii) uma rede neural recorrente do tipo LSTM com múltiplas camadas, (iii) uma camada de predição estruturada. Os sistemas anteriores para a tarefa para o idioma português são baseados em explorar os seguintes aspectos: atributos sintáticos alimentados para um separador linear SVM (20); tirar proveito da estrutura hierárquica da linguagem, ao fazer uso de redes convolutivas (41); explorar as múltiplas subtarefas através de um pipeline (22). Aqui, a motivação é elaborar uma arquitetura que dispensa o uso de atributos linguísticos, ou a implementação de uma seqüência de subtarefas.

\section{1}

\section{Representação de Palavras}

A representação das palavras é um aspecto fundamental em qualquer modelo de aprendizado de máquina no domínio da PLN, pois ela tem forte impacto na qualidade do aprendizado. Especificamente em AAPS, as primeiras abordagens $(24,51,45)$ contavam com a representação do tipo one-hot encoding. Neste caso, dado o vocabulário $\mathbf{V}$ com todas as palavras do corpus, onde $V=|\mathbf{V}|$ é o número de palavras, $\mathbf{X} \in \mathbb{R}^{V \times V}, \mathbf{X}_{\bullet k}$ é o vetor coluna representando a $k$-ésima palavra de $\mathbf{V}$, e $x_{i k}$ é o $i$-ésimo elemento desse vetor, temos então

$$
x_{i k}=\left\{\begin{array}{l}
1, \text { se } i=k \\
0, \text { caso contrário }
\end{array}\right.
$$

Um exemplo era então composto de tokens assim representados eram concatenados com atributos. Esses exemplos por sua vez, eram representados por pontos no espaço hiperdimensional, e alimentados à um separador linear $(8,27,20)$. No entanto, esse tipo de representação é proibitivo para redes neurais, dado que o tempo de treino e inferência está associada à complexidade em tempo de execução por sua vez que está associada ao espaço de parâmetros. A dimensionalidade dos paramêtros está diretamente ligada ao tamanho do vocabulário $V$, e finalmente o tamanho do vocabulário pode ser arbitrariamente grande. 
Apenas para o idioma inglês é estimada a existência de 13 milhões de tokens, por exemplo.

Uma outra limitação da representação é que elas carecem de qualquer semântica. Bengio, et al (52) propõem o conceito de word embeddings fundamentados na hipótese distributiva - palavras que coocorrem dividem o mesmo sentido semântico. Todos os modelos de representação de palavras, nessa seção expostos, têm como objetivo estimar a probabilidade de ocorrência, de uma palavra ou conjunto de palavras dado o contexto em que aparece. Uma forma de converter representações vetoriais esparsas, em representações densas, com sentido semântico é através de um modelo word2vec. Tomamos um caso simples, no qual uma rede neural tem como entrada a palavra atual, e como saída a palavra seguinte.

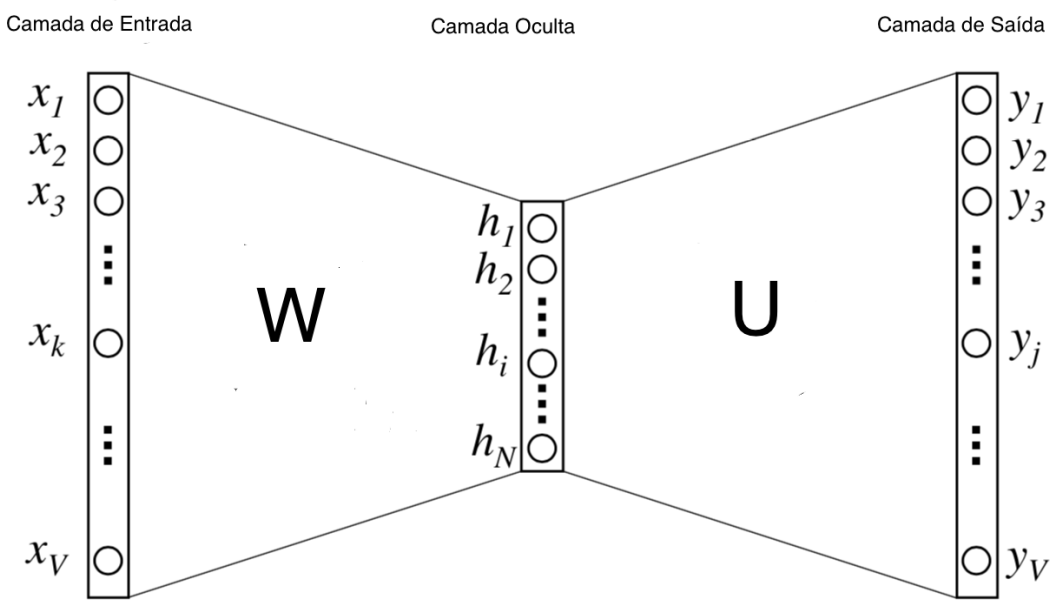

Figura 4.1: word2vec (53)

A Figura 4.1 ilustra uma rede do tipo feed forward com uma camada oculta, de tamanho $D<<V$ e função de ativação linear. Os pesos das camadas de entrada e saída, são dados pelas matrizes $\mathbf{W} \in \mathbb{R}^{V \times D}$ e $\mathbf{U} \in \mathbb{R}^{D \times V}$ respectivamente. Neste modelo o contexto, é dado pela próxima palavra, e.g na frase 'Quando os ventos sopram' um par válido de treino é ('ventos', 'sopram'), associados aos vetores, $\mathbf{x}_{k} \in \mathbf{X}$ e $\mathbf{y}_{j} \in \mathbf{X}$, cabe a rede estimar $\mathbb{P}$ ('sopram'|'ventos'), conforme Equações 4-2 


$$
\begin{aligned}
& \mathbf{h}=\mathbf{W}^{T} \mathbf{x}_{k}=\mathbf{w}_{k} \\
& \mathbf{u}=\mathbf{U}^{T} \mathbf{w}_{k} \\
& \tilde{\mathbf{y}}=\operatorname{softmax}(\mathbf{u})=\frac{\exp \{\mathbf{u}\}}{\sum_{V} \exp \{\mathbf{u}\}}
\end{aligned}
$$

\subsection{1}

\section{Word2Vec}

O modelo word2vec foi introduzido por Mikolov, et al, 2013 (54) e trata-se de uma flexibilização do contexto $C$ em torno da entrada ou saída, em relação a rede da Figura 4.1.

\subsubsection{1}

\section{CBOW: Sacola de palavras contínua}

CBOW é uma generalização do modelo representado na Figura 4.1. Onde, ao invés do contexto ser definido, como o token antecedente, o contexto tem tamanho fixo $C$, e o alvo é o token intermediário. Cabe à camada oculta, o papel de construir um resumo das representações. A Figura 4.2 mostra a arquitetura CBOW.

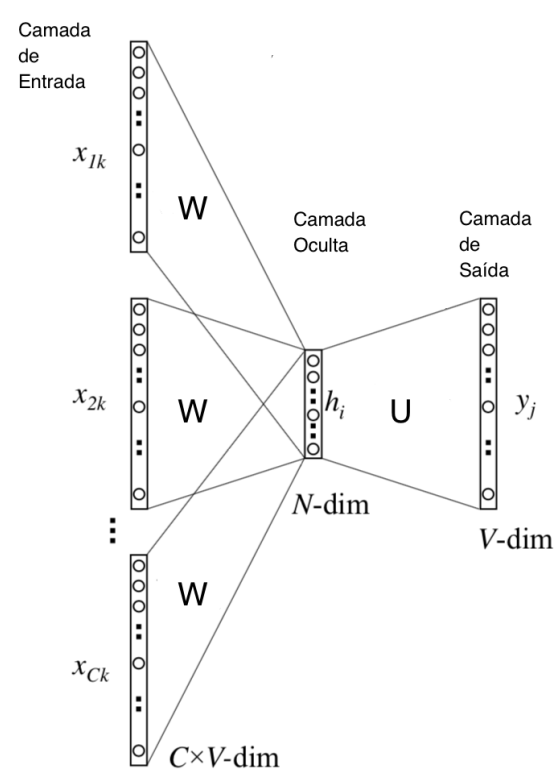

Figura 4.2: CBOW: sacola contínua de palavras (53) 


\subsubsection{2}

\section{Skipgram}

Skipgram pode ser entendido como o modelo recíproco ao CBOW. Onde, dado um token $\mathbf{x}_{k}$ a rede deve produzir um contexto de tamanho fixo $C$. A Figura 4.3 mostra a arquitetura da rede Skipgram.

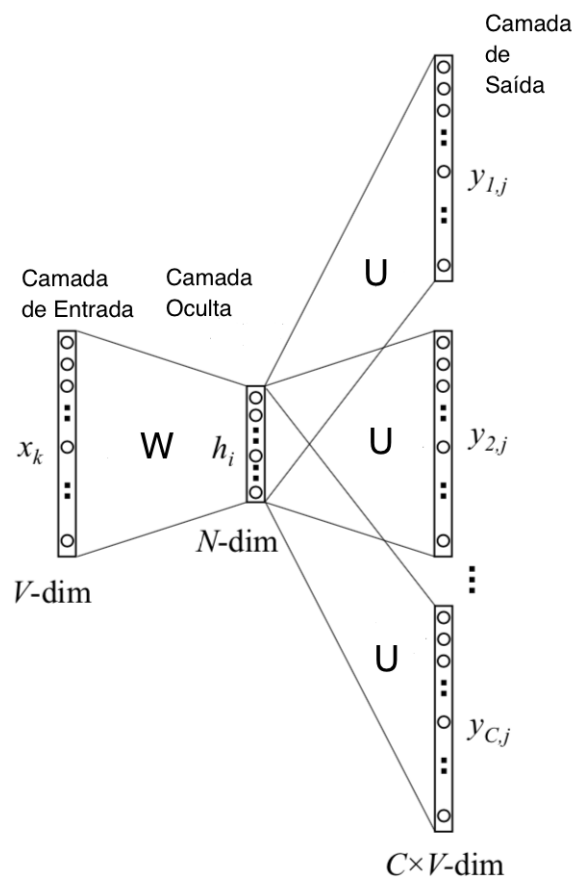

Figura 4.3: Skipgram (53)

\subsection{2}

\section{Wang2Vec}

Em Ling, et al (68), são propostas duas modificações simples para os modelos word2vec: CBOW, os vetores coluna representando os tokens no contexto, são concatenados. Skipgram, é utilizada uma matriz de pesos diferente para cada posição do contexto de saída.

\subsection{3}

\section{GloVe}

GloVe é um método proposto por Pennington, et al (55), e obteve resultados estado de arte para tarefas sintáticas e semânticas em tarefas de analogia. O método consiste em uma matriz de coocorrência $\mathbf{M}$ que é construida olhando-se cada token em relação ao seu contexto. Cada elemento $\mathbf{M}_{i j}$ na matriz representa a probabilidade da palavra $i$ ser próxima à palavra 
j. Na matriz $M$, as linhas, ou vetores, são geradas aleatóriamente, e treinadas obedecendo a Equação 4-3 (56).

$$
\mathbb{P}\left(\mathbf{w}_{i}, \mathbf{w}_{j}\right)=\mathbf{w}_{i} \cdot \mathbf{w}_{j}+b_{i}+b_{j}=\log \left(\mathbf{M}_{i j}\right)
$$

\section{2}

\section{Redes Neurais Recorrentes}

As redes neurais recorrentes são redes especializadas em modelar seqüências que são representadas por uma coleções de vetores cada qual na forma $\mathbf{x}^{(1)}, . ., \mathbf{x}^{(t)}, \ldots \mathbf{x}^{(\tau)}$ onde $\mathbf{x}^{(t)}$ representa um vetor em uma posição $t$ arbitrária $\mathrm{e}$ $\tau$ o seu comprimento máximo. Neste trabalho o conjunto de desenvolvimento, é composto por proposições. Por sua vez cada proposição é formada por tokens e cada token é enriquecido com atributos. Os tokens são representados por vetores conforme a Seção 4.1, e que são concatenados aos seus respectivos atributos formando $\mathbf{x}^{(t)}$.

O grafo de computação é um recurso visual para ilustrar dependências entre variáveis de entrada, saída e operações e estão formalmente definidos no Apêndice A ou (57). O processo de forward propagation de rede neural recorrente pode ser representada pelo grafo de computação na Figura 4.4, (a) versão compacta do processo de Feed forward (b) versão desdobrada no tempo. Os parâmetros U, V, W são compartilhados entre iterações: (i) U pesos do entre nós de entrada e oculto (ii) $\mathbf{W}$ pesos entre nós ocultos (iii) $\mathbf{V}$ pesos entre nó oculto e observável. As Equações 4-4 definem o relacionamento entre variáveis. $\mathrm{O}$ estado $\mathbf{h}$ representa um resumo das informação até o momento $t$. Os interceptos b, c foram omitidos sem perda de generalidade.

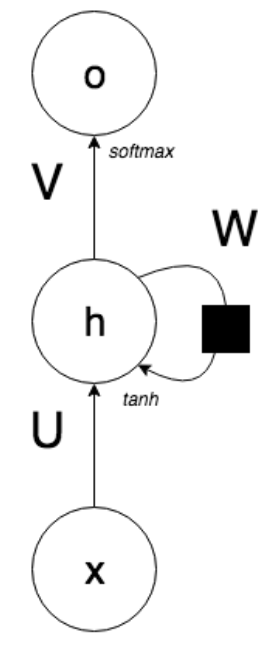

(a)

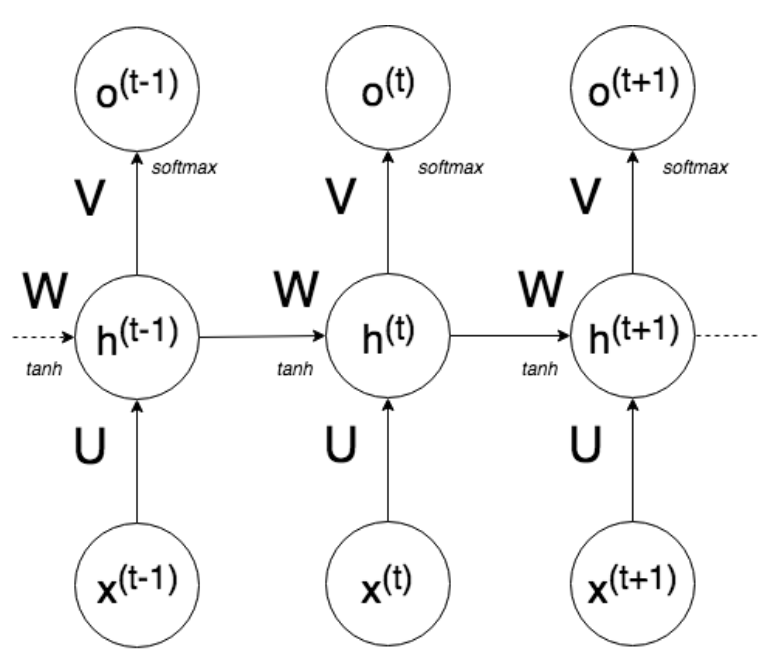

(b)

Figura 4.4: O grafo de computação de uma RNR 


$$
\begin{aligned}
\mathbf{h}^{(t)} & =\tanh \left(\mathbf{W} \mathbf{h}^{(t-1)}+\mathbf{U x}^{(t)}\right), \\
\mathbf{o}^{(t)} & =\operatorname{softmax}\left(\mathbf{V h} \mathbf{h}^{(t)}\right)
\end{aligned}
$$

\subsection{1}

\section{Redes Neurais Recorrentes Bidirecionais}

As RNRs Bidirecionais como o próprio nome indica, combinam RNRs que se movem do início ao fim da seqüência, i.e para frente no tempo, e RNRs que se movem do fim ao início da seqüência, i.e de trás para frente no tempo. Em alguns casos como reconhecimento de voz e de escrita, modelos se beneficiam em receber a informação dos vetores sucedentes da seqüência para decidir a saída atual (57). Especificamente, na tarefa de anotação de papéis semânticos, o sistema pode tirar proveito que a etiqueta A0 já foi realizada no passado, e que a etiqueta A2 já foi realizada no futuro, para gerar uma pontuação favorável para a etiqueta $\mathrm{A} 1$.

As Bi RNRs contam com duas estruturas de recorrência siamesas, a Figura 4.5 (a) demonstra duas relações de recorrência uma causal (sentido horário) e a outra não causal (sentido antihorário), cada qual gera uma pontuação normalizada $\mathbf{o}, \mathbf{z}$ que é concatenada no vetor y (b) grafo de computação desdobrado. Para cada instante $t$, o nó oculto $\mathbf{h}^{(t)}$ armazena um resumo da informação passada e o nó oculto $\mathbf{g}^{(t)}$ armazena um resumo da informação futura. Como na Figura 4.4 os parâmetros U, W, V são compartilhados, apenas entre a RNR que avança no tempo. Enquanto K, I, J são compartilhados, apenas entre a RNR que retroage pelo tempo.
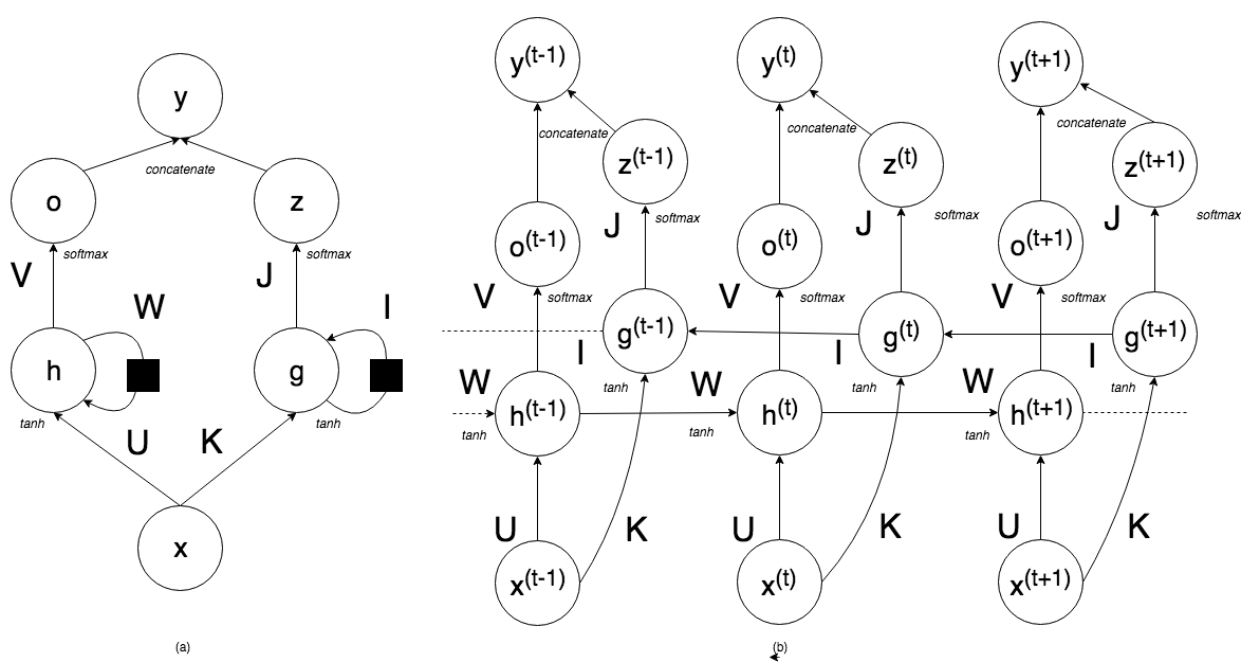

Figura 4.5: O grafo de computação de uma Bi RNR 


\subsection{2}

\section{O problema do gradiente minguante explosivo}

Um desafio para treinar redes profundas é o problema do gradiente minguante ou explosivo (PGME) que está associado ao algoritmo de retropropagação (backpropagation) $(58,59)$. Cabe ao algoritmo computar os valores de ajustes nos pesos da rede, através de aplicações da regra da cadeia, de forma a diminuir uma função de perda. Como o produto de vários fatores menores que um, pode rapidamente convergir para zero, o ajuste de pesos nas camadas mais profundas serão mitigados, resultando em uma não diminuição da função de perda. Redes neurais recorrentes, sofrem do problema de forma ainda mais aguda, uma vez que o aprendizado se dá através de uma variação do algoritmo de retro-propagação, o chamado algoritmo de retro propagação através do tempo (BPTT: backpropagation throught time). Onde o ajuste de pesos ocorre com respeito ao grafo de computação desenrolado, através do tempo, e.g Figura 4.5 (b). Como as sentenças podem ser arbitrariamente longas, assim também o ajuste de pesos deve ocorrer em um número arbitrário de passos. Para ilustrar o problema basta tomar a relação mais simples da relação de recorrência na Equação 4-5 (57), com $\mathbf{W} \in \mathbb{R}^{d \times d}$ e $\mathbf{h} \in \mathbb{R}^{d}$

$$
\mathbf{h}^{(t)}=\mathbf{W}^{T} \mathbf{h}^{(t-1)}
$$

A Equação 4-5 pode ser reescrita em função do estado de partida $\mathbf{h}^{(0)}$ e pela potência dos parâmetros $\mathbf{W}$ :

$$
\mathbf{h}^{(t)}=\left(\mathbf{W}^{(t)}\right)^{T} \mathbf{h}^{(0)}
$$

Se a matriz $\mathbf{W}$ é positiva definida então ela admite fatoração ortonormal com $\Lambda \in \mathbb{R}^{d \times d}$ matriz diagonal com os autovalores e $\mathbf{Q Q}^{T}=\mathbf{I}$ e $\mathbf{I}$ matriz identidade, então $\mathbf{W}$, pode ser reescrita como:

$$
\mathbf{W}=\mathbf{Q} \Lambda \mathbf{Q}^{T}
$$

E finalmente temos que:

$$
\mathbf{h}^{(t)}=\mathbf{Q}^{T} \mathbf{\Lambda}^{(t)} \mathbf{Q h}^{(0)}
$$

$\Lambda^{(t)}$ explode para autovalores maiores que um e mingua para autovalores menores que zero a demonstração se encerra. 


\subsection{3}

\section{Long Short Term Memory}

Uma variação da redes neurais recorrentes inspiradas em unidades de memória RAM, foi proposta por Hochreiter e Schmidhuber (60). A Figura 4.6 ilustra um grafo de computação das LSTM (Long Short Term Memory). Três portas foram criadas para facilitar o fluxo do gradiente no grafo de computação. São as portas; (i) forget $\mathbf{f}$ que quando ativada remove o conteúdo do estado interno (ii) input $\mathbf{g}$ controla a contribuição da entrada no estado interno (iii) external q controla o que é propagado para a saída. Adicionalmente, a rede conta com um estado de saída h e um estado interno s. As variáveis ( nós ) anônimos no grafo foram criados para facilitar a visualização. O sistema de Equações 4-9 descreve a interação entre portas e parâmetros que ocorre dentro da unidade. Já o sistema de Equações 4-10 descreve a interação entre as diferentes portas e estados da LSTM.

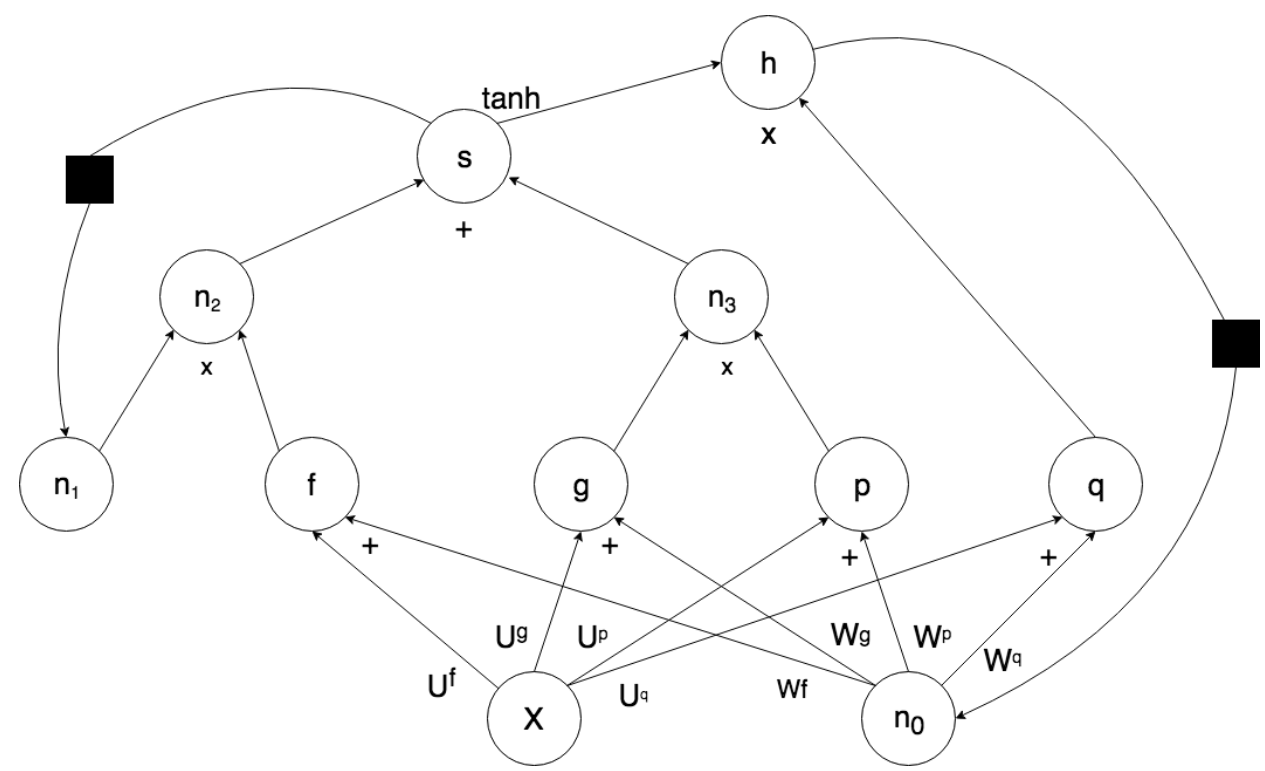

Figura 4.6: O grafo de computação de uma LSTM 


$$
\begin{gathered}
\mathbf{f}=\sigma\left(\mathbf{U}^{f} \mathbf{X}+\mathbf{W}^{f} \mathbf{n}_{0}\right) \\
\mathbf{g}=\sigma\left(\mathbf{U}^{g} \mathbf{X}+\mathbf{W}^{g} \mathbf{n}_{0}\right) \\
\mathbf{p}=\sigma\left(\mathbf{U}^{p} \mathbf{X}+\mathbf{W}^{p} \mathbf{n}_{0}\right) \\
\mathbf{q}=\sigma\left(\mathbf{U}^{q} \mathbf{X}+\mathbf{W}^{q} \mathbf{n}_{0}\right) \\
\mathbf{n}_{2}=\mathbf{f} \times \mathbf{n}_{1} \\
\mathbf{n}_{3}=\mathbf{g} \times \mathbf{p} \\
\mathbf{s}=\mathbf{n}_{2}+\mathbf{n}_{3} \\
\mathbf{h}=\tanh (\mathbf{s}) \times \mathbf{q} \\
\mathbf{f}^{(t)}=\sigma\left(\mathbf{U}^{f} \mathbf{X}^{(t)}+\mathbf{W}^{f} \mathbf{h}^{(t-1)}\right) \\
\mathbf{g}^{(t)}=\sigma\left(\mathbf{U}^{g} \mathbf{x}+\mathbf{W}^{g} \mathbf{h}^{(t-1)}\right) \\
\mathbf{p}^{(t)}=\sigma\left(\mathbf{U}^{p} \mathbf{X}+\mathbf{W}^{p} \mathbf{h}^{(t-1)}\right) \\
\mathbf{q}^{(t)}=\sigma\left(\mathbf{U}^{q} \mathbf{x}+\mathbf{W}^{q} \mathbf{h}^{(t-1)}\right) \\
\mathbf{s}^{(t)}=\mathbf{f}^{(t)} \times \mathbf{s}^{(t-1)}+\mathbf{g}^{(t)} \times \mathbf{p}^{(t-1)} \\
\mathbf{h}^{(t)}=\tanh \left(\mathbf{s}^{(t)}\right) \times \mathbf{q}^{(t)}
\end{gathered}
$$

As portas efetivamente criam caminhos por onde o computo do gradiente pode fluir(60), mitigando o PGME. Na prática, as LSTMs foram adotadas pelos pesquisadores e o seu uso se tornou quase um sinônimo para redes neurais recorrentes.

\section{3}

\section{Predição Estruturada}

Em aprendizado de máquina usualmente o interesse está em modelar o comportamento de uma variável de saída y, seja ela discreta ou contínua, em função de um conjunto de atributos x. Essa arranjo implicitamente reflete uma importante premissa - que o valor da variável $\mathbf{y}$ depende apenas de $\mathbf{x}$, e que não existe interdependência entre observações passadas e atuais de $\mathbf{y}$. É a prerrogativa da predição estruturada gerar saídas mais ricas que variáveis discretas ou contínuas, tais como variáveis discretas ordenáveis (61), intervalos (62), árvores ou grafos (63).

Em AAPS, sob o padrão PropBank, a tarefa consiste em simultaneamente segmentar e classificar intevalos. Como a saída deve representar intervalo, o comportamento dos papéis semânticos é interdependente. Um outro exemplo são as classes dado que dois intervalos, na mesma proposição, não podem 
assumir a etiqueta A1 por exemplo. E pesquisadores fizeram largamente o uso de restrições lingüísticas em seus sistemas (8) (27) (21). Essa seção expõe os dois modos de predição estruturadas pertinentes à essa dissertação.

\subsection{1}

\section{Conditional Random Fields}

Modelos Gráficos é uma família de distribuições de probabilidade que são fatoradas por um grafo associado. A idéia geral é representar uma distribuição sobre um conjunto grande de variáveis aleatórias por um produto de funções locais que dependem apenas de um pequeno subconjunto de variáveis (64).

Definição 4.1 Conditional Random Field Um distribuição de probabilidade $p(\mathbf{x}, \mathbf{y})$ pode ser representado por variáveis aleatórias $V=X \cup Y$ onde $X$ é um conjunto de variáveis de entradas observadas e $Y$ é um conjunto de variáveis de saída. $\mathbf{x}$ é uma realização de $X$ em particular $\mathbf{x}_{A}$ é uma realização que pertence ao subconjunto $A \subset V$, e analogamente para $Y$.

$$
p(\mathbf{x}, \mathbf{y})=\frac{1}{Z} \prod_{A} \Psi_{A}\left(\mathbf{x}_{A}, \mathbf{y}_{A}\right)
$$

A constante $\mathrm{Z}$ é um fator de normalização definido por:

$$
Z=\sum_{x, y} \prod_{A} \Psi_{A}\left(\mathbf{x}_{A}, \mathbf{y}_{A}\right)
$$

CRFs podem representar cadeias de Markov conforme a equação 4-13. As cadeias de Markov fazem duas premissas de independência sobre o conjunto de dados $X$ e $Y$; (i) cada estado dependende apenas de seu predecessor, i.e $p\left(y_{t} \mid y_{t-1}, y_{t-2}, \ldots, y_{1}, y_{0}\right)=p\left(y_{t} \mid y_{t-1}\right)$ (ii) a probabilidade de emissão $p\left(x_{t} \mid y_{t}\right)$ depende apenas do seu estado atual $y_{t}$.

$$
p(\mathbf{x}, \mathbf{y})=\prod_{t=1}^{T} p\left(y_{t} \mid y_{t-1}\right) p\left(x_{t} \mid y_{t}\right)
$$

A equação 4-13 pode ser escrita na forma 4-11:

$$
p(\mathbf{x}, \mathbf{y})=\frac{1}{Z} \exp \left\{\sum_{t} \sum_{i, j} \lambda_{i, j} \mathbb{I}_{\left\{y_{t}=i\right\}\left\{y_{t-1}=j\right\}}+\sum_{t} \sum_{i \in S} \sum_{o \in O} \mu_{i, j} \mathbb{I}_{\left\{x_{t}=o\right\}\left\{y_{t}=i\right\}}\right\}
$$


com

$$
\begin{aligned}
\theta & =\left\{\lambda_{i, j}, \mu_{o, i}\right\} \\
\lambda_{i, j} & =\log p\left(y=i \mid y^{\prime}=j\right) \\
\mathbb{I}_{x=x^{\prime}} & =\left\{\begin{array}{l}
1, x=x^{\prime} \\
0, c c
\end{array}\right.
\end{aligned}
$$

Definição 4.2 linear-chain conditional random field Seja $Y, X$ vetores aleatórios, $\Lambda=\left\{\lambda_{k}\right\} \in R^{K}$ um vetor de parâmetro, e $\left\{f_{k}\left(y, y^{\prime}, \mathbf{x}_{t}\right)\right\}_{k=1}^{K}$ seja um conjunto de funções reais. Então um campo aleatório condicional do tipo cadeia linear linear-chain conditional random field tem distribuição condicional $p(\mathbf{y} \mid \mathbf{x})$ que toma a forma:

$$
p(\mathbf{y} \mid \mathbf{x})=\frac{1}{Z(\mathbf{x})} \exp \left\{\sum_{k=1}^{K} \lambda_{k} f_{k}\left(y_{t}, y_{t-1}, \mathbf{x}_{t}\right)\right\}
$$

Onde $Z(\mathbf{x})$ é uma função de normalização, específica para o conjunto de dados:

$$
Z(\mathbf{x})=\sum_{y} \exp \left\{\sum_{k=1}^{K} \lambda_{k} f_{k}\left(y_{t}, y_{t-1}, \mathbf{x}_{t}\right)\right\}
$$

Pode ser mostrado que, as equações 4-15 e 4-16 acomodam as premissas da cadeia de Markov fazendo (64):

$$
p(\mathbf{y} \mid \mathbf{x})=\frac{1}{Z(\mathbf{x})} \exp \left\{\sum_{t} \sum_{i, j} \lambda_{i, j} \mathbb{I}_{\left\{y_{t}=i\right\}\left\{y_{t-1}=j\right\}}+\sum_{t} \sum_{i \in S} \sum_{o \in O} \mu_{o, i} \mathbb{I}_{\left\{x_{t}=o\right\}\left\{y_{t}=i\right\}}\right\}
$$

$$
Z(\mathbf{x})=\sum_{y} \exp \left\{\sum_{t} \sum_{i, j} \lambda_{i, j} \mathbb{I}_{\left\{y_{t}=i\right\}\left\{y_{t-1}=j\right\}}+\sum_{t} \sum_{i \in S} \sum_{o \in O} \mu_{o, i} \mathbb{I}_{\left\{x_{t}=o\right\}\left\{y_{t}=i\right\}}\right\}
$$

A função densidade de probabilidade conjunta $p(\mathbf{x}, \mathbf{y})$ na Equação 4-14 fatora uma HMM, enquanto a função de desidade de probabilidade marginal nas 4-17 e 4-18 fatora uma linear-chain conditional random field. A família de parâmetros $\theta=\left\{\lambda_{i, j}, \mu_{o, i}\right\}$ pode ser estimada por gradiente descendente, programação dinâmica ou otimizando por máxima verossimilhança. 


\subsection{2}

\section{Perceptron Estruturado}

Um perceptron (65) é uma representação matemática para um neurônio humano. Trata-se de uma função determinada por uma entrada $\mathbf{x} \in \mathbb{R}^{n} \mathrm{um}$ vetor de pesos $\mathbf{w} \in \mathbb{R}^{n}$, um escalar (viés) $\mathbf{b} \in \mathbb{R}$ e uma função de disparo $g(\nu) \in\{-1,1\}$. Tanto os pesos como o viés podem ser estimados pelo algoritmo do perceptron, à essa estimativa de parâmetros é dado o nome de aprendizado.

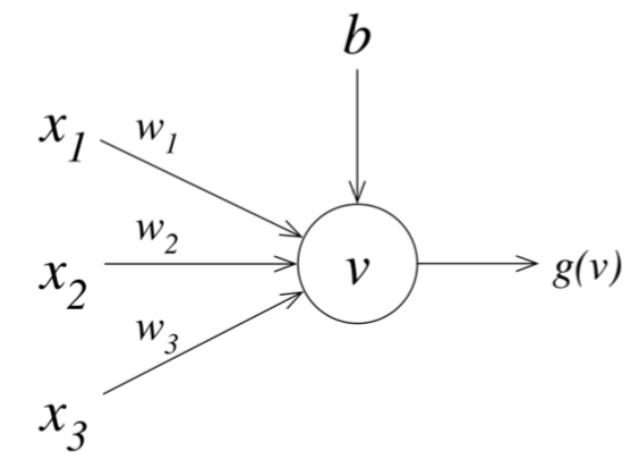

Figura 4.7: O perceptron (62)

$$
\nu=\sum_{i=1}^{n} w_{i} x_{i}+b
$$

Sem perda de generalidade tomando-se $w_{0}=b$ e $x_{0}=1$ pode-se escrever:

$$
\nu=\sum_{i=0}^{n} w_{i} x_{i}=\mathbf{w} \cdot \mathbf{x}
$$

E a função de disparo $g$ pode ser definida como:

$$
g(\nu)=\left\{\begin{array}{c}
-1 \text { se } \nu<0 \\
+1 \text { se } \nu>=0
\end{array}\right.
$$

As redes neurais modernas ainda são constituidas por camadas de perceptrons, com variações na função de disparo. Embora sejam treinadas através do método do gradiente descendente.

Em 2002, Collins (66) extende o lema de convergência do perceptron, generalizando a função de disparo $g(\nu)$ para uma função $\Phi(\mathbf{x}, \mathbf{y})$. A Figura 1 mostra o algortimo de treino, i.e ajustes de pesos, para o perceptron estruturado. Para cada par $\left(\mathbf{x}_{i}, \mathbf{y}_{i}\right)$ no conjunto de treino $D$, a previsão é feita escolhendo-se o $\hat{\mathbf{y}}_{i}$ que maximize o produto $\omega \cdot \Phi\left(\mathbf{x}_{i}, \hat{\mathbf{y}}_{i}\right)$. O lema de convergência do perceptron estruturado garante que se $\Phi(\mathbf{x}, \mathbf{y})$ separa o pontos no espaço 


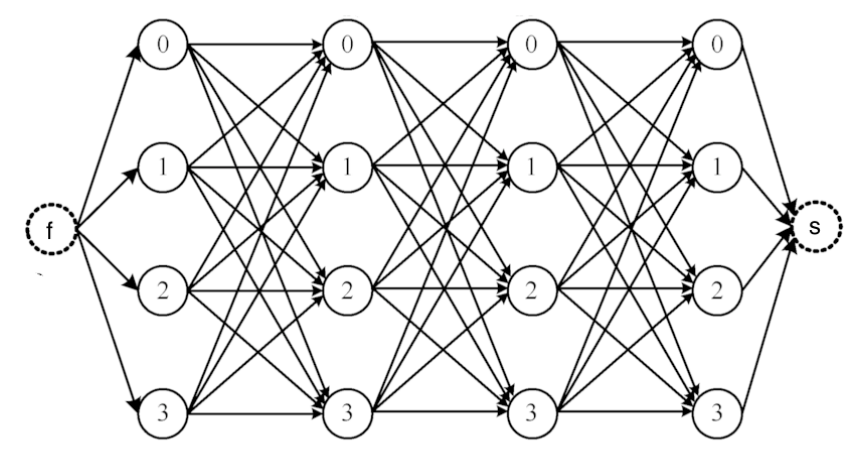

Figura 4.8: Treliça

então $\omega$ converge. Modelar um problema utilizando o perceptron estruturado significa definir $h(\mathbf{x})$ na Equação 4-21:

$$
\hat{\mathbf{y}}=h(\mathbf{x})=\operatorname{argmax}_{z \in \mathcal{Y}(\mathbf{x})}\{\mathbf{w} \cdot \Phi(\mathbf{x}, \mathbf{z})\}
$$

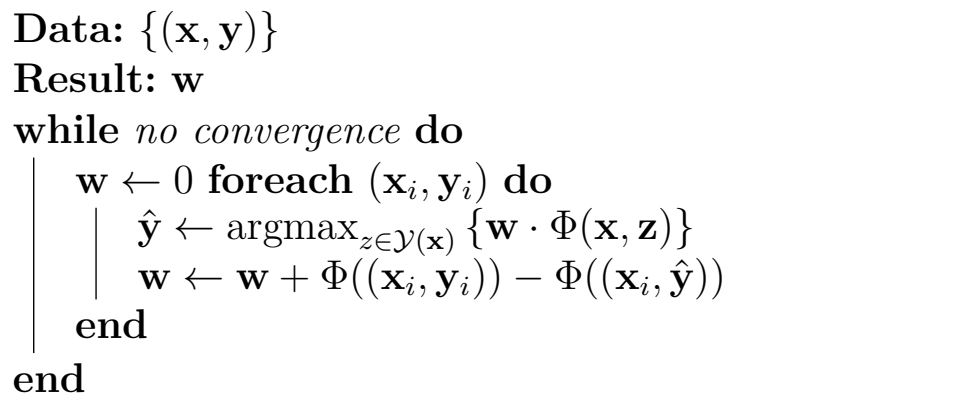

Algorithm 1: Treino do Perceptron Estruturado

Em 2018, Milidiú e Rocha (63), propõe uma aplicação do perceptron estruturado para modelar sequências. Reescrevendo Equação 4-21 como:

$$
\hat{\mathbf{y}}=h(\mathbf{x})=h_{1}\left(h_{0}(\mathbf{x} ; \Theta)\right)
$$

Onde $h_{0}(\mathbf{x} ; \Theta)$ são os custos latentes induzidos pela estrutura nesse caso um grafo direcionado acíclico, em camadas chamadol de treliça Figura 4.8 e $\Theta$ o seu conjunto associado de parâmetros. $h_{1}$ camada estruturada, responsável por encontrar $\hat{\mathbf{y}}$ no espaço de soluções viável $\mathcal{Y}(\mathbf{x})$ através da resolução de um problema de otimização combinatória.

A estrutura é dada pela treliça, que é construída a partir dos exemplos (proposições) $\{(\mathbf{x}, \mathbf{y})\}$ no corpus $\mathcal{D}$ tem comprimento de $\tau$ tokens. Dois nós especiais são introduzidos; $\mathbf{f}$ fonte e s sorvedouro, pontos de partida e chegada respectivamente na seqüência de etiquetas $\mathcal{Y}$. Na Figura 4.8, os nós $\{0,1,2,3\}$ 
correspondem a representação de $k=4$ classes possíveis para $\mathcal{Y}$ e a proposição tem comprimento $\tau=4$, dado pelo número de camadas do grafo.

Com a estrutura definida, o próximo passo para definir $h_{0}(\mathbf{x} ; \Theta)$ é escolher os átomos - a parte da estrutura que receberá atributos. Nesse caso serão as arestas (63), cada aresta pode ser denominada como o par $(u, v)$. O mapa ou descrição para cada aresta é dado por $\phi(\mathbf{x}, t, u, v)$, com $\mathbf{x}$ atributos para cada $t, t$ a posição dentro da proposição, e $u$ e $v$ duas classes em $\mathbf{Y}$ então o mapa dado pela primeira aresta é $\phi\left(\mathbf{x}, 0, f, y_{0}\right)$ o da última é $\phi\left(\mathbf{x}, \tau, y_{\tau}, s\right)$ com $y_{0}$ e $y_{\tau}$ em $\mathbf{y}$. E em geral os mapas induzidos pela estrutura são dados por $\phi(\mathbf{x}, t, u, v)$ com $\mathbf{x} \in \mathcal{X}$, e $\mathcal{X}$ conjunto admissível de todas as combinações possíves de atributos de tamanho $\tau, t=0 \ldots \tau$ e $u, v \in \mathcal{Y}(\mathbf{x}), \mathcal{Y}(\mathbf{x})$ conjunto de todas as seqüências possíveis de classe de tamanho $\tau$, ou caminhos na treliça.

A Figura 4.9 apresenta um exemplo, como entrada temos três atributos: (i) $A_{1}$ conjunto de palavras, (ii) $A_{2}$ função indicadora se o verbo da proposição foi encontrado, (ii) $A_{3}$ verbo. A entrada $\mathbf{x}_{t}$ é obtida concatenando-se os elementos para cada $t=0 \ldots 4$, com $\tau=4$. A treliça é construída tomando-se o conjunto de todas as sequências de tamanho $\tau=4$ de $k=4$ classes $\mathbf{Y}^{4}$. O conjunto de todos os caminhos $\mathcal{Y}$ dado por Equação 4-23

$$
\mathcal{Y}=\left\{\left(y_{0}, y_{1}, y_{2}, y_{3}, y_{4}\right) \mid y_{0}=\mathbf{f} \wedge y_{4}=\mathbf{s} \wedge y_{i} \in \mathbf{Y}^{4}, i=1 \ldots 3\right\}
$$

Os mapas de custo deveriam dar-se para cada um dos tempos pelas Figuras 4.10- 4.14

Já a camada estruturada $h_{1}$ é definida pela assinatura $\Phi(\mathbf{x}, \mathbf{y})$, dada pela soma dos mapas para cada aresta. E o argmax é dado pela resolução de um problema de maior caminho. Se $\mathbf{z} \equiv\left(z_{1}, \ldots, z_{\tau}\right) \in \mathcal{Y}$, representa a seqüência de nós relacionada a saída y então:

$$
\mathbf{z}=\cup_{t=0, \ldots, \tau}\left\{\left(t, z_{t}, z_{t+1}\right)\right\}
$$

Com $z_{0}=f, z_{\tau+1}=s$, então o custo correspondente pode ser escrito como:

$$
\Phi(\mathbf{x}, \mathbf{z})=\sum_{t=0}^{\tau} \phi\left(\mathbf{x}, t, z_{t}, z_{t+1}\right)
$$

A partir da função assinatura na Equação 4-25 podemos gerar os custos $c\left(\mathbf{x}, t, z_{t}, z_{t+1}\right)(63)$

$$
w \cdot \Phi(\mathbf{x}, \mathbf{z})=\sum_{t=0}^{\tau} c\left(\mathbf{x}, t, z_{t}, z_{t+1}\right)
$$


$A_{1}$ (algumas, pessoas, constroem, moinhos)

$A_{2}(0,0,1,1)$

$A_{3}$ (constroem, constroem, constroem, constroem)

$\mathrm{Y}^{4}(\mathrm{~B}-\mathrm{A0}, \mathrm{I}-\mathrm{A} 0, \mathrm{~V}, \mathrm{~B}-\mathrm{A} 1)$

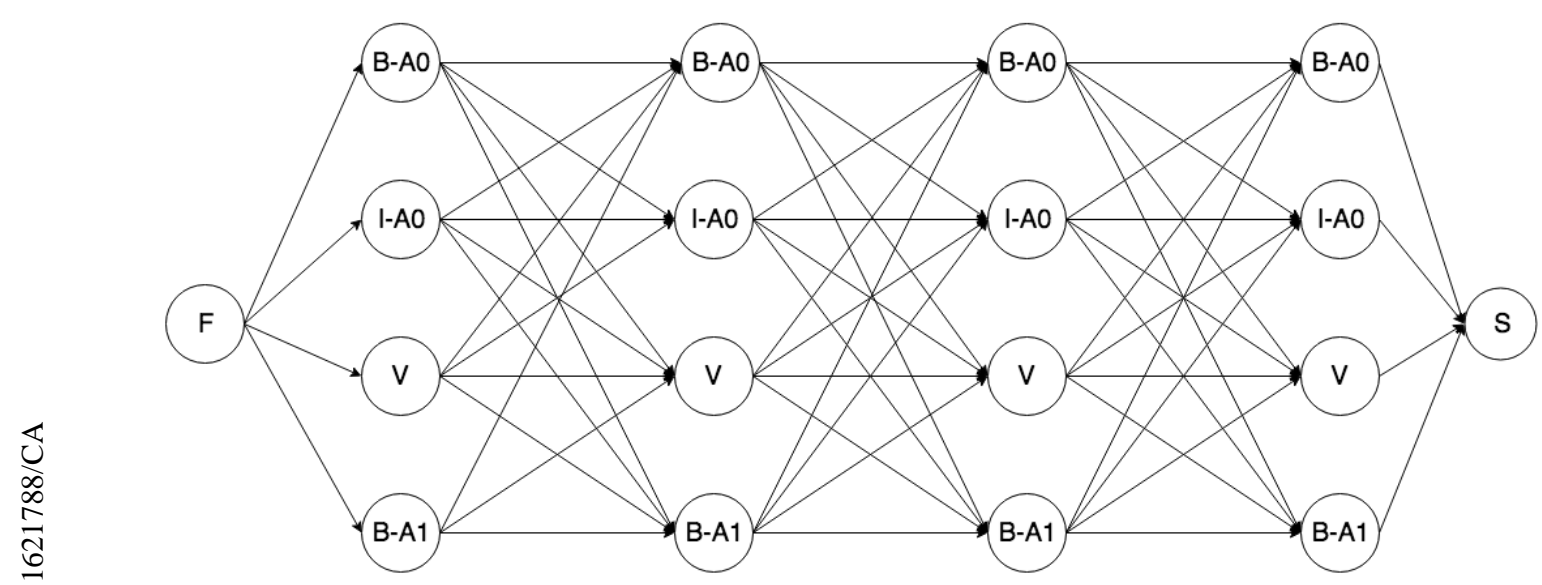

Figura 4.9: Treliça

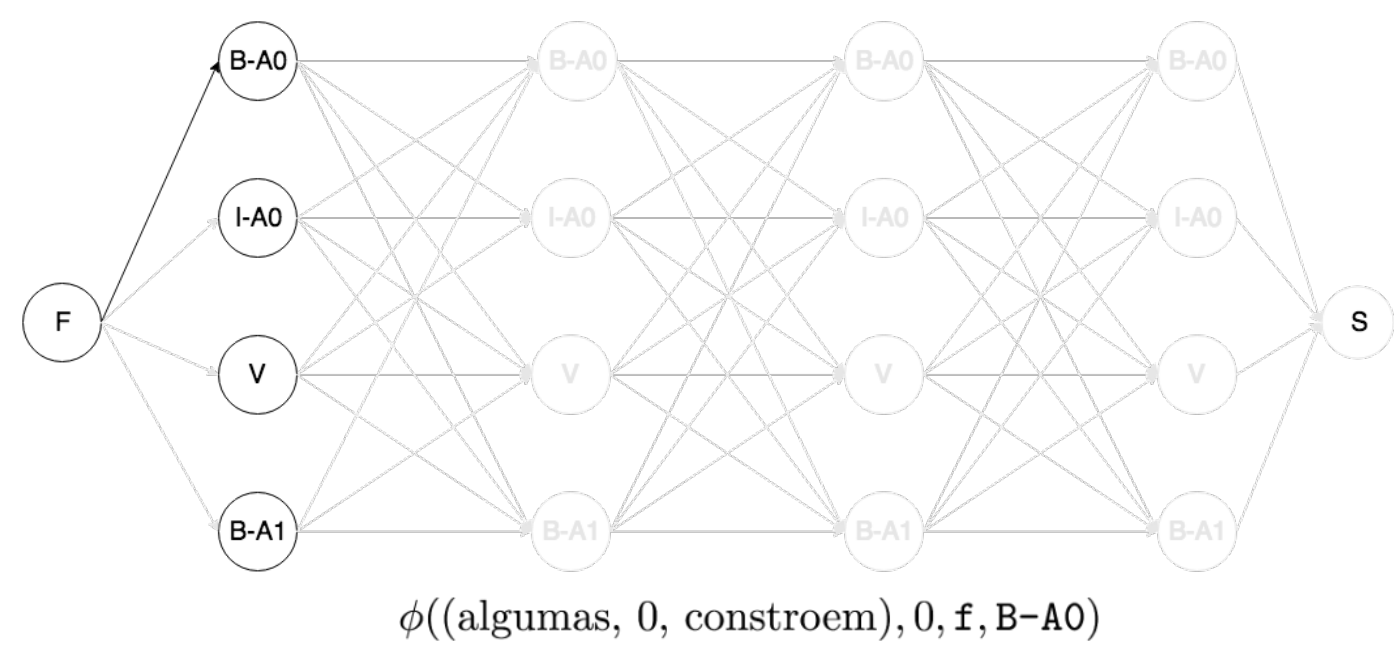

Figura 4.10: Mapa de custo $t=0$ 


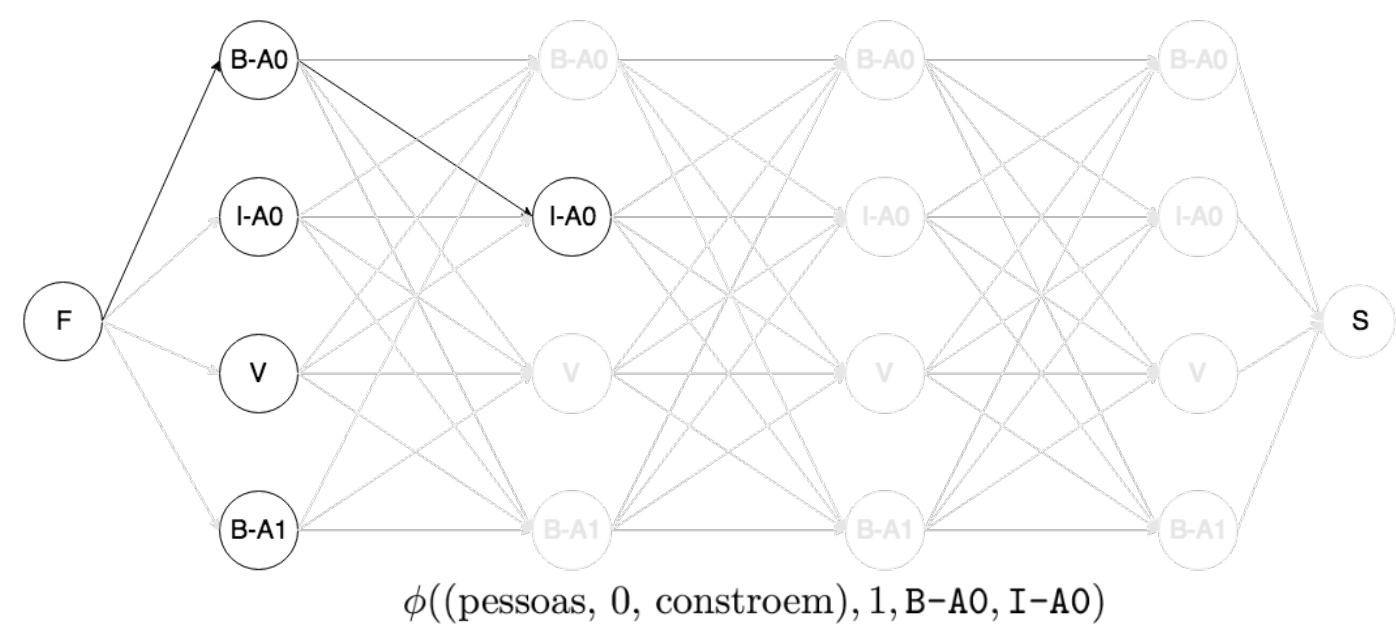

Figura 4.11: Mapa de custo $t=1$

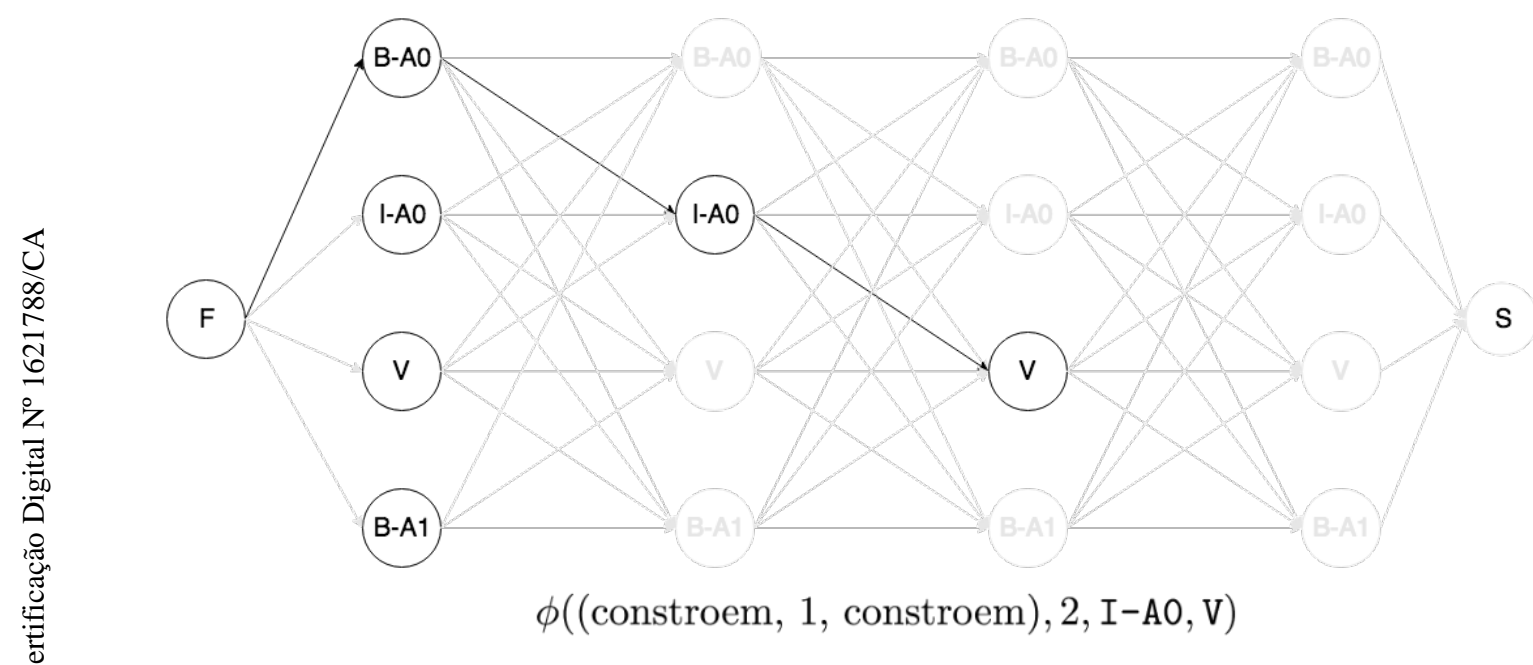

Figura 4.12: Mapa de custo $t=2$

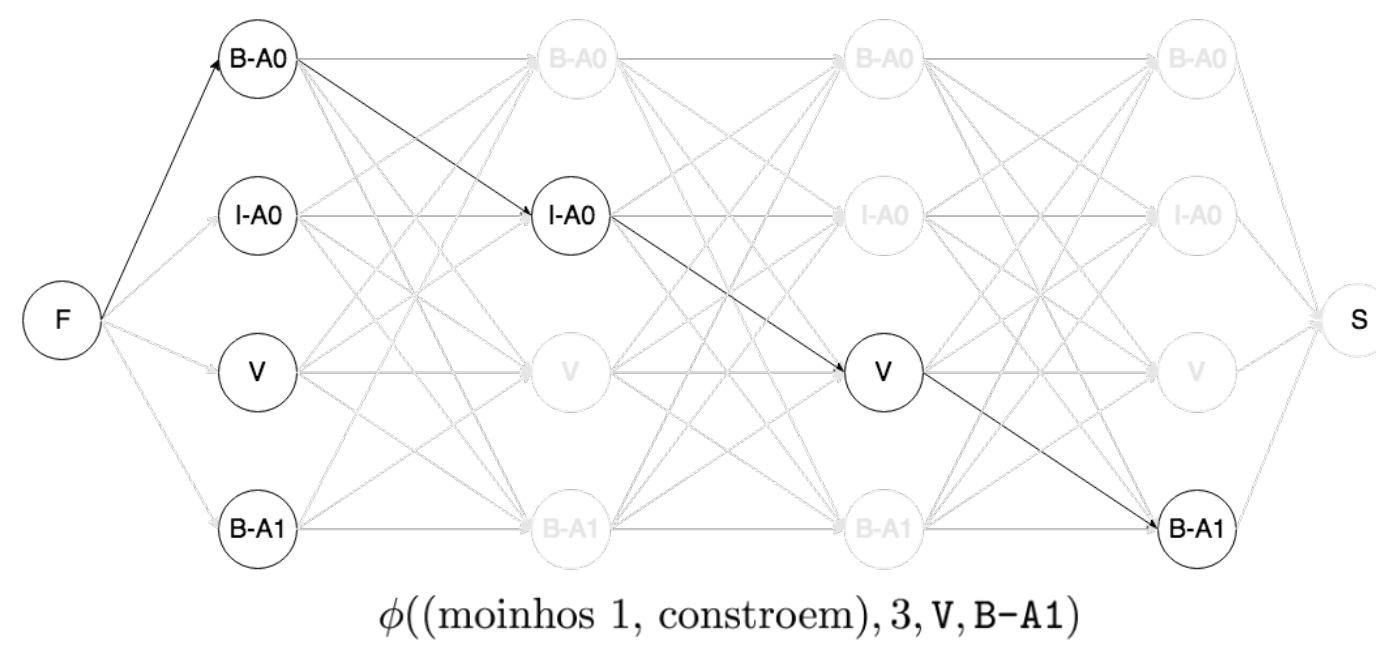

Figura 4.13: Mapa de custo $t=2$ 


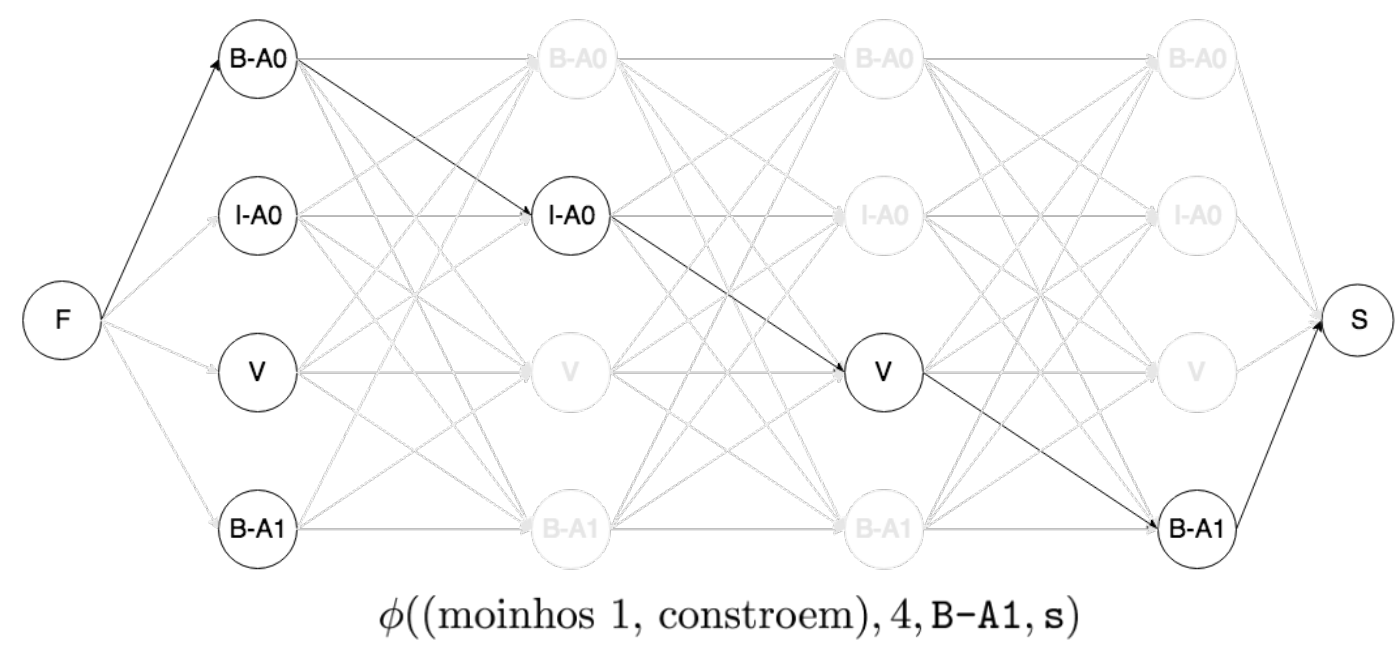

Figura 4.14: Mapa de custo $t=4$

Combinando as Equações 4-21, 4-25 e 4-26, teremos:

$$
\hat{\mathbf{y}}=\operatorname{argmax}_{\mathbf{z} \in \mathcal{Y}(\mathbf{x})} \sum_{t=0}^{\tau} c\left(\mathbf{x}, t, z_{t}, z_{t+1}\right)
$$

Onde argmax é resolvido através da resolução de um problema de maior caminho. Conluindo a demonstração. 


\section{Metodologia}

O objetivo dessa dissertação é aplicar para o português do Brasil, a arquitetura de aprendizado profundo através de redes neurais recorrentes que estabeleceu-se como estado da arte, em 2015, para o idioma do inglês. Neste Capítulo finalmente especificamos o sistema de aprendizado profundo de papéis semânticos.

\section{1}

\section{Pré processamento}

O pré processamento têm três partes; a seleção de atributos padrão ouro, a conversão de tokens em embeddings e a criação de atributos artificiais.

\section{1 .1}

\section{Seleção de atributos padrão ouro}

Um das características dessa dissertação é fazer um uso parcimonioso de atributos linguísticos. De fato o único utilizado são as etiquetas Part-ofspeech padrão ouro. A escolha pela sua utilização deu-se pela crença de que podem completar o sentido dado pela semântica dos embeddings e por outro lado podem ser gerados por uma tarefa com alta acurácia. Os atributos padrão ouro utilizados são:

- FORM: São as palavras do corpus tokenizadas.

- GPOS: São Part-of-speech padrão ouro. A Tabela 5.1 resume os valores possíveis.

- PRED: É o verbo que atua como predicado na proposição, esse predicado ainda será processado conforme Seção 5.1.3.

O resultado desta etapa está ilustrado no primeiro quadro da Figura 5.1. Nessa dissertação tomamos a sub tarefa de reconhecimento de predicado alvo da Seção 2.2.5 como resolvida - a mesma premissa da competição da CoNLL. Como a sentença da Figura 3.3 tem duas proposições ela gera dois exemplos no conjunto de dados pós processado. 


\begin{tabular}{ll} 
GPOS & Descrição \\
\hline substantivos & $\mathrm{n}$ \\
substantivos/adjetivos & $\mathrm{n}$-adj \\
adjetivos & adj \\
nomes próprios & prop \\
advébios & adv \\
verbos finitos & v-fin \\
verbos gerúndios & v-ger \\
verbos particípios & v-pcp \\
verbos infinitivos & v-inf \\
artigos & art \\
pronomes determinativos & pron-det \\
pronomes relativos & pron-rel \\
pronomes pessoais & pron-pess \\
preposições & prep \\
interjeições & intj \\
conjunções subordinativas & conj-c \\
conjunções coordenativas & conj-s \\
prefixos & ec \\
pontuações & pu
\end{tabular}

Tabela 5.1: Part-of-Speech

1a ETAPA

\begin{tabular}{|c|c|c|c|c|c|c|c|}
\hline \multicolumn{4}{|c|}{ EXEMPLO 1} & \multicolumn{4}{|c|}{ EXEMPLO 2} \\
\hline FORM & GPOS & PRED & ARG & FORM & GPOS & PRED & ARG \\
\hline$\ll$ & $\mathrm{PU}$ & $=$ & (A1* & $\ll$ & $\mathrm{PU}$ & - & $*$ \\
\hline$\hat{E}$ & V-FIN & - & $*$ & É & V-FIN & - & $*$ \\
\hline uma & ART & - & $*$ & uma & ART & - & $*$ \\
\hline coisa & $\mathrm{N}$ & - & $*$ & coisa & $\mathrm{N}$ & - & * \\
\hline de & PRP & - & $*$ & de & PRP & - & $*$ \\
\hline 0 & ART & - & $*$ & 0 & ART & - & * \\
\hline Primeiro_ML & PROP & - & $*$ & Primeiro_ML & PROP & - & $*$ \\
\hline$\gg$ & $\mathrm{PU}$ & - & *) & $\gg$ & $\mathrm{PU}$ & - & $*$ \\
\hline , & $\mathrm{PU}$ & - & 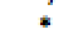 & , & PU & - & * \\
\hline afirmou & V-FIN & afirmar & $\left(V^{*}\right)$ & afirmou & V-FIN & - & * \\
\hline 0 & ART & - & $\left(\mathrm{AO}^{*}\right.$ & 0 & ART & - & $*$ \\
\hline levantador & $\mathrm{N}$ & - & $*$ & levantador & $\mathrm{N}$ & - & * \\
\hline Maurício & PROP & - & *) & Maurício & PROP & - & $*$ \\
\hline 1 & $\mathrm{PU}$ & - & 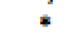 & 1 & $\mathrm{PU}$ & - & * \\
\hline leia & V-FIN & - & $*$ & leia & V-FIN & ler & $\left(V^{*}\right)$ \\
\hline matéria & $\mathrm{N}$ & - & $*$ & matéria & $\mathrm{N}$ & . & $\left(\mathrm{A} 1^{*}\right)$ \\
\hline a & PRP & - & * & $a$ & PRP & - & $\left(\mathrm{AM}-\mathrm{LOC}^{*}\right.$ \\
\hline 0 & ART & - & $*$ & 0 & ART & - & $*$ \\
\hline lado & $\mathrm{N}$ & - & $*$ & lado & $\mathrm{N}$ & - & *) \\
\hline ) & $\mathrm{PU}$ & - & * & 1 & $\mathrm{PU}$ & - & . \\
\hline . & $\mathrm{PU}$ & $=$ & $*$ &. & $\mathrm{PU}$ & $=$ & $*$ \\
\hline
\end{tabular}

Figura 5.1: Pré processamento $1^{\mathrm{a}}$ etapa.

\subsection{2}

\section{Transformação de tokens}

Nem todas as palavras pertencentes ao corpus estão presentes nos embeddings utilizados e produzidos por (56). A conversão de palavras em tokens geralmente recai sobre uma das regras abaixo:

- conversão em letra minúscula : todos os tokens estão em letra minúscula.

- horários, tempos e ordinais: foram convertidos para o caracter ' 0 ' 
- palavras compostas: e.g Primeiro_Mundo foram convertidas para minúscula e o valor do vetor de embeddings equivale à média dos vetores de embeddings que a compõe, no caso 'primeiro' e 'mundo'.

- palavras não encontradas: são substituídas por 'unk'.

Os exemplos após essa etapa encontram-se na Figura 5.2 no segundo quadro.

\begin{tabular}{|c|c|c|c|c|c|c|c|}
\hline \multicolumn{8}{|c|}{ 2a ETAPA } \\
\hline FORM & GPOS & PRED & ARG & FORM & GPOS & PRED & ARG \\
\hline$\ll$ & $\mathrm{PU}$ & - & $\left(\mathrm{A} 1^{*}\right.$ & $<<$ & $\mathrm{PU}$ & - & 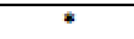 \\
\hline é & V-FIN & - & $*$ & é & V-FIN & - & * \\
\hline uma & ART & - & $*$ & uma & ART & - & $*$ \\
\hline coisa & $\mathrm{N}$ & - & $*$ & coisa & $\mathrm{N}$ & - & $*$ \\
\hline de & PRP & - & $*$ & de & PRP & - & $*$ \\
\hline 0 & ART & - & * & 0 & ART & - & * \\
\hline primeiro_mu & PROP & - & $*$ & primeiro_mu & PROP & - & $*$ \\
\hline$\gg$ & PU & - & *) & $\gg$ & PU & - & $*$ \\
\hline , & PU & - & $*$ & , & PU & - & $*$ \\
\hline afirmou & $\mathrm{V}$-FIN & afirmar & $\left(V^{*}\right)$ & afirmou & V-FIN & - & $*$ \\
\hline 0 & ART & - & $\left(\mathrm{AO}^{*}\right.$ & 0 & ART & - & $*$ \\
\hline levantador & $\mathrm{N}$ & - & $*$ & levantador & $\mathrm{N}$ & - & $*$ \\
\hline unk & PROP & - & *) & unk & PROP & - & $*$ \\
\hline 1 & PU & - & $*$ & 1 & PU & $=$ & $*$ \\
\hline leia & V-FIN & - & $*$ & leia & V-FIN & ler & $\left(V^{*}\right)$ \\
\hline matéria & $\mathrm{N}$ & - & $*$ & matéria & $\mathrm{N}$ & - & $\left(\mathrm{A} 1^{*}\right)$ \\
\hline a & PRP & - & $*$ & a & PRP & - & (AM-LOC* \\
\hline 0 & ART & - & $*$ & 0 & ART & $=$ & $*$ \\
\hline lado & $\mathrm{N}$ & - & $*$ & lado & $\mathrm{N}$ & - & *) \\
\hline ) & PU & - & $*$ & ) & PU & - & $*$ \\
\hline . & PU & - & $*$ & . & $\mathrm{PU}$ & - & $*$ \\
\hline
\end{tabular}

Figura 5.2: Pré processamento $2^{\mathrm{a}}$ etapa.

\subsection{3}

\section{Extração de atributos}

Nesta etapa seguimos o exemplo de Zhou e Xu (9) onde dois atributos foram criados para auxiliar as redes neurais recorrentes à controlar posição do token com relação ao predicado e o contexto em torno do predicado. Os atributos são:

1. MARKER trata-se de uma função indicadora marcando se o predicado da proposição foi visto ou não.

2. CTX_P uma janela em torno do predicado, contendo os tokens mais à direita e mais à esquerda que são repetidos para cada passo no tempo.

Adicionalmente os tokens a saída é representada no formato BIO. O resultado após a etapa de extração de atributos pode ser na Figura 5.3. 


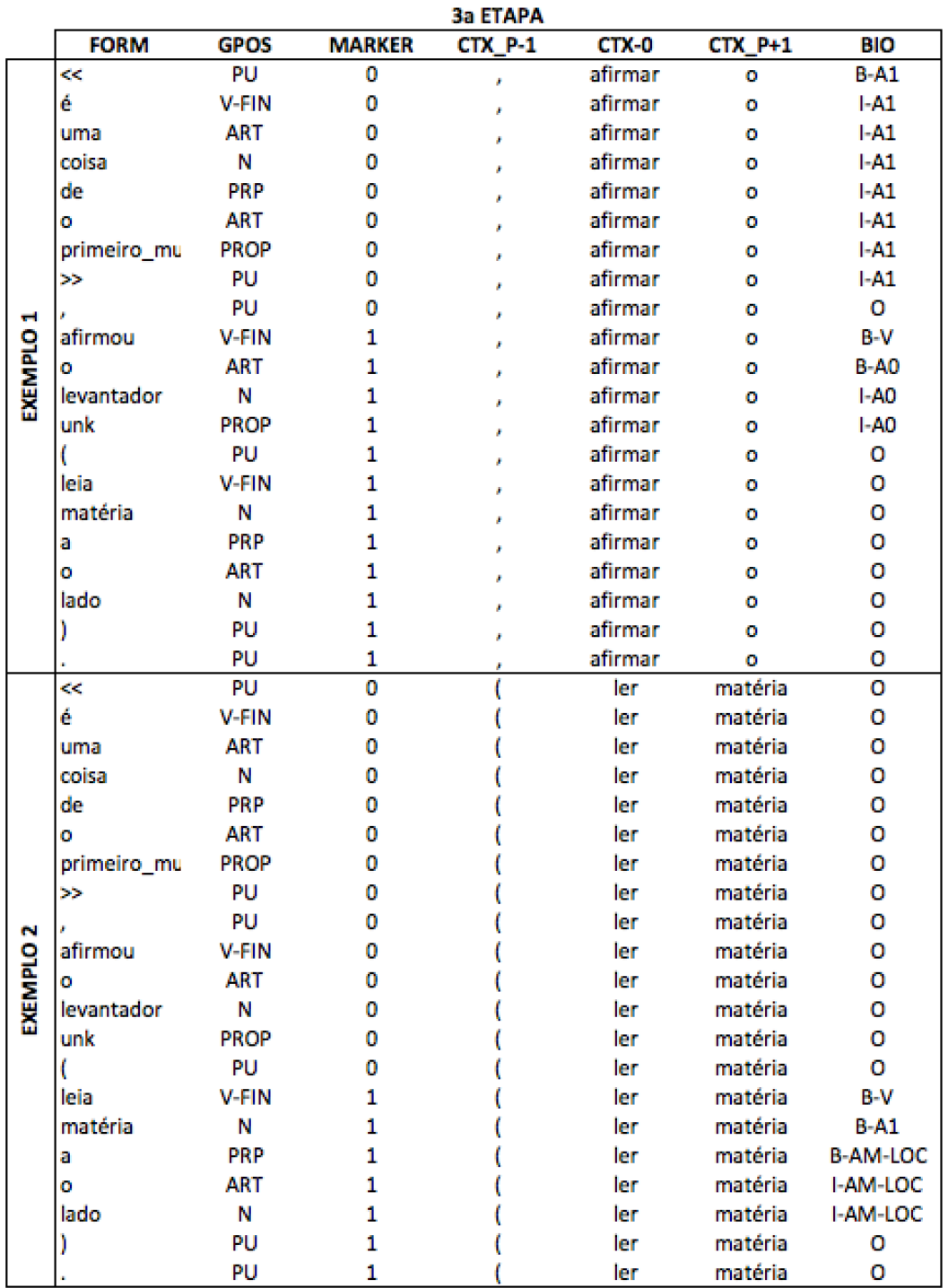

Figura 5.3: Pré processamento $3^{\mathrm{a}}$ etapa.

\section{2}

\section{Redes Neurais Recorrentes}

A motivação do uso de redes neurais recorrentes é a geração automática de atributos e que elas explicitamente acomodam exemplos, proposições, de tamanho variável. Neste trabalho testamos camadas do tipo BiLSTM (Seção 4.2.1) e DBLSTM (9). Difentente do Capítulo 4 os diagramas nessa Seção não fazem uso do grafo de computação.

\subsection{1}

\section{BiLSTM}

O diagrama da Figura 5.4 mostra duas camadas de uma rede BiLSTM. $\mathbf{X}_{t}$ representa um vetor de atributos de entrada correspondente à t-ésima linha 
da Figura 5.3 por exemplo. $\mathbf{S}_{t}$ representa um score ou uma pontuação gerada automáticamente pela rede refente ao momento $t$. As unidades $h_{t}^{(c)}$ movem-se para frente no tempo enquanto as unidades $g_{t}^{(c)}$ movem-se no sentido inverso, em ambas $c$ indica a camada. Os círculos com • representam a operação de concatenação de vetores.

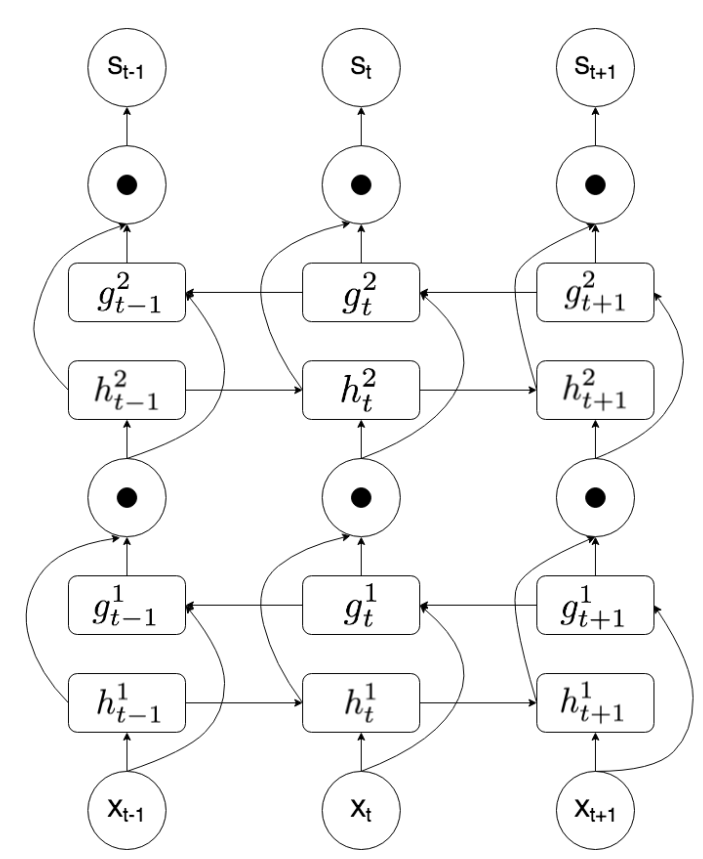

Figura 5.4: BiLSTM Diagrama

\subsection{2 \\ DBLSTM}

As DBLSTM foram introduzidas por Zhou e Xu (9) e segundo os autores essa estrutura é essencial para a resolução da tarefa para o idioma do inglês. O diagrama da Figura 5.5 mostra duas camadas de uma rede DBLSTM, seguindo a mesma nomenclatura da Figura 5.4. DBLSTM significa Dual Bidirectional LSTM e é caracterizada pelo padrão entrelaçado entre camadas. Cada camada têm profundidade 2 e os autores defendem que tal arranjo é necessário para obter o alto desempenho da tarefa.

\section{3}

\section{Predição Estruturada}

Enquanto o relacionamento intertemporal de tokens e atributos está contemplada pelas redes neurais recorrentes e que o contexto dos tokens influência as classes candidatas. Uma outra pergunta pertinente é: 'Como as escolha das classes anteriores impacta na escolha atual?'. Para a tarefa de anotação automática de papéis pesquisadores fazem largo uso de camadas 


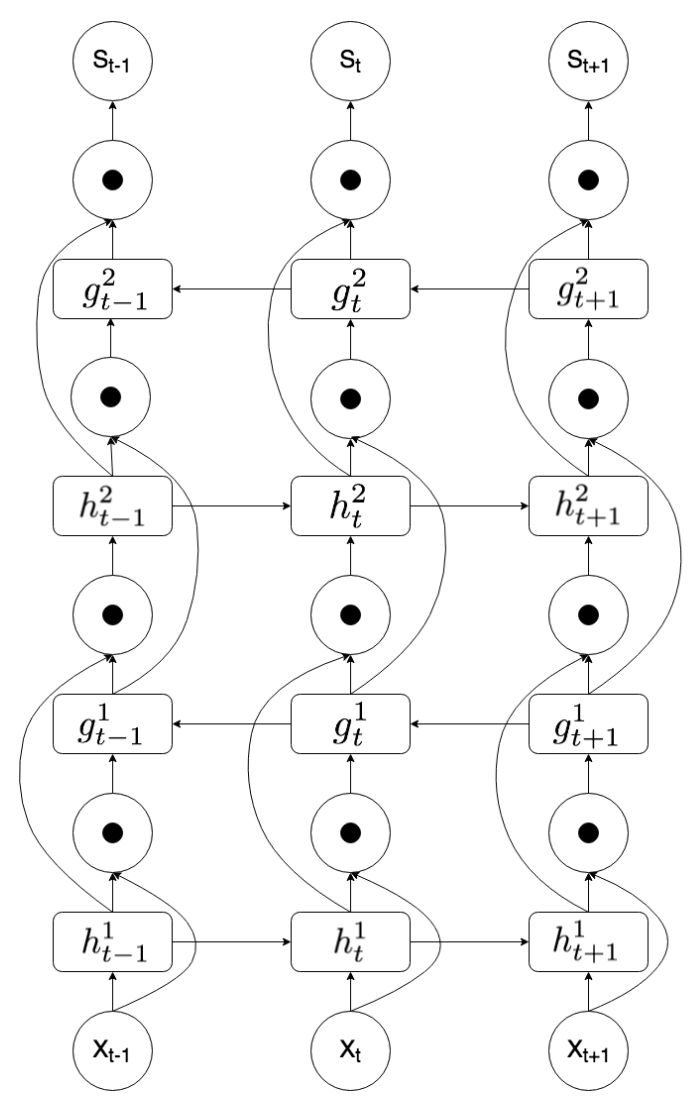

Figura 5.5: DBLSTM Diagrama

de predição estruturada (9) (21). A abordagem tem a dupla vantagem de permitir modelar o impacto de escolhas de classes passadas na escolha atual e inclusive reforçar restrições como proibir dois seguimentos com etiquetas A1. Nessa dissertação testamos CRF e a treliça conforme apresentado no Capítulo 4 Seção 4.3 . 


\section{6 \\ Resultados Experimentais}

Neste Capítulo comparamos os resultados do sistema ao de outros autores para o PropBank.Br. O código foi escrito na linguagem de programação Python utilizando o framework TensorFlow. Os testes foram executados em um Intel(R) Core(TM) i7-5960X CPU @ 3.00GHz 64 GB RAM o learning rate foi mantido fixo em $5 \cdot 10^{-4}$ por simplicidade. A motivação foram experimentos preliminares indicaram que os resultados são pouco sensíveis a variações deste hiper parâmetro. O otimizador escolhido foi o AdamOptimizer (69). Os experimentos foram treinados por Gradiente descendente estocástico, mantendo o tamanho da amostra fixo em 250. E todos os modelos de palavras foram treinados através da variante CBOW. O script utilizado para avaliação dos resultados é o script da CoNLL Shared Task 2004 - o mesmo utilizado por (22) escrito na linguagem de programação Pearl.

\section{1}

\section{Etapa 1}

$\mathrm{Na}$ primeira fase do teste mantemos o modelo de embeddings fixo no wang2vec de tamanho 50. O nosso objetivo é testar: Qual é o tipo de rede neural recorrente DBLSTM ou BiLSTM que desempenha melhor? Quais são os tamanhos e a profundidade, mais apropriados para as camadas escondidas? Quais das duas camadas de predição estruturada CRF ou SPN modela melhor a estrutura das saídas?

Os resultados da primeira fase, encontram-se na Tabela 6.1 ordenados em ordem descrescente por pontuação $F_{1}$. O padrão mais evidente está na coluna P.E (predição estruturada) - a camada CRF superou o perceptron estruturado. Entre os 10 melhores modelos nenhum deles contava com SPN. SPN é um modelo que permite tem uma maior expressividade: Na CRF a probabilidade de transição é fixa enquanto no SPN a transição é modelada através de atributos. Aparentemente o espaço de busca não contem um regularidade suficiente para que os parâmetros possam se ajustar. Discernir entre as camadas do tipo DBLSTM e BiLSTM, já não é tão simples, já que entre os 10 melhores se encontram igualmente representados com 5 registros cada. E ainda os modelos que tendem a ter melhor desempenho tiveram profundidade 2 e tamanhos de 
256 e 512. Estes resultados se chocam com os publicados por (9) onde foi informado que a estrutura de DBLSTM é crucial para o desempenho e que o modelo final tinha um tamanho de camada escondida de 32 e profundidade 4 . Estas camadas ocultas tem portanto tamanho muito superior. A configuração vencedora nessa primeira fase foi BiLSTM com profundidade 2 e camadas ocultas de tamanho 256 cada, e cuja previsão estruturada deu-se por CRF. Obtendo uma pontuação $F_{1} 66,25 \%$ no conjunto de validação. Concluímos que a BiLSTM de profundidade 2 e tamanho 252 e modelo de predição estruturada por CRF tiveram o melhor desempenho.

\begin{tabular}{|c|c|c|c|c|c|c|c|}
\hline & \multicolumn{2}{|c|}{$F_{1}$} & \multicolumn{2}{|c|}{ modelo de palavras } & \multicolumn{2}{|c|}{ LSTM } & P.E \\
\hline & validação & treino & nome & dimensão & camada & tamanho & modelo \\
\hline 1 & 66,25 & 88,3 & wang2vec & 50 & bilstm & $256 \times 256$ & crf \\
\hline 2 & 63,55 & 89,33 & wang $2 \mathrm{vec}$ & 50 & dblstm & $512 \times 512$ & $\operatorname{crf}$ \\
\hline 3 & 63,52 & 92,29 & wang $2 \mathrm{vec}$ & 50 & bilstm & $128 \times 128$ & $\mathrm{crf}$ \\
\hline 4 & 63,3 & 87,98 & wang $2 \mathrm{vec}$ & 50 & dblstm & 128 & $\mathrm{crf}$ \\
\hline 5 & 62,75 & 92,99 & wang2vec & 50 & bilstm & $512 \times 512$ & $\mathrm{crf}$ \\
\hline 6 & 62,28 & 84,7 & wang2vec & 50 & dblstm & 256 & $\operatorname{crf}$ \\
\hline 7 & 62,24 & 96,11 & wang2vec & 50 & bilstm & 512 & $\operatorname{crf}$ \\
\hline 8 & 61,88 & 82,43 & wang2vec & 50 & bilstm & 256 & $\operatorname{crf}$ \\
\hline 9 & 61,61 & 92,7 & wang2vec & 50 & dblstm & $256 \times 256$ & $\operatorname{crf}$ \\
\hline 10 & 60,93 & 87,31 & wang $2 \mathrm{vec}$ & 50 & dblstm & $512 \times 512$ & $\operatorname{crf}$ \\
\hline 11 & 60,89 & 88,84 & wang2vec & 50 & dblstm & 512 & spn \\
\hline 12 & 60,84 & 80,23 & wang $2 \mathrm{vec}$ & 50 & dblstm & 512 & crf \\
\hline 13 & 60,72 & 73,94 & wang $2 \mathrm{vec}$ & 50 & dblstm & $256 \times 256$ & $\mathrm{crf}$ \\
\hline 14 & 60,56 & 82,85 & wang2vec & 50 & dblstm & 512 & $\mathrm{crf}$ \\
\hline 15 & 60,52 & 88,91 & wang2vec & 50 & bilstm & 128 & $\mathrm{crf}$ \\
\hline 16 & 60,3 & 93,2 & wang2vec & 50 & bilstm & $512 \times 512$ & spn \\
\hline 17 & 59,74 & 80,42 & wang2vec & 50 & dblstm & 256 & $\operatorname{crf}$ \\
\hline 18 & 59,41 & 84,6 & wang2vec & 50 & dblstm & 256 & spn \\
\hline 19 & 59,4 & 84,77 & wang2vec & 50 & dblstm & 64 & $\operatorname{crf}$ \\
\hline 20 & 59,06 & 72,36 & wang2vec & 50 & dblstm & $128 \times 128$ & $\operatorname{crf}$ \\
\hline 21 & 59,01 & 88,16 & wang $2 \mathrm{vec}$ & 50 & dblstm & $128 \times 128$ & crf \\
\hline 22 & 58,98 & 88,12 & wang2vec & 50 & bilstm & $256 \times 256$ & spn \\
\hline 23 & 58,34 & 85,12 & wang $2 \mathrm{vec}$ & 50 & dblstm & 128 & spn \\
\hline 24 & 58,34 & 92,16 & wang $2 \mathrm{vec}$ & 50 & dblstm & $256 \times 256$ & $\mathrm{crf}$ \\
\hline 25 & 58,14 & 83,22 & wang $2 \mathrm{vec}$ & 50 & dblstm & $512 \times 512$ & spn \\
\hline 26 & 57,45 & 85,06 & wang2vec & 50 & dblstm & $256 \times 256$ & spn \\
\hline 27 & 57,27 & 90,62 & wang2vec & 50 & dblstm & $64 \times 64$ & crf \\
\hline 28 & 56,86 & 83,19 & wang2vec & 50 & bilstm & $128 \times 128$ & spn \\
\hline 29 & 56,12 & 81,28 & wang $2 \mathrm{vec}$ & 50 & dblstm & $128 \times 128$ & spn \\
\hline 30 & 55,94 & 81,49 & wang2vec & 50 & dblstm & 128 & spn \\
\hline 31 & 55,91 & 85,79 & wang $2 \mathrm{vec}$ & 50 & dblstm & $512 \times 512$ & spn \\
\hline 32 & 55,82 & 75,4 & wang2vec & 50 & bilstm & 512 & spn \\
\hline 33 & 55,57 & 81,28 & wang2vec & 50 & dblstm & $32 \times 32$ & $\operatorname{crf}$ \\
\hline 34 & 55,54 & 82,82 & wang $2 \mathrm{vec}$ & 50 & bilstm & 256 & spn \\
\hline 35 & 55,46 & 84,31 & wang2vec & 50 & dblstm & 256 & spn \\
\hline 36 & 55,37 & 81,51 & wang2vec & 50 & dblstm & 256 & spn \\
\hline 37 & 54,71 & 83,59 & wang2vec & 50 & dblstm & 512 & $\mathrm{crf}$ \\
\hline 38 & 54,71 & 72,11 & wang2vec & 50 & dblstm & 32 & spn \\
\hline 39 & 53,92 & 72,84 & wang2vec & 50 & dblstm & $64 \times 64$ & spn \\
\hline 40 & 52,66 & 77,1 & wang2vec & 50 & dblstm & $128 \times 128$ & spn \\
\hline 41 & 52,66 & 70,35 & wang $2 \mathrm{vec}$ & 50 & bilstm & 128 & spn \\
\hline 42 & 52,47 & 73,67 & wang2vec & 50 & dblstm & 64 & spn \\
\hline 43 & 51,14 & 74,02 & wang $2 \mathrm{vec}$ & 50 & dblstm & 128 & spn \\
\hline 44 & 49,09 & 73,29 & wang2vec & 50 & dblstm & $32 \times 32$ & spn \\
\hline 45 & 47,54 & 71,47 & wang $2 \mathrm{vec}$ & 50 & dblstm & 32 & spn \\
\hline
\end{tabular}

Tabela 6.1: Resultados da experimentais 1. 


\section{2 \\ Etapa 2}

Na segunda fase do teste testamos o modelo de embeddings entre word2vec e 3 tamanhos diferentes na representação no caso do wang2vec. O tipo de camada de LSTMs foi fixa na BiLSTM por parcimônia: Ela apresenta melhor desempenho com um número de parâmetros reduzido. No entanto variamos o tamanho e profundidade em busca de uma melhor configuração. Foram testados tamanhos de camadas entre 64 e 400, enquanto a máxima profundidade testada foi de 4 . O melhor experimento foi incluído nessa fase para fins de comparação.

Os resultados da segunda fase, encontram-se na Tabela 6.2. Nota-se que ao aumentar a profundidade da rede ou a representação vetorial dos atributos não se consegue superar a configuração anterior. Uma razão apontada por $(20,41,22)$, é o baixo número de exemplos: O PropBank.Br tem 5.773 proposições e 13.594 argumentos contra 99.265 proposições e 262.281 argumentos do PropBank (WSJ) (45). A versão americana é portanto cerca de 17 à 19 vezes maior. O fundamento por trás da geração automática de atributos é que existe uma repetição de exemplos suficientemente grande no conjunto de treinamento de tal forma que os exemplos do conjunto de teste estão bem representados. E o tamanho do corpus parece agir como um fator limitante. Vale lembrar que o PropBank.Br utilizou uma metodologia diferente ao do PropBank devido a restrições orçamentárias conforme (47). Os efeitos na qualidade final da anotação devido à essa diferença metodológica, parecem ser até o momento indeterminados. O melhor resultado é a configuração do primeiro experimento.

A Tabela 6.3 mostra a saída do script de avaliação CoNLL Shared Task 2004 para o conjunto de teste. O número de proposições total é de 239 e a percentagem de proposições com os argumentos perfeitamente alocados é de 45,19\%. Na coluna à esquerda podemos ver os argumentos, depois temos as seguintes colunas: correto (acertos), excesso (falso positivo), perdidas (falso negativo), e as pontuações de precisão e cobertura. O $F_{1}$ final foi de $66,23 \%$

Por fim nas Tabelas 6.4 e 6.5 mostram um comparativo entre os sistemas desenvolvidos respectivamente por $(20,41,22)$ não apenas quantitativo mas também qualitativo. Na primeira linha temos a pontuação $F_{1}$. A Tabela 6.4 traz os atributos padrão outro, a exceção da posição ID e o token FORM dado que ao menos a palavra e a sua posição devem servir de entrada para qualquer sistema de anotação de papéis semânticos. Os demais atributos padrão ouro utilizados para comparação são o LEMMA, MORPH, CTREE (arvore sintagmática) e predicado alvo. Adicionalmente, sistemas que utilizam 


\begin{tabular}{|c|c|c|c|c|c|c|c|}
\hline & \multicolumn{2}{|c|}{$F_{1}$} & \multicolumn{2}{|c|}{ modelo de palavras } & \multicolumn{2}{|c|}{ LSTM } & P.E \\
\hline & validação & treino & nome & dimensão & camada & tamanho & modelo \\
\hline 1 & 66,25 & 88,3 & wang2vec & 50 & bilstm & $256 \times 256$ & crf \\
\hline 2 & 64,25 & 90,41 & wang2vec & 100 & bilstm & $300 \times 300$ & $\operatorname{crf}$ \\
\hline 3 & 63,5 & 88,48 & wang2vec & 100 & bilstm & $128 \times 128 \times 128$ & $\operatorname{crf}$ \\
\hline 4 & 63,43 & 87,44 & wang2vec & 50 & bilstm & $300 \times 300$ & $\operatorname{crf}$ \\
\hline 5 & 62,77 & 81,12 & wang2vec & 50 & bilstm & $350 \times 350$ & $\operatorname{crf}$ \\
\hline 6 & 62,59 & 90,55 & wang2vec & 100 & bilstm & $400 \times 400$ & $\operatorname{crf}$ \\
\hline 7 & 62,58 & 96,72 & word2vec & 50 & bilstm & $350 \times 350$ & $\operatorname{crf}$ \\
\hline 8 & 62,58 & 80,62 & wang2vec & 50 & bilstm & $100 \times 100 \times 100$ & $\operatorname{crf}$ \\
\hline 9 & 62,26 & 79,12 & wang2vec & 50 & bilstm & $450 \times 450$ & $\operatorname{crf}$ \\
\hline 10 & 62,23 & 75,97 & wang2vec & 50 & bilstm & $128 \times 128 \times 128$ & $\operatorname{crf}$ \\
\hline 11 & 62,01 & 92,47 & wang2vec & 50 & bilstm & $400 \times 400$ & $\operatorname{crf}$ \\
\hline 12 & 61,93 & 90,49 & wang2vec & 50 & bilstm & $256 \times 256$ & $\operatorname{crf}$ \\
\hline 13 & 61,9 & 75,93 & wang2vec & 100 & bilstm & $450 \times 450$ & $\operatorname{crf}$ \\
\hline 14 & 61,61 & 83,47 & wang2vec & 100 & bilstm & $100 \times 100 \times 100$ & $\operatorname{crf}$ \\
\hline 15 & 61,55 & 95,63 & wang2vec & 300 & bilstm & $350 \times 350$ & $\operatorname{crf}$ \\
\hline 16 & 61,33 & 92,04 & word2vec & 50 & bilstm & $128 \times 128 \times 128$ & $\operatorname{crf}$ \\
\hline 17 & 60,6 & 86,43 & wang2vec & 50 & bilstm & $50 \times 50 \times 50$ & $\operatorname{crf}$ \\
\hline 18 & 60,46 & 72,15 & wang2vec & 100 & bilstm & $350 \times 350$ & $\operatorname{crf}$ \\
\hline 19 & 60,05 & 81,7 & wang2vec & 100 & bilstm & $64 \times 64 \times 64 \times 64$ & $\operatorname{crf}$ \\
\hline 20 & 59,45 & 71,04 & wang2vec & 50 & bilstm & $64 \times 64 \times 64 \times 64$ & $\operatorname{crf}$ \\
\hline 21 & 59,38 & 93,03 & word2vec & 50 & bilstm & $64 \times 64 \times 64 \times 64$ & $\operatorname{crf}$ \\
\hline 22 & 58,59 & 72,41 & wang2vec & 100 & bilstm & $50 \times 50 \times 50$ & $\operatorname{crf}$ \\
\hline 23 & 58,3 & 94,94 & wang2vec & 300 & bilstm & $128 \times 128 \times 128$ & $\operatorname{crf}$ \\
\hline 24 & 57,71 & 91,01 & wang2vec & 300 & bilstm & $64 \times 64 \times 64 \times 64$ & $\operatorname{crf}$ \\
\hline
\end{tabular}

Tabela 6.2: Resultados etapa 2.

separadores lineares fazem uso de uma série de atributos artificiais baseados nesses atributos padrão outro. Como por exemplo, o caminho do token até o predicado ou uma variável indicadora que diz se a sentença está ou não na voz passiva (27). Enquanto atributos manufaturados baseados no corpus contém conhecimento de domínio, certos atributos não carregam informação linguística alguma e.g uma variável que diz se o token está em letra maiúscula.

A Tabela 6.5 traz os outros items tratam-se de sub tarefas intermediárias que compõe alguns dos sistemas. Estas tarefas estão ordenadas de cima para baixo em ordem crescente de complexidade.

Neste trabalho consideramos que o predicado é dado e não precisamos resolver tarefa intermediária alguma, enquanto mantemos um uso de conhecimento específico sobre o idioma baixo. 
Número de Proposições: 239

Percentagens de proposições perfeitas: $\quad$ 45,19

\begin{tabular}{lcccccc} 
& corretos & excesso & perdidas & precisão & cobertura & $F_{1}$ \\
\cline { 1 - 5 } Total & 353 & 173 & 187 & 67,11 & 65,37 & 66,23 \\
\cline { 1 - 3 } A0 & 99 & 16 & 267 & 86,09 & 79,20 & 82,50 \\
A1 & 159 & 53 & 53 & 75,00 & 75,00 & 75,00 \\
A2 & 8 & 13 & 31 & 38,10 & 20,51 & 26,67 \\
A3 & 0 & 0 & 2 & 0,00 & 0,00 & 0,00 \\
A4 & 0 & 2 & 1 & 0,00 & 0,00 & 0,00 \\
AM-ADV & 9 & 8 & 11 & 52,94 & 45,00 & 48,65 \\
AM-CAU & 1 & 4 & 0 & 20,00 & 100,00 & 33,33 \\
AM-DIR & 0 & 0 & 2 & 0,00 & 0,00 & 0,00 \\
AM-DIS & 8 & 8 & 3 & 50,00 & 72,73 & 59,26 \\
AM-EXT & 0 & 2 & 2 & 0,00 & 0,00 & 0,00 \\
AM-LOC & 12 & 14 & 16 & 46,15 & 42,86 & 44,44 \\
AM-MNR & 6 & 9 & 13 & 40,00 & 31,58 & 35,29 \\
AM-NEG & 16 & 5 & 2 & 76,19 & 88,89 & 82,05 \\
AM-PNC & 2 & 4 & 3 & 33,33 & 40,00 & 36,36 \\
AM-PRD & 0 & 9 & 7 & 0,00 & 0,00 & 0,00 \\
AM-REC & 2 & 3 & 3 & 40,00 & 40,00 & 40,00 \\
AM-TMP & 31 & 23 & 12 & 57,41 & 72,09 & 63,92
\end{tabular}

Tabela 6.3: Resultados finais.

Atributo $\mid F_{1}$
LEMMA
GPOS
MORPH
CTREE
PRED
MANUFATURADOS

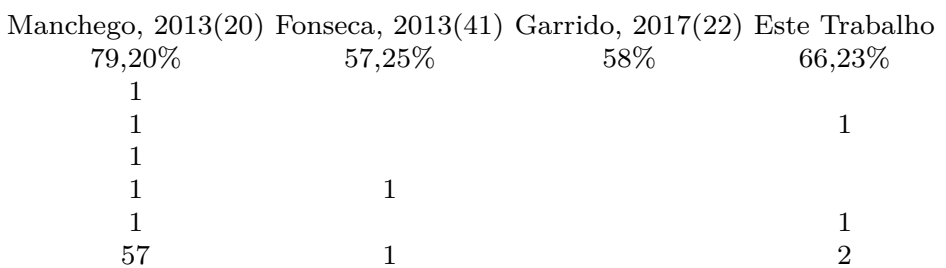

Tabela 6.4: Sistemas por atributos padrão ouro

Atributo $\mid F_{1}$

PART-OF-SPEECH

CHUNKING

RECONHECIMENTO DE PREDICADO ALVO

PODA DE SINTÁGMAS

INDENTIFICAC̄ÃO DE ARGUMENTOS

CLASSIFICAÇÃO DE ARGUMENTOS
Manchego, 2013(20) Fonseca, 2013(41) Garrido, 2017(22) Este Trabalho $79,20 \% \quad 57,25 \% \quad 58 \% \quad 66,23 \%$

Tabela 6.5: Sistemas por sub tarefas 


\section{Conclusão}

O objetivo dessa dissertação é construir um sistema de aprendizado profundo, com baixa dependência de atributos linguísticos e portanto adotamos a arquitetura que se estabeleceu em 2015 como o estado da arte para a tarefa interrompendo um período de 10 anos sem avanços siginificativo para o idioma do Inglês. Como a arquitetura é menos dependende de conhecimento de domínio, i.e da diferença entre idiomas do Inglês e Português, a expectativa antes do projeto era de que o resultado o resultado pudesse superar o estado da arte para o Português. Os resultados experimentais apontam para um comportamente diferente. Entretanto, o sistema foi capaz de superar outras arquiteturas que executam uma pipeline de sub tarefas ou que fazem uso de chunk.

As contribuições dessa dissertação foram: A adoção de dois modelos de linguagem para o corpus em português, wang2vec e word2vec (56) na tarefa de anotação de papéis semânticos. A proposição de uma arquitetura de aprendizado profundo baseadas em redes neurais recorrentes. O teste comparativo entre duas camadas de predição estruturada: CRF e SPN.

O trabalho futuro orientado ao modelo de linguagem é aplicar GloVe (55) embeddings e a variante skipgram para wang2vec e word2vec. Uma outra opção seria treinar ELMo embeddings (70) para o português dado que o modelo tem mostrado resultados promissores para a resolução da tarefa $(35,39)$. Um outra possibilidade de melhoria é utilizar o SPN com restrições lingüísticas, sem repetição de argumento e.g dois argumentos B-A0. Enquanto o vetor de progresso para a tarefa tem mostrado sistemas com menos atributos sintáticos, o estado da arte (39) re introduz esses atributos. Indicando que o processo de geração automática ainda se beneficia de conhecimento específico - arquiteturas que fazem uso comedido desses atributos têm o pontencial de mitigar os efeitos do baixo número de exemplos do PropBank.Br. Uma outra abordagem promissora seria implementar uma rede convolutiva to tipo gated linear units (71) que são especializadas em aprender seqüências enquanto são capazes de capturar relacionamentos hierárquicos no texto(34) enquanto sofrem de forma menos severa do problema do gradiente minguante explosivo. 


\section{Referências bibliográficas}

[1] FILLMORE, C. J.. The case for case. Holt, Rinehart \& Winston, New York, 1968.

[2] FILLMORE, C. J.. Frames and the semantics of understanding. Quaderni di Semantica, 6(2):222-254, 1985.

[3] FILLMORE, C. J.; BAKER, C. F. ; SATO, H.. Framenet as a 'net'. In: PROCEEDINGS OF LREC, volumen 4, p. 1091-1094, Lisbon, 2004. ELRA, ELRA.

[4] R DOWTY, D.. Thematic proto-roles and argument selection. Language, 67:547-619, 091991.

[5] MÀRQUEZ, L.; CARRERAS, X.; LITKOWSKI, K. C. ; STEVENSON, S.. Semantic role labeling: An introduction to the special issue. Comput. Linguist., 34(2):145-159, June 2008.

[6] LEVIN, B.; SOMERS, H.. English Verb Classes and Alternations: A Preliminary Investigation. 1993.

[7] DANG, H. T.; KIPPER, K.; PALMER, M. ; ROSENZWEIG, J.. Investigating regular sense extensions based on intersective levin classes. In: IN PROCEEDINGS OF COLING-ACL98, p. 293-299, 1998.

[8] KOOMEN, P., PUNYAKANOK, V., R. Y.. Generalized inference with multiple semantic role labeling systems. In: CONFERENCE ON COMPUTATIONAL NATURAL LANGUAGE LEARNING (CONLL), p. 181184, 2005.

[9] ZHOU, JIE, X.. End-to-end learning of semantic role labeling using recurrent neural networks. In: PROC. OF THE ANNUAL MEETING OF THE ASSOCIATION FOR COMPUTATIONAL LINGUISTICS (ACL)., 2015.

[10] CHAMBERS, N.; JURAFSKY, D.. Template-based information extraction without the templates. p. 976-986, 012011.

[11] BASTIANELLI, EMANUELE, CASTELLUCCI, GIUSEPPE, C. B.. Textual inference and meaning representation in human robot interaction. p. 65-69, 2013. 
[12] SHEN, D.; LAPATA, M.. Using semantic roles to improve question answering. In: PROCEEDINGS OF THE 2007 JOINT CONFERENCE ON EMPIRICAL METHODS IN NATURAL LANGUAGE PROCESSING AND COMPUTATIONAL NATURAL LANGUAGE LEARNING (EMNLP-CONLL), 2007.

[13] YAN, S.; WAN, X.. Srrank: Leveraging semantic roles for extractive multi-document summarization. Audio, Speech, and Language Processing, IEEE/ACM Transactions on, 22:2048-2058, 122014.

[14] WU, D.; FUNG, P.. Semantic roles for smt: A hybrid two-pass model. In: PROCEEDINGS OF HUMAN LANGUAGE TECHNOLOGIES: THE 2009 ANNUAL CONFERENCE OF THE NORTH AMERICAN CHAPTER OF THE ASSOCIATION FOR COMPUTATIONAL LINGUISTICS, COMPANION VOLUME: SHORT PAPERS, NAACL-Short '09, p. 13-16, Stroudsburg, PA, USA, 2009. Association for Computational Linguistics.

[15] AZIZ, WILKER, RIOS, MIGUEL, S.. Shallow semantic trees for smt. In: PROCEEDINGS OF THE SIXTH WORKSHOP ON STATISTICAL MACHINE TRANSLATION, p. 316-322. Association for Computational Linguistics, 2011.

[16] LIU, DING, G.. Semantic role features for machine translation. 2010.

[17] HARTMANN, NATHAN SIEGLE, A.. Anotação automática de papéis semânticos de textos jornalísticos e de opinião sobre árvores sintáticas não revisadas. Master's thesis, USP, 2017.

[18] AMANCIO, M. A.; ALUÍZIO, S. M.. Elaboração textual via definição de entidades mencionadas e de perguntas relacionadas aos verbos em textos simplificados do português. Master's thesis, USP, 2011.

[19] HACIOGLU, K.; PRADHAN, S.; WARD, W.; MARTIN, J. H. ; JURAFSKY, D.. Semantic role labeling by tagging syntactic chunks. In: IN PROCEEDINGS OF CONLL 2004 SHARED TASK, p. 110-113, 2004.

[20] MANCHEGO, F. E. A.. Anotação automática semissuperviosionada de papéis semânticos para o português do brasil. Master's thesis, 2013.

[21] HE, L.; LEE, K.; LEWIS, M. ; ZETTLEMOYER, L.. Deep semantic role labeling: What works and what's next. In: PROCEEDINGS OF 
THE ANNUAL MEETING OF THE ASSOCIATION FOR COMPUTATIONAL LINGUISTICS, 2017.

[22] GARRIDO, LUAN BARBOSA, X.. Anotação de papés semânticos para o português por CONDITIONAL RANDOM FIELDS. Master's thesis, 2017.

[23] XUE, N.; PALMER, M.. Calibrating features for semantic role labeling. In: PROCEEDINGS OF THE 2004 CONFERENCE ON EMPIRICAL METHODS IN NATURAL LANGUAGE PROCESSING, EMNLP 2004, A MEETING OF SIGDAT, A SPECIAL INTEREST GROUP OF THE ACL, HELD IN CONJUNCTION WITH ACL 2004, 25-26 JULY 2004, BARCELONA, SPAIN, p. 88-94, 2004.

[24] GILDEA, D.; JURAFSKY, D.. Automatic labeling of semantic roles. Computational Linguistics, 28:245-288, 2002.

[25] BAKER, C. F.; FILLMORE, C. J. ; LOWE, J. B.. The berkeley framenet project. In: PROCEEDINGS OF THE 36TH ANNUAL MEETING OF THE ASSOCIATION FOR COMPUTATIONAL LINGUISTICS AND 17TH INTERNATIONAL CONFERENCE ON COMPUTATIONAL LINGUISTICS VOLUME 1, ACL '98/COLING '98, p. 86-90, Stroudsburg, PA, USA, 1998. Association for Computational Linguistics.

[26] MARCUS, M. P.; MARCINKIEWICZ, M. A. ; SANTORINI, B.. Building a large annotated corpus of english: The penn treebank. Comput. Linguist., 19(2):313-330, June 1993.

[27] PUNYAKANOK, V, ROTH, D, Y.. The importance of syntactic parsing and inference in semantic role labeling. Computational Linguistics, 2008.

[28] COllobert, RONAN, WESTON, JASON, B. K. K. K.. Natural language processing (almost) from scratch. 2011.

[29] SRIVASTAVA, R. K.; GREFF, K. ; SCHMIDHUBER, J.. Training very deep networks. CoRR, abs/1507.06228, 2015.

[30] ZHANG, Y.; CHEN, G.; YU, D.; YAO, K.; KHUDANPUR, S. ; GLASS, J. R.. Highway long short-term memory rnns for distant speech recognition. CoRR, abs/1510.08983, 2015.

[31] SRIVASTAVA, N.; HINTON, G.; KRIZHEVSKY, A.; SUTSKEVER, I. ; SALAKHUTDINOV, R.. Dropout: A simple way to prevent neural 
networks from overfitting. J. Mach. Learn. Res., 15(1):1929-1958, Jan. 2014.

[32] TAN, Z.; WANG, M.; XIE, J.; CHEN, Y. ; SHI, X.. Deep semantic role labeling with self-attention. CoRR, abs/1712.01586, 2017.

[33] VASWANI, A.; SHAZEER, N.; PARMAR, N.; USZKOREIT, J.; JONES, L.; GOMEZ, A. N.; KAISER, L. ; POLOSUKHIN, I.. Attention is all you need. CoRR, abs/1706.03762, 2017.

[34] CHENG, J.; DONG, L. ; LAPATA, M.. Long short-term memorynetworks for machine reading. CoRR, abs/1601.06733, 2016.

[35] HE, L.; LEE, K.; LEVY, O. ; ZETTLEMOYER, L.. Jointly predicting predicates and arguments in neural semantic role labeling. CoRR, abs/1805.04787, 2018.

[36] LEE, K.; HE, L.; LEWIS, M. ; ZETTLEMOYER, L.. End-to-end neural coreference resolution. CoRR, abs/1707.07045, 2017.

[37] PRADHAN, S.; RAMSHAW, L. A.; MARCUS, M. P.; PALMER, M.; WEISCHEDEL, R. M. ; XUE, N.. Conll-2011 shared task: Modeling unrestricted coreference in ontonotes. In: PROCEEDINGS OF THE FIFTEENTH CONFERENCE ON COMPUTATIONAL NATURAL LANGUAGE LEARNING: SHARED TASK, CONLL 2011, PORTLAND, OREGON, USA, JUNE 23-24, 2011, p. 1-27, 2011.

[38] PRADHAN, S.; MOSCHITTI, A.; XUE, N.; URYUPINA, O. ; ZHANG, Y.. Conll-2012 shared task: Modeling multilingual unrestricted coreference in ontonotes. In: JOINT CONFERENCE ON EMPIRICAL METHODS IN NATURAL LANGUAGE PROCESSING AND COMPUTATIONAL NATURAL LANGUAGE LEARNING - PROCEEDINGS OF THE SHARED TASK: MODELING MULTILINGUAL UNRESTRICTED COREFERENCE IN ONTONOTES, EMNLP-CONLL 2012, JULY 13, 2012, JEJU ISLAND, KOREA, p. 1-40, 2012.

[39] STRUBELL, E.; VERGA, P.; ANDOR, D.; WEISS, D. ; MCCALLUM, A.. Linguistically-informed self-attention for semantic role labeling. CoRR, abs/1804.08199, 2018.

[40] CARUANA, R.. Multitask learning: A knowledge-based source of inductive bias. In: PROCEEDINGS OF THE TENTH INTERNATIONAL CONFERENCE ON MACHINE LEARNING, p. 41-48. Morgan Kaufmann, 1993. 
[41] FONSECA, ERICK ROCHA. Uma aboradgem conexista para anotação de papéis semânticos. Master's thesis, 2013.

[42] COLLOBERT, R.; WESTON, J.. A unified architecture for natural language processing: Deep neural networks with multitask learning. 2008.

[43] PALMER, M., GILDEA, D., K.. The proposition bank: An annotated corpus of semantic roles. Computational Linguistics, p. 71-105, March 2005.

[44] BONIAL, C.; BABKO-MALAYA, O.; CHOI, J.; HWANG, J. ; PALMER, M.. Propbank annotation guidelines. 122010.

[45] CARRERAS, XAVIER, M.. Introduction to the conll-2005 shared task: Semantic role labeling. In: for Computational Linguistics, A., editor, PROCEEDINGS OF THE 9TH CONFERENCE ON COMPUTATIONAL NATURAL LANGUAGE LEARNING (CONLL), p. 152-164, 2005.

[46] BURCHARDT, A.; ERK, K.; FRANK, A.; KOWALSKI, A. ; PADÓ, S.. Salto-a versatile multi-level annotation tool. 012006.

[47] DURAN, M. S, A.. Propbank-br: a brazilian treebank annotated with semantic role labels. In: EIGHTH INTERNATIONAL CONFERENCE ON LANGUAGE RESOURCES AND EVALUATION, 2012.

[48] AFONSO, S.; BICK, E.; HABER, R. ; SANTOS, D.. floresta sintá(c)tica": a treebank for portuguese. In: IN PROCEEDINGS OF THE 3RD INTERN. CONF. ON LANGUAGE RESOURCES AND EVALUATION (LREC, 2002.

[49] BICK, E.. The Parsing System Palavras Automatic Grammatical Analysis of Portuguese in a Constraint Grammar Framework. Aarhus University Press, 2000.

[50] DURAN M. S., SEPÚLVEDA-TORRES, L., C. H. A.. Seleção e preparação de sentenças do córpus pln-br para compor o córpus de anotação de papéis semânticos propbank-br.v2., 0124.

[51] CARRERAS, X.; MÀRQUEZ, L.. Introduction to the conll-2004 shared task: Semantic role labeling. In: PROCEEDINGS OF THE EIGHTH CONFERENCE ON COMPUTATIONAL NATURAL LANGUAGE LEARNING, CONLL 2004, HELD IN COOPERATION WITH HLT-NAACL 2004, BOSTON, MASSACHUSETTS, USA, MAY 6-7, 2004, p. 89-97, 2004. 
[52] BENGIO, Y.; DUCHARME, R.; VINCENT, P. ; JANVIN, C.. A neural probabilistic language model. J. Mach. Learn. Res., 3:1137-1155, Mar. 2003.

[53] RONG, X.. word2vec parameter learning explained. CoRR, abs/1411.2738, 2014.

[54] MIKOLOV, T.; CHEN, K.; CORRADO, G. ; DEAN, J.. Efficient estimation of word representations in vector space. CoRR, abs/1301.3781, 2013.

[55] PENNINGTON, J.; SOCHER, R. ; MANNING, C. D.. Glove: Global vectors for word representation. In: EMPIRICAL METHODS IN NATURAL LANGUAGE PROCESSING (EMNLP), p. 1532-1543, 2014.

[56] HARTMANN, N.; FONSECA, E. R.; SHULBY, C.; TREVISO, M. V.; RODRIGUES, J. ; ALUÍSIO, S. M.. Portuguese word embeddings: Evaluating on word analogies and natural language tasks. CoRR, abs/1708.06025, 2017.

[57] GoOdfEllow, I.; BengiO, Y. ; COURVILlE, A.. Deep Learning. MIT Press, 2016. http://www. deeplearningbook.org.

[58] HOCHREITER, S.. Untersuchungen zu dynamischen neuronalen Netzen. Diploma thesis, Institut für Informatik, Lehrstuhl Prof. Brauer, Technische Universität München, 1991.

[59] BENGIO, Y.; SIMARD, P. ; FRASCONI, P.. Learning long-term dependencies with gradient descent is difficult. Trans. Neur. Netw., 5(2):157-166, Mar. 1994.

[60] HOCHREITER, S, S.. Long short term memory. Neural Computation, $9(8): 1735-1780,1997$.

[61] CRAMMER, K.; SINGER, Y.. Pranking with ranking. In: ADVANCES IN NEURAL INFORMATION PROCESSING SYSTEMS 14, p. 641-647. MIT Press, 2001.

[62] DOS REIS SILVA, R.. ExtraÇÃo de citaÇÕes diretas e indiretas para o portuguÊs. Master's thesis, PUC-Rio, 2017.

[63] MILIDIU, RUY LUIZ, R.. Structured prediction networks. 2018.

[64] SUTTON, C.. 1 an introduction to conditional random fields for relational learning. 2007. 
[65] ROSENBLATT, F.. The perceptron: A probabilistic model for information storage and organization in the brain. Psychological Review, p. 65-386, 1958.

[66] COLLINS, M.. Discriminative training methods for hidden markov models: Theory and experiments with perceptron algorithms. p. $1-8,2002$.

[67] BELTRÃO, A.. Anotação de papéis semânticos para o português. 2016.

[68] LING, W.; DYER, C.; W BLACK, A. ; TRANCOSO, I.. Two/too simple adaptations of word2vec for syntax problems. 052015.

[69] KINGMA, D. P.; BA, J.. Adam: A method for stochastic optimization. CoRR, abs/1412.6980, 2014.

[70] PETERS, M. E.; NEUMANN, M.; IYYER, M.; GARDNER, M.; CLARK, C.; LEE, K. ; ZETTLEMOYER, L.. Deep contextualized word representations. CoRR, abs/1802.05365, 2018.

[71] DAUPHIN, Y. N.; FAN, A.; AULI, M. ; GRANGIER, D.. Language modeling with gated convolutional networks. CoRR, abs/1612.08083, 2016.

[72] SCHULER, K. K.. VerbNet: A broad-coverage, comprehensive verb lexicon. PhD thesis, 2005.

[73] WEISCHEDEL, R.; HOVY, E.; MARCUS, M.; PALMER, M.; BELVIN, R.; PRADHAN, S.; RAMSHAW, L. ; XUE, N.. Ontonotes: A large training corpus for enhanced processing. 012011.

[74] SURDEANU, M.; JOHANSSON, R.; MEYERS, A.; MÀRQUEZ, L. ; NIVRE, J.. The conll-2008 shared task on joint parsing of syntactic and semantic dependencies. In: PROCEEDINGS OF THE TWELFTH CONFERENCE ON COMPUTATIONAL NATURAL LANGUAGE LEARNING, CoNLL '08, p. 159-177, Stroudsburg, PA, USA, 2008. Association for Computational Linguistics.

[76] HAJIČ, J.; CIARAMITA, M.; JOHANSSON, R.; KAWAHARA, D.; MARTÍ, M. A.; MÀRQUEZ, L.; MEYERS, A.; NIVRE, J.; PADÓ, S.; ŠTĚPÁNEK, J.; STRAŇÁK, P.; SURDEANU, M.; XUE, N. ; ZHANG, Y.. The conll2009 shared task: Syntactic and semantic dependencies in multiple languages. In: PROCEEDINGS OF THE THIRTEENTH CONFE- 
RENCE ON COMPUTATIONAL NATURAL LANGUAGE LEARNING: SHARED TASK, CoNLL '09, p. 1-18, Stroudsburg, PA, USA, 2009. Association for Computational Linguistics. 


\section{Apêndice}

\section{A.1}

\section{O Grafo de Computação}

Há várias formas de formalizar um grafo de computação (57). O grafo de computação é um instrumento útil para representar relacionamentos entre variaveis de entrada e saída aplicação de funções. Cada nó no grafo de computação contém uma variável que pode ser um escalar, vetor, matriz ou tensor. Uma operação que é uma aplicação de uma função em uma ou mais variáveis. Sem perda de generalidade essa função, retorna apenas uma variável. Se a variável $y$ é computada por uma aplicação de $x$ então uma aresta é desenhada entre $x$ e $y$. Algumas variáveis podem ser rotuladas com nomes de funções, como no caso de operações com mais de uma variável de entrada. Variáveis podem ser nomeadas ou não. Arestas podem ser rotuladas ou não. Na Figura A.1 são dois grafos distintos que representam as operações (a) $z=x y$ (b) $\mathbf{y}=\sigma\left(\mathbf{w}^{T} \mathbf{x}+\mathbf{b}\right)$

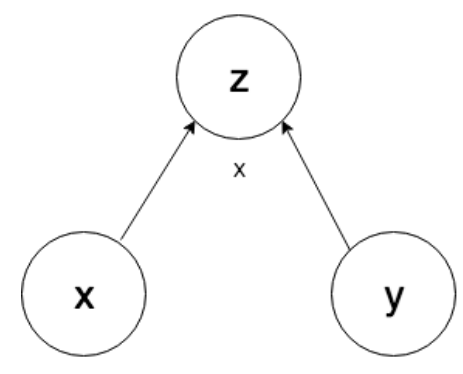

(a)

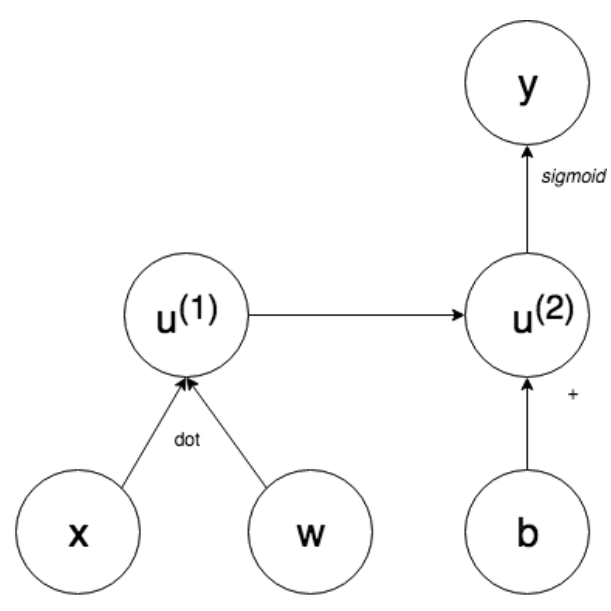

(b)

Figura A.1: O gráfico de computação.

No caso das RNRs é útil definir desdobramento (unfolding) de uma computação recursiva, que tem uma estrutura repetitiva correspondendo à uma cadeia de eventos, e que divide os seus parâmetros $\theta$ através do tempo. A equação A-1 define um sistema dinâmico clássico, ela é recursiva porque $\mathbf{s}$ 
no tempo $t$ se refere a ela própria no tempo $t-1$. Para um número finito $\tau$, o grafo pode ser desdobrado $\tau-1$ vezes, A.1. À esquerda da Figura A.2 um quadrado representado um passo no tempo, à direita está o seu equivalente desdobrado, ambas representam a Equação A-1 Os parâmetros $\theta$ são divididos no tempo.

$$
\begin{aligned}
& \mathbf{s}^{(t)}=f\left(\mathbf{s}^{(t-1)} ; \theta\right) \\
\mathbf{s}^{(4)} & =f\left(\mathbf{s}^{(3)} ; \theta\right) \\
& =f\left(f\left(\mathbf{s}^{(2)} ; \theta\right) ; \theta\right) \\
& =f\left(f\left(f\left(\mathbf{s}^{(1)} ; \theta\right) ; \theta\right) ; \theta\right)
\end{aligned}
$$
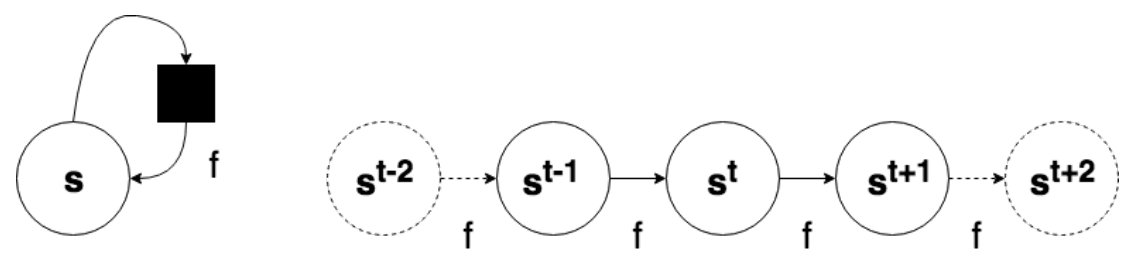

Figura A.2: Desdobramento do grafo de computação. 